\title{
CN TOWER CURRENT WAVEFRONT PARAMETERS
}

\author{
by \\ Elvir Burnazovic \\ B.Sc., University of Sarajevo, 1986.
}

\author{
A thesis \\ Presented to Ryerson University \\ in partial fulfillment of the \\ requirements for the degree of \\ Master of Applied Science \\ In the program of \\ Electrical and Computer Engineering \\ Toronto, Ontario, Canada, 2011 \\ @ Elvir Burnazovic 2011
}




\section{Author's Declaration}

I hereby declare that I am the sole author of this thesis.

Only after June 10, 2013, I authorize Ryerson University to lend this thesis to other institutions or individuals for the purpose of scholarly research.

Signature

Only after June 10, 2013, I further authorize Ryerson University to reproduce this thesis by photocopying or by other means, in total or in part, at the request of other institutions or individuals for the purpose of scholarly research.

Signature 


\begin{abstract}
CN TOWER CURRENT WAVEFRONT PARAMETERS

Elvir Burnazovic

Master of Applied Science in Electrical Engineering

Ryerson University, 2011.
\end{abstract}

This work is focused on the establishment of comprehensive statistics concerning the characteristics of the lightning current measured at the CN Tower during five years (1992-1996). Negative lightning currents are characterized with two distinguished impulses: short risetimes’ impulses, and impulses with substantially larger risetimes and larger current peaks in comparison with fast impulses. The slower negative current impulses were found to occur either in single stroke flashes or as first strokes in multiple stroke flashes, suggesting that they may belong to downward-initiated lightning to the CN Tower.

The statistical analysis illustrates that there is a substantial difference in current wavefront parameter of ordinary negative fast wavefront impulses and those for slow wavefront negative impulses.

The obtained statistics are very important for building lightning protection means against direct strikes to power lines, substation and communication equipments, as well as against lightning occurring in their vicinities.

Keywords: Tall-structure lightning, lightning return-stroke, lightning current parameters. 


\section{ACKNOWLEDGMENTS}

I would like to express my deep gratitude and appreciation to my supervisor Prof. Dr. Ali Hussein for his invaluable support, excellent guidance, and encouragement during my research work on this thesis.

I also would like to thank the Department of Electrical and Computer Engineering and the School of Graduate Studies of Ryerson University for accepteing me to participate on this interesting research.

Furthermore, I would like to thank Dr. Mariusz Milewski for his help. 


\section{Contents}

1. Introduction $\quad 1$

1.1 Physics of Lighting Discharge And Lighting Terminology 2

1.1.1 Negative Cloud-to-Ground Lightning 4

1.1.2 Positive Cloud-to-Ground Lightning 6

1.1.3 Upward Lightning Initiated by Ground-Based Objects

$\begin{array}{ll}\text { 1.1.3.1Tall Structure Lightning } & 9\end{array}$

1.2 Practical Importance of Current Measurements 11

1.2.1 Lightning Protection of Power Stations and Power Lines 13

1.2.1.1 Direct Strike Lightning Protection of Power Lines 14

1.2.1.2 Direct Strike Lightning Protection of Power Stations 16

$\begin{array}{ll}\text { 1.2.1.3 Overvoltage Protection } & 17\end{array}$

1.3 The Lightning Current Measuring Equipment 19

2. CN Tower Lightning Measurement System 27

$\begin{array}{ll}2.1 \text { Introduction } & 27\end{array}$

2.2 CN Tower Video and High Speed Camera Monitoring System 29

2.3 CN Tower Lightning Current Sensors 33

2.4 CN Tower Field Sensors 35

2.5 Recording Equipment 37 
3. The Lightning Current 39

3.1 Relevant Current Parameters 39

3.2 Measurement of CN Tower Return-Stroke Current Derivative 44

3.2.1 Associated Noise in The Lightning Return-Stroke Current

Derivative Signal $\quad 44$

3.3 CN Tower Return-Stroke Current Waveforms 47

4. Statistical Analysis $\quad 59$

4.1 Determination of Return-Stroke Current 59

Wavefront Parameters

4.1.1 Determination of Current Derivative Parameters 59

4.1.2 Determination of Current Parameters 60

4.2 Statistical analysis of Lightning Discharge on CN Tower

$\begin{array}{ll}1992-1996 & 61\end{array}$

4.2.1 Statistical Analysis of Lightning Flash Parameters 61

4.2.2 Statistical Analysis of Current Wavefront Parameters 68

4.2.2.1 The Current impulse Derivative Parameters’ Analysis 69

4.2.2.2 The Current impulse Derivative Parameters’ Analysis 72

4.3 First and Subsequent Return Strokes for Two Distinguished

$\begin{array}{ll}\text { Negative Flash Categories } & 77\end{array}$

$\begin{array}{lll}\text { 5. Conclusion } & 83\end{array}$

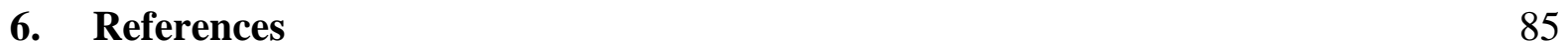




\section{List of Tables}

Table 1.1. Data for Ostankino Television Tower Lightning Strikes

Table 4.1. Number of strokes for different flash types

Table 4.2. Summary of current derivative data

76

Table 4.3. Summary of return data

77 


\section{List of Figures}

1.1 Types of lightning effectively lowering cloud charge to ground, direction of propagation of the initial leader and the polarity of the cloud charge are indicated. 3

1.2 (a) Still camera image, (b) streak camera image, current waveform corresponding to the camera images.

1.3 (a) Examples of continuing-current waveforms with superimposed. M-components in triggered lightning. 5

1.4 EGM for Power Transmission Line Direct Lightning Strike Protection. 14

1.5 EGM for Direct Lightning Strike Protection of Power Station. 17

$\begin{array}{lll}1.6 & \text { Transmission line EMTP model. } & 19\end{array}$

1.7 Lightning Current Measuring System at Gaisberg Tower Austria. 20

1.8 Rogowski coil principle. $\quad 22$

1.9 Minimization of impact of nearby current carrying conductors. 23

1.10 Flexible Rogowski coil. $\quad 23$

$\begin{array}{lll}1.11 & \text { Rogowski coil with integrator. } & 24\end{array}$

1.12 Rogowski coil external field shielding. 26

1.13 Double-shielded cable. 26

$2.1 \quad$ The CN Tower and locations of instruments. 28

2.2 Typical video camera record of a flash striking the CN Tower at the tip. 30

2.3 Lightning strike $45 \mathrm{~m}$ below the tip of the CN Tower. 30

2.4 HSC record of a CN Tower lightning flash. 31

2.5 Old Rogowski coil connections and its installation at the CN Tower. 34

2.6 New Rogowski coil connection and its installation at the CN Tower. 35

$\begin{array}{lll}2.7 & \text { Sony-Tektronix RTD-710A digitizer. } & 37\end{array}$

3.1 A schematic representation of lightning return-stroke. 41

3.2a Double exponential presentation of lightning return-stroke current. 42 
3.2b Heidler function from IEC 62305 - Table B1 - first return-stroke. 43

3.3 A lightning current derivative signal recorded at the CN Tower in 1996.

3.4 The current waveform obtained by numerical integration of the current derivative signal shown in 3.3. 45

3.5 CN Tower current waveform resulted after the removal of the DC offset. 46

3.6 A typical negative lightning return-stroke current derivative signal measured at the CN Tower. It belongs to fast current rising impulses. 48

3.7 The lightning return-stroke current obtained by numerically integrating the measured current derivative signal shown in 3.6.

3.8. A negative lightning return-stroke current derivative signal measured at the CN Tower. It belongs to slow current rising impulses.

3.9 The lightning return-stroke current obtained by numerically integrating the measured current derivative signal shown in 3.8.

3.10 The current derivatives of a CN Tower flash containing 4 return-strokes. All return-strokes current derivative signals are of the fast current rise category.

3.11 Return-stroke currents obtained by numerical integration of currents derivative signals shown in 3.10 .

3.12 Current derivatives of a CN Tower flash containing 8 return-strokes. The first return-stroke has a much lower current rate of rise.

3.13 Return-strokes currents obtained by numerical integration of derivative signals shown in 3.12 .

3.14 A positive lightning return-stroke current derivative signal recorded at the CN Tower.

3.15 The CN Tower positive lightning return-stroke current obtained by numerical integration of the measured current derivative signal shown in 3.14.

3.16 A positive lightning current derivative signal measured at the CN Tower. It belongs to positive impulse in a bipolar flash.

3.17 A positive lightning return-stroke current obtained by numerical integration of derivative signal shown in 3.16 . 
3.18 The current derivative signals of a CN Tower flash containing one positive and two negative return-strokes.

3.19 Return-strokes currents obtained by numerical integration of derivative signals shown in 3.18 .

4.1 Determination of lightning current derivative peak and current derivative risetime.

4.2 Determination of lightning current impulse peak and current impulse risetime.

4.3 Frequency distribution of 82 CN Tower flashes (1992-1996). 63

4.4 Cumulative statistics of number of strokes in flash (1992-1996). 64

4.5 Cumulative statistics of flash duration (1992-1994). 65

4.6 Cumulative statistics of flash (1995-1996). 66

4.7 Cumulative statistics of flash duration (1992-1996). 66

4.8 Frequency distribution of distinguished return-strokes (1992-1996). 69

4.9 Cumulative Statistics of Current Derivative Maximum for 269 return-strokes in 82 Flashes.

4.10 Frequency distribution of current derivative risetime for the determined Intervals of time (e.g. $0.25 \mu \mathrm{s}$ - presents, time interval from 0 - $0.5 \mu$ s etc.).

4.11 Cumulative statistics of current derivative rise-time (10\%-90\%) for all 269 return-strokes (1992-1996).

4.12 Frequency distribution of current peak for ordinary strokes and strokes with slow current wavefront.

4.13 Cumulative statistics of current (1992 - 1996).

4.14 Frequency distribution of current risetime of ordinary strokes (1992-1996, 248 ordinary negative strokes).

4.15 Frequency distribution of current risetime of slow wavefront strokes (1992-1996, 18 slow wavefront negative strokes).

4.16 Cumulative statistics of current risetime (1992-1996, 269 strokes).

4.17 Cumulative statistics of return-stroke current derivative peak for slow wavefront current impulse. 
4.18 Cumulative statistics of return-stroke current derivative peak for fast wavefront current impulse.

4.19 Cumulative statistics of return-stroke current derivative risetime for slow wavefront current impulse.

4.20 Cumulative statistics of return-stroke current derivative risetime for fast wavefront current impulse.

4.21 Cumulative statistics of return-stroke current peak for slow wavefront current impulse.

4.22 Cumulative statistics of return-stroke current peak for fast wavefront current impulse.

4.23 Cumulative statistics of return-stroke current risetime for slow wavefront current impulse.

4.24 Cumulative statistics of return-stroke current risetime for fast wavefront current impulse. 


\section{Chapter 1}

\section{Introduction}

The first scientific study about lighting was published by Benjamin Franklin in 1749. From that time till today lightning research is of interest in many different engineering branches $[1],[2]$.

For power engineers, the characteristics of the lightning flash and its components, including the return-stroke current and its associated electromagnetic field, are very important for the design of lightning protection systems for power stations and power lines. For electromagnetic field researchers, lightning represents a tall antenna that generates broadband electromagnetic pulses. For the telecommunication engineers lighting is a source of noise and surge from which they have to protect their equipments that are directly or indirectly connected to overhead lines or underground cables.

The Canadian National $(\mathrm{CN})$ Tower, at the height of $553 \mathrm{~m}$, represents the tallest instrumented manmade standing alone structure in the world. It usually receives many tens of lightning strikes yearly [3].

Because of the stochastic nature of lightning it is not possible to choose time and location on the ground for the lightning current measurements. The lightning current has been measured at tall structures, such as the Empire State Building in New York, Moscow tower and the CN Tower, or at towers installed on mountains (e.g. Monte San Salvatore Towers). Also, the lightning current has been measured by artificially initiating lightning (rocket-triggered lightning). The current measuring equipment could be installed on the top of a tower, just below 
its lightning rod, or at the bottom of the tower. Although the lightning flash density in Toronto

area is only 2 flashes $/ \mathrm{km}^{2}$ /year, the CN Tower is yearly struck on average with $40-50$ lightning flashes. The CN Tower with its great height and slim structure presents an ideal object to observe lightning and to build statistics concerning the characteristics of lightning visual parameters (flash trajectory, branching, luminosity variation, etc), current and the associated lightning electromagnetic pulse. CN Tower lightning data also provides a way to assess lightning returnstroke models at elevated objects. Further more, these data is very important for electrical power engineers to understand the lightning process and to design lightning protection systems.

\subsection{PHYSICS OF THE LIGHTING DISCHARGE AND LIGHTING TERMINOLOGY}

Lighting is a transient, high current discharge whose length is measured in kilometres [1]. The primary source of lighting is the thundercloud cloud, which is called the lightning-producing cumulonimbus [4].

A lightning discharge is usually termed a lightning flash or just flash. The terms "return stroke" apply only to components of cloud to ground or cloud to grounded object discharges [5]. Berger (1978) has categorized lightning between the cloud and the ground in terms of direction of motion, upward or downward, and the sign of the charge, positive and negative. The categorization is illustrated in Figure 1.1, which presents four types of lightning:

(a) downward negative lightning

(b) upward positive lightning

(c) downward positive lightning 
(d) upward negative lightning.

All the above mentioned types represent cloud-to-ground (CG) discharges. About $90 \%$ percent or more of global CG lightning are downward negative flashes, type (a) and 10\% or less of all cloud-to-ground discharges are downward positive lightning flashes, type (c). Upward lightning discharges, types (b) and (d), are observed at tall objects (usually higher than 100m), at objects of lower heights that are located on mountain tops or artificially provoked lightning (rocket triggered lightning).

(a)

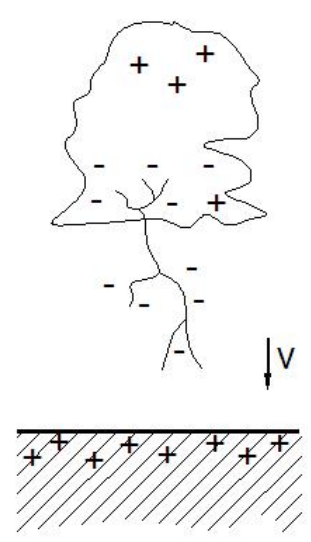

(b)

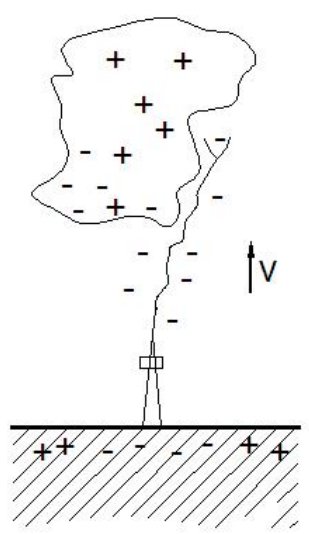

(c)

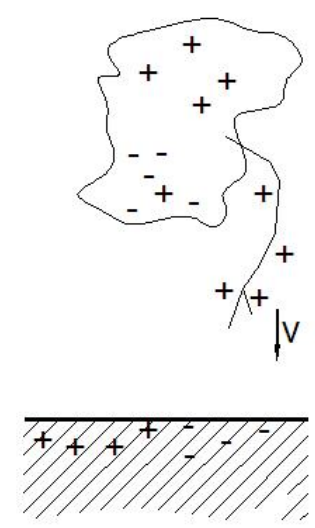

(d)

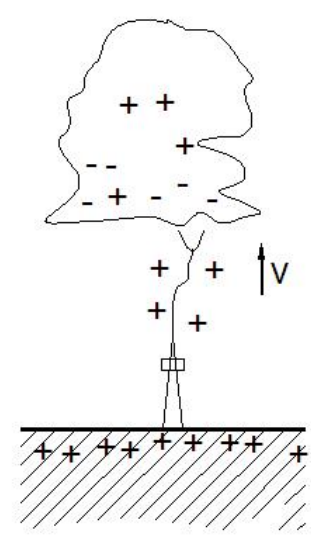

Figure 1.1 Types of lightning effectively lowering cloud charge to ground, direction of propagation of the initial leader and the polarity of the cloud charge are indicated.

Lightning often appears to "flicker" because of the human eye limitations. The total discharge, named a flash, is made up of various discharge components, amongst them are typically several current pulses called return strokes. 


\subsubsection{NEGATIVE CLOUD-TO-GROUND LIGHTNING}

As explained before, the majority of cloud to ground lightning discharges is downward negative lightning discharges. These discharges, which are initiated in the cloud, are initially developed by a downward directed and transfer negative charge from the cloud to the ground. Negative downward lightning flashes could be made of one or more return strokes.

Each negative lightning flash consists of four modes of charge transfer in Figure 1.2:

(a) A stepped leader followed by a first return stroke

(b) dart-leader-return-strokes sequences

(c) continuing currents with possibly M-components (see Figure1.3)

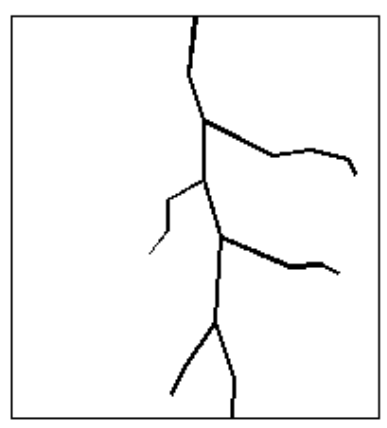

(a)
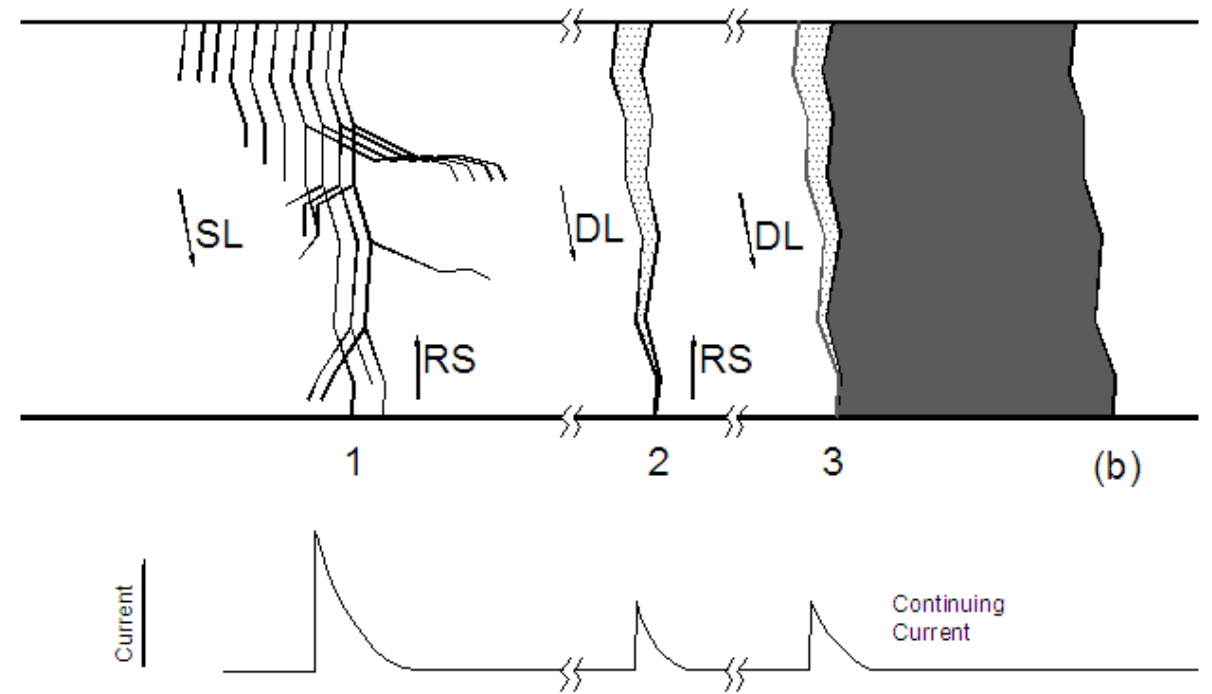

Time

Figure 1.2 (a) Still camera image, (b) streak camera image, current waveform corresponding to the camera images [2].

(a) The stepped leader propagates from cloud to ground in a series of discrete steps and then initiates the first return stroke in the flash 
(b) In the following leader-return-stroke sequence, a descending dart leader follows the same trajectory path between the negative cloud charge source and ground and deposits negative charge along this path. The subsequent return stroke uses the same ionized path, moving from ground towards the cloud charge source and neutralizing it. Thus, both leader and return stroke processes provide transfer of negative charge from the cloud to the ground. The current peak could be in the range of 20kA or more. The first return stroke could be followed by several subsequent return strokes following the same lightning channel. The current peaks of the subsequent return strokes, although in the $\mathrm{kA}$ range, are usually lower than the peak of the first return stroke, but with faster rate of current rise.
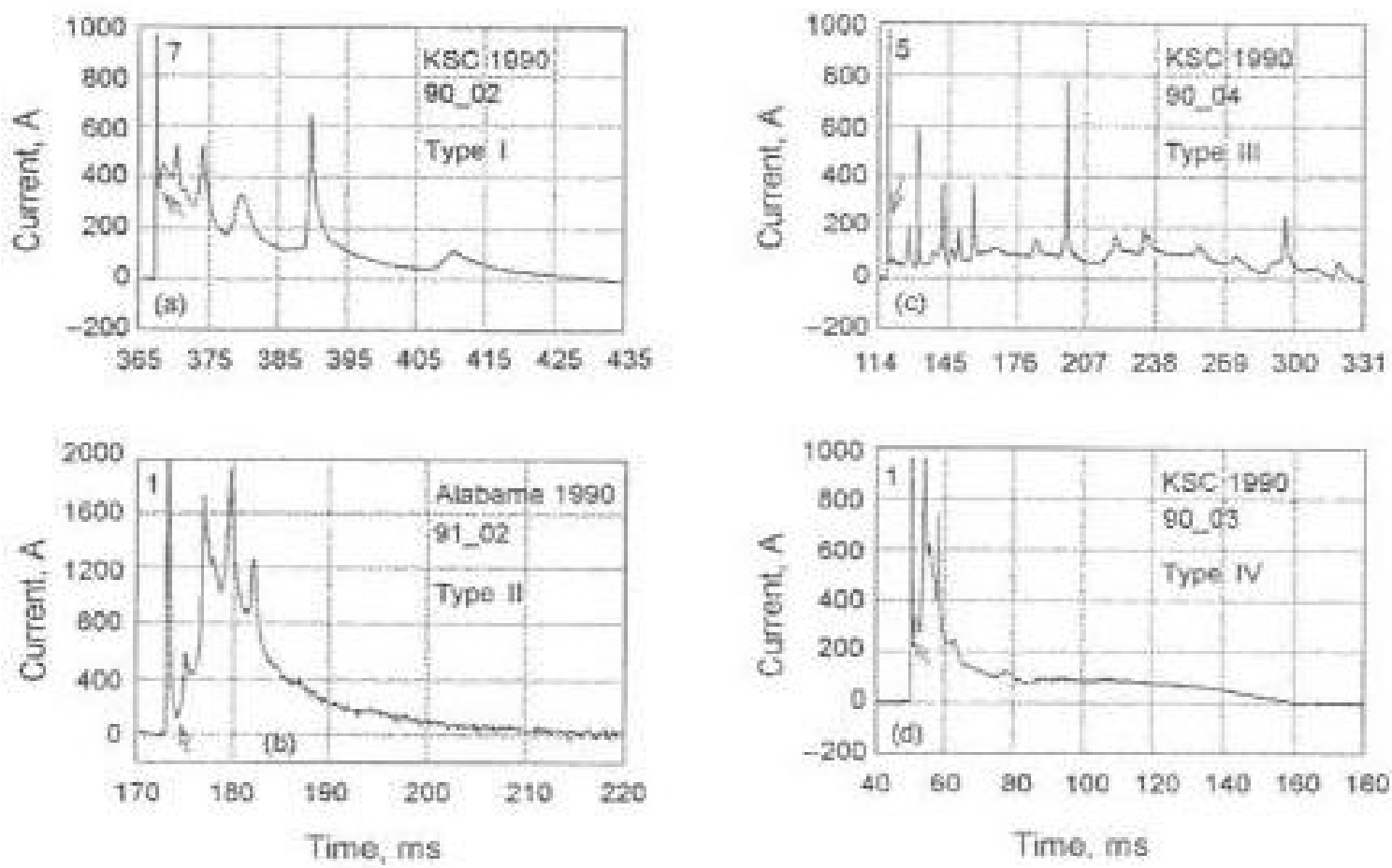

Figure 1.3. Examples of continuing-current waveforms with superimposed M-components in triggered lightning [2], [6]. (Courtesy Dr. Rakov). 
(c) Continuing current can be viewed as quasi stationary arcs between the cloud charge source and ground. Continuing currents always follow immediately after return strokes. The continuing current differ from the return stroke current significantly having much lower current amplitude in the range of up to hundreds of amperes and with a duration that is up to some hundreds of milliseconds. Because of its large duration, continuing currents are responsible for most serious lightning damage associated with thermal effects, e.g. burned holes in the metal sheets of aircrafts [1]. Most continuing currents in grounded wye electrical system can flow readily to ground through the transformer winding without causing any damage. Lightning M-components can be viewed as relatively short perturbations (or surges) on the continuing current and in the associated channel luminosity [6]. The "M" stands for D.J. Malan, who together with Collens first identified enhancement in luminosity of luminous continuing current channel [7]. Fisher et al reported current records which were correlated to the optical records [8] Figure 1.3. A typical M-component is characterized with current peak $100-200 \mathrm{~A}$, but sometimes in the range of $\mathrm{kA}[1]$, with a risetime in the range of 300-500 $\mu \mathrm{s}$.

\subsubsection{POSITIVE CLOUD-TO-GROUND LIGHTNING}

Positive Cloud-to-Ground Lightning discharges are defined as those transporting positive charge from cloud to ground. As is it was mentioned before, less than $10 \%$ of all cloud-toground lightning are positive. Positive and negative flashes to ground transfer their charge in very different ways; negative flashes with multiple discrete strokes (often) and positive flashes 
with single strokes followed by continuing currents. Negative CG flashes are impulsive and brief, whereas that for positive flashes are long and sustained [9].

K. Berger and co-workers first documented a study of positive lightning. Berger [10] initially considered positive lightning discharges as downward flashes and later Berger and Garbagnati characterized 67 positive flashes observed on Monte San Salvatore to the upward discharge category [11]. A reliable current peak statistics was not available, as his data was a mix of different discharges [1].

Median charge transfer by positive flashes is about an order in magnitude greater than that by negative flashes [2]. The knowledge of the physics of positive lightning is poorer that that of negative lightning. Positive return strokes appear very often after in-cloud discharges. Bipolar lightning discharges are usually initiated by upward leaders from tall objects. It appears that positive and negative charge sources in the cloud may use two different branches of the lightning channel.

Positive discharges have attracted considerable attention because of the following reasons:

(a) K. Berger and E. Vogelsanger [11] indicated that lightning protection should be based on positive strokes.

(b) The directly measured positive lightning current peaks were found to exceed 100kA and such currents did not cease after several hundred $\mu \mathrm{s}$, which is the usual duration in the case of negative lightning return strokes. 
(c) Shunt resistors designed to measure the lightning current were destroyed by positive lightning at Monte San Salvatore [12], as well as during triggered-lightning experiments at Kennedy Space Center, Florida [13] and at Camp Blanding, Florida [14].

K. Berger and co-workers first documented a study of positive lightning. Berger initially considered positive lightning discharges as downward flashes. But in [11], Berger and Garbagnati characterized 67 positive flashes observed on Monte San Salvatore to the upward discharge category.

\subsubsection{UPWARD LIGHTNING INITIATED BY GROUND-BASED OBJECTS}

Lightning initiated by leaders that originate from stationary grounded objects taller than $500 \mathrm{~m}$ (such as the $\mathrm{CN}$ Tower are assumed to be mostly upward flashes. Before artificially initiating lightning (rocket triggered lightning, e.g. Camp Blanding, Florida), instrumented tall structures or structures located on the top of mountains were the only means to measure the lightning current.

An object initiated discharge begins when the electric field at the top of the object reaches its breakdown value. The existence of electric field strength higher than the breakdown value near the object top at shorter distance is not sufficient for the formation of a self propagating discharge (leader) [15].

Current pulses recorded at a strike object due to upward initiated lightning can be divided into three main categories. The first category includes pulses superimposed on an initial continuous current (ICC). The second category includes return-stroke pulses that are necessarily preceded by an essentially zero current interval. The third category includes M-component pulses that are superimposed on the continuing currents following some return strokes. In rocket- 
triggered lightning, ICC pulses were found to have smaller peaks and slow risetime about $20 \mu \mathrm{s}$, similar to the M-component pulses superimposed on continuing currents [20].

An upward initiated flash usually transports negative charge to ground [5] and starts with a positive upward stepped leader (Figure 1.1). The current records on tall building are similar to artificial triggered lightning [20].

\subsubsection{Tall Structures Lightning}

Only three tall structures, higher than 400m, Empire State building, Ostankino Television Tower and $\mathrm{CN}$ Tower were equipped with current, field measuring and video observation systems.

Modern lightning locating systems such as North American Lightning Detection Network (NALDN) provide lightning return stroke peak currents estimated from measured magnetic field peaks. Direct measurements of lightning currents on tall structures could be used for testing the validity of the field-current relations [16].

\section{Empire State Building in New York}

Empire State Building in New York is a steel framed building surmounted by a tower whose top is $1250 \mathrm{ft}$ above street level. During the three years of the investigation, from 1935 to 1937, the building was struck 68 times [17]. This presents the beginning of observation of lightning on tall structures.

\section{Ostankino Television Tower of Moskow}

Ostankino Television Tower of Moskow is $540 \mathrm{~m}$ high structure and presents one of the tallest structures in the world. The lightning observations on Moscow tower have been done by high speed camera [18]. Over the 8-year period, from 1968 to 1975, 185 flashes were observed. 9 hit 
the tower below its tip. The strike locations ranged from $325 \mathrm{~m}$ to $525 \mathrm{~m}$. Table 1.1. shows data related to strikes below the tip:

Table 1.1. Data for Ostankino Television Tower Lightning strikes

\begin{tabular}{|c|c|c|}
\hline $\begin{array}{c}\text { Number of } \\
\text { Strikes }\end{array}$ & $\begin{array}{c}\text { Strike point } \\
\text { from the tip }(\mathrm{m})\end{array}$ & $\begin{array}{c}\text { Average strike point } \\
\text { distance from the tip }\end{array}$ \\
\hline 2 & 15 & 15 \\
\hline 2 & 35 & 35 \\
\hline 3 & $60-110$ & 85 \\
\hline 2 & $200-215$ & 207.5 \\
\hline
\end{tabular}

It is interesting to note that $4.48 \%$ of the strikes hit the tower below the tip.

In the paper [19], Gorin et Shkilev showed different current waveforms and current peaks for the measurements at three different heights, near bottom $(47 \mathrm{~m}$ ), middle (at $272 \mathrm{~m}$ ) and near top (at $533 \mathrm{~m})$. For the measurement on top Gorin and Shkilev used the sample set of 58 measurements.

For the current wavefront impulses with a current risetime smaller than $3.5 \mu$, measured current impulse waveform at the top had two peaks initial and absolute. At the bottom, the measured current impulse had only one peak and it had much higher peak than that measured at the top. It was not possible to distinguish the reflection of the original current impulse at the bottom. The $50 \%$ current peak value for top $(533 \mathrm{~m})$ and bottom $(47 \mathrm{~m})$ measurements were 18 and $9 \mathrm{kA}$ respectively. Gorin et al. measured the current at the three tower heights, and, in order to get the current peak value they had to model the current path assuming that the lightning channel characteristic impedance vary from $600 \Omega$ to $2.5 \mathrm{k} \Omega$, the characteristic impedance of the tower to be $300 \Omega$ and grounding impedance to be $0 \Omega$ (the low-current, low-frequency measured value was about $0.2 \Omega$ ).

Gorin and Shkilev inferred that the characteristic impedance of the channel was much higher than that of the tower. They showed the importance of the current impulse waveform measurement on the top tall structures, so that the reflected current impulse does not overlap the initial current peak. This is not the case with shorter towers e.g. Monte San Salvatore where return-stroke current measurement sample set was 176. Gorin et al. showed that current measurements at the bottom of a tall structure are higher than real current values. 
The current measurements at Ostankino tower, showed the importance of the current measurement at the top of tall structures in order to get true current impulse wavefront parameter.

\subsection{PRACTICAL IMPORTANCE OF CURRENT MEASUREMENTS}

It is well known that lightning striking an object can cause damage to it and to equipments in its vicinity. Lightning can also cause equipment failure and insulator flashovers that could destroy electronic devices and cables. The type and level of the damage depend on flash characteristics (flash duration and number of strokes per flash) and lightning current parameters (such as the current peak, current risetime and maximum current steepness).

In order to investigate the damages caused to equipment and stations in power systems, the following situations shall be taken in account:

a) Lightning to the station

b) Lightning close to the station

c) Lightning to the power lines or telecommunication lines connected to station equipments

d) Lightning close to the power lines or telecommunication lines which are connected to station equipments.

(a) Lightning flashes to stations and equipments can cause:

- fire and/or explosion, immediate mechanical damage due to the lightning arc or ohmic overheating of conductors; 
- fire and/or explosion triggered by sparks caused by overvoltages resulting from resistive and inductive coupling with one part or full lightning currents;

- failure or malfunction of protection/control system due to the lightning electromagnetic pulse (LEMP), produced by the currents flowing through the grounding conductor.

(b) Lightning flashes in the vicinity of the stations

- failure or malfunction of internal system due to LEMP.

(c) Lightning flashes to power lines or telecommunication lines connected to the station or equipment

- fire and/or explosion caused by sparks due to overvoltages transmitted through connected power lines;

- failure or malfunction of protection/control system due to overvoltages appearing on connected communication lines and transmitted to the station.

(d) Lightning close to the telecommunication lines which are connected to station equipment:

- failure or malfunction of protection/control system due to overvoltages appearing on connected communication lines and transmitted to the station.

In order to provide appropriate protection, lightning flash parameters, such as the number of strokes per flash and flash duration, and current parameters, such as maximum current 
steepness, current peak and current risetime, must be known. The above mentioned damages could be avoided with some precautions mentioned below.

\subsubsection{LIGHTNING PROTECTION OF POWER STATIONS AND POWER LINES}

The aim of lightning protection in general is to protect human beings and properties.

Lightning protection of power stations and power lines could be divided in two different categories. First and foremost, we must protect power substation and power lines from direct lightning strikes, and secondly we must protect from overvoltages caused by lightning.

The aim of the direct strike lightning protection system is to protect human life and property by diverting lightning strikes. Lightning strikes could cause damage in different ways. There is an intensive heat produced in the electric arc between lightning channel and the lightning hit object. In some situations, this energy could be large enough to melt the struck objects.

Nowadays, the predominant model for direct strike lightning protection design of power conductors is the electro-geometric model, which is based on the determination of the striking distance. The striking distance determines the maximum prospective lightning current peak which can bypass protection (shielding) and strike directly the phase conductor.

Wagner [21], Young [22], Brown and Whitehead [23], Anderson [24], and Mousa [25] have contributed to the establishment of the electro-geometric model (EGM) dealing with of the last step or the striking distance of the lightning flash. 


\subsubsection{Direct strike lightning protection of power lines}

Transmission lines are any overhead line with a phase-to-phase voltage exceeding $69 \mathrm{kV}$ and an average conductor height of more than $10 \mathrm{~m}$. The transmission line is usually shielded by one or more overhead ground wires (OHGWs). Their purpose is to take over lightning strikes and prevent the phase conductors from lightning direct strikes.

The EGM for transmission lines is defined by striking distance to OHGW, striking distance to phase conductor and striking distance to the ground. Figure 1.4 presents EGM for two different towers, with positive and negative shielding angles. The method is called last step leader. This method considers protection from downward initiated flashes, but not from upward initiated flashes. In Figure 1.4 we can see that the whole region has not been protected. It is assumed that the leader will strike the conductor if it touches the arc between A and B.

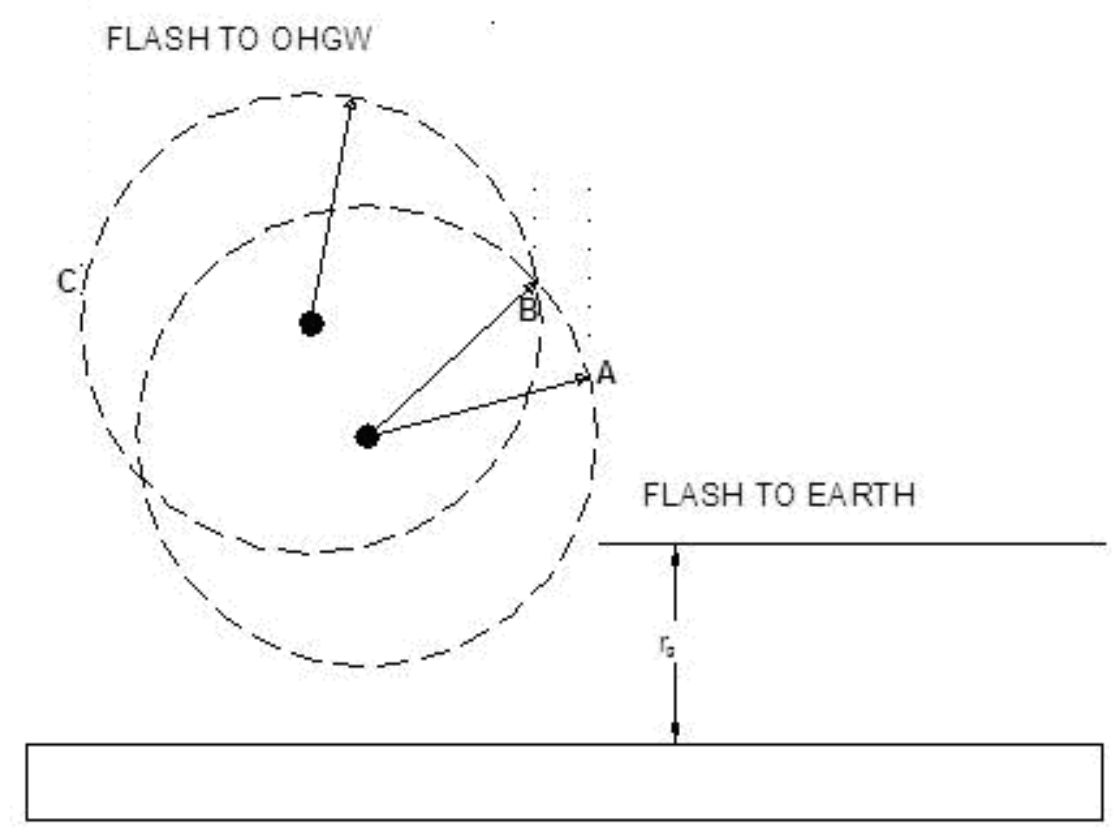

Figure 1.4 EGM for power transmission line direct lightning strike protection. 
The recommended values in IEEE Std 1243-1997 [26] are:

$$
r_{c}=10 I^{0.65}
$$

$$
r_{g}= \begin{cases}{\left[3.6+1.7 \ln \left(43-y_{c}\right)\right] I^{0.65}} & y_{c}>40 m \\ 5.5 I^{0.65} & y_{c} \leq 40 m\end{cases}
$$

$r_{c}$ striking distance for OHGW and phase conductor in meters

$r_{g}$ striking distance for ground in meters

$y_{c}$ is the average conductor height in meters

I first stroke peak

The protection is limited to the current values which will produce flashover. The critical current $I_{c}$ that produces flashover on phase conductor is

$$
\begin{aligned}
& I_{c}=\frac{2 C F O}{Z_{\text {surge }}} \\
& Z_{\text {surge }}=60 \sqrt{\ln \frac{2 h}{r} \ln \frac{2 h}{R_{c}}}
\end{aligned}
$$

where

$Z_{\text {surge }}$ is the conductor surge impedance under corona

$\mathrm{h} \quad$ is the average conductor height $(\mathrm{m})$ 
$\mathrm{r} \quad$ is the conductor radius $(\mathrm{m})$

$R_{c} \quad$ is the corona radius of the conductor at a gradient of $1500 \mathrm{kV} / \mathrm{m}$

CFO is the critical flashover voltage, as defined in [18, 22]

\subsubsection{Direct lightning protection of power stations}

EGM - Rolling sphere method is a technique for the shielding of substations [27]. The technique involves rolling an imaginary sphere of prescribed radius over the surface of a substation. The sphere rolls up and over and is stopped by lightning masts, shield wires, fences, and other grounded metal objects (such as barriers, rods, etc.) intended for lightning shielding. A piece of equipment is protected from direct strikes if it remains below the sphere surface. Equipment that touch the sphere or penetrates the sphere surface is considered not to be protected, Figure 1.5. The radius of the sphere is equal to the striking distance.

Striking distance is defined by:

$$
S=8 k I^{0.65}
$$

where:

$S \quad$ is the strike distance in meters,

I is the return stroke current peak in kiloamperes,

$k \quad$ is a coefficient to account for different striking distances to a mast, a shield wire, or the ground plane,

$k=1$ for strikes to wires or the ground plane, 
$k=1.2$ for strikes to a lightning mast.

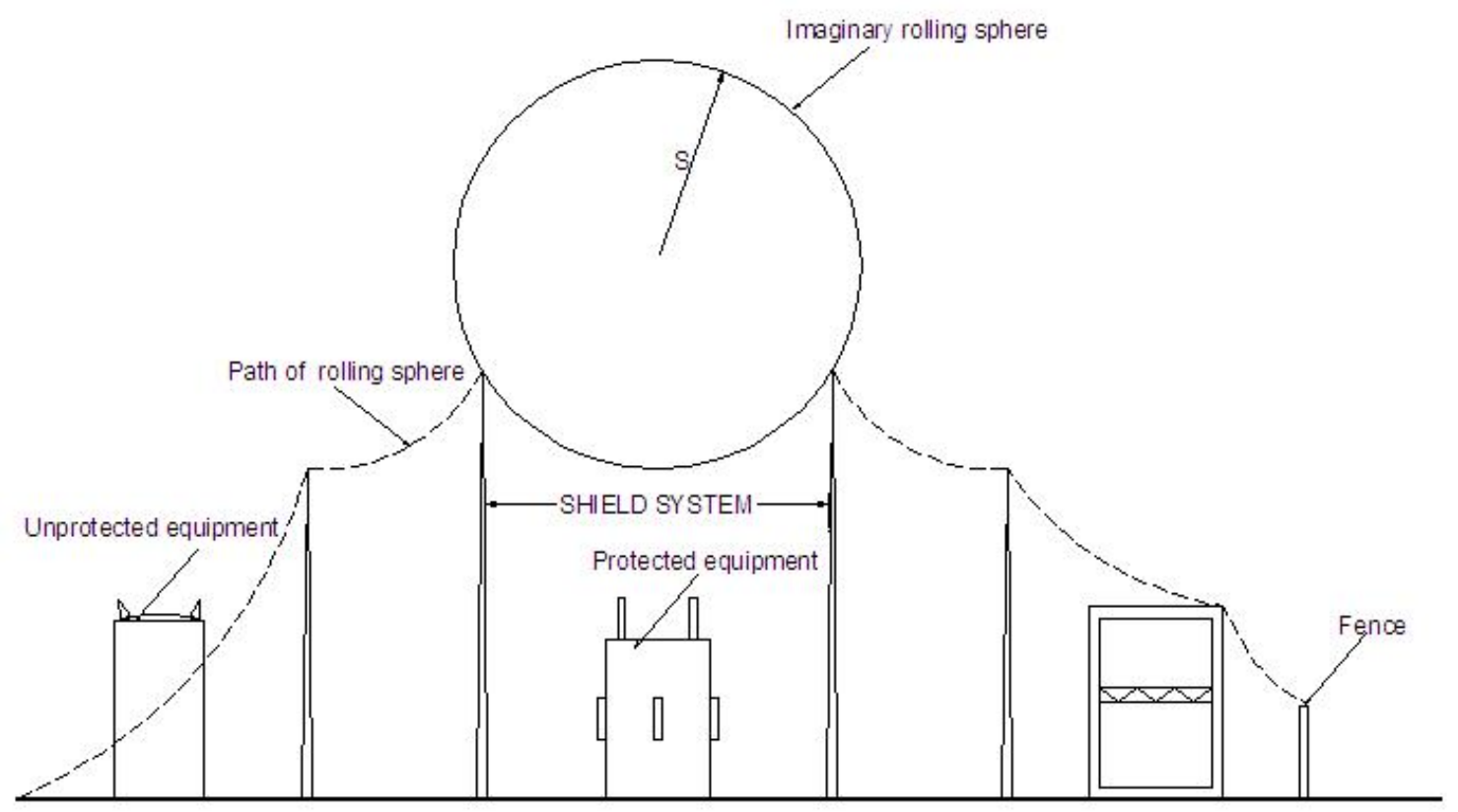

Figure 1.5. EGM for direct lightning strike protection of power station.

\subsubsection{Overvoltage protection}

More than $50 \%$ of negative downward flashes contain more than one return stroke [28]. If first stroke is lower than shielded current level (shielded current level is lower than critical current) it could pass through direct lightning strike protection system (direct lightning strike shielding system), the subsequent strokes follow path of first stroke the subsequent will follow the first return stroke path. In downward initiated lightning the subsequent return strokes have higher current rate-of-rise (lower current peak risetime).

In $12 \%$ of the cases for downward initiated lightning flashes, the subsequent return stroke currents are higher then the peak of the first return stroke current. In most cases, if the 
subsequent return stroke current peak is significantly higher than first return stroke current peak, this subsequent stroke current may cause flashover on the line or in the substation.

Higher overvoltages could be also expected on the termination of overhead lines to cable, GIL (Gas insulated line) or GIS (Gas insulated switchgear).

Practice shows that failure caused by direct lightning strikes to phase conductors is less likely because of direct lightning strike shielding system. The greater concern in practice shows for backflashovers. The backflashover happens when lightning return stroke hits the OHGW or tower and cause overvoltage which is large enough to cause the flashover over insulators. Usually, backflashovers cause temporary line-to-ground fault which should be cleared by circuit breakers.

Digital transient programs, usually used for lightning modelling are Electro-Magnetic Transient Programs (EMTP) such as ATP-EMTP, PSCAD-EMDC and EMTP-RV.

The lightning current peak and risetime are on the list of critical parameters for lightning analysis. Heidler model is used for the mathematical simulation of the lightning current [29].

Typical circuits used for the lightning modeling is shown on Figure 1.6. 


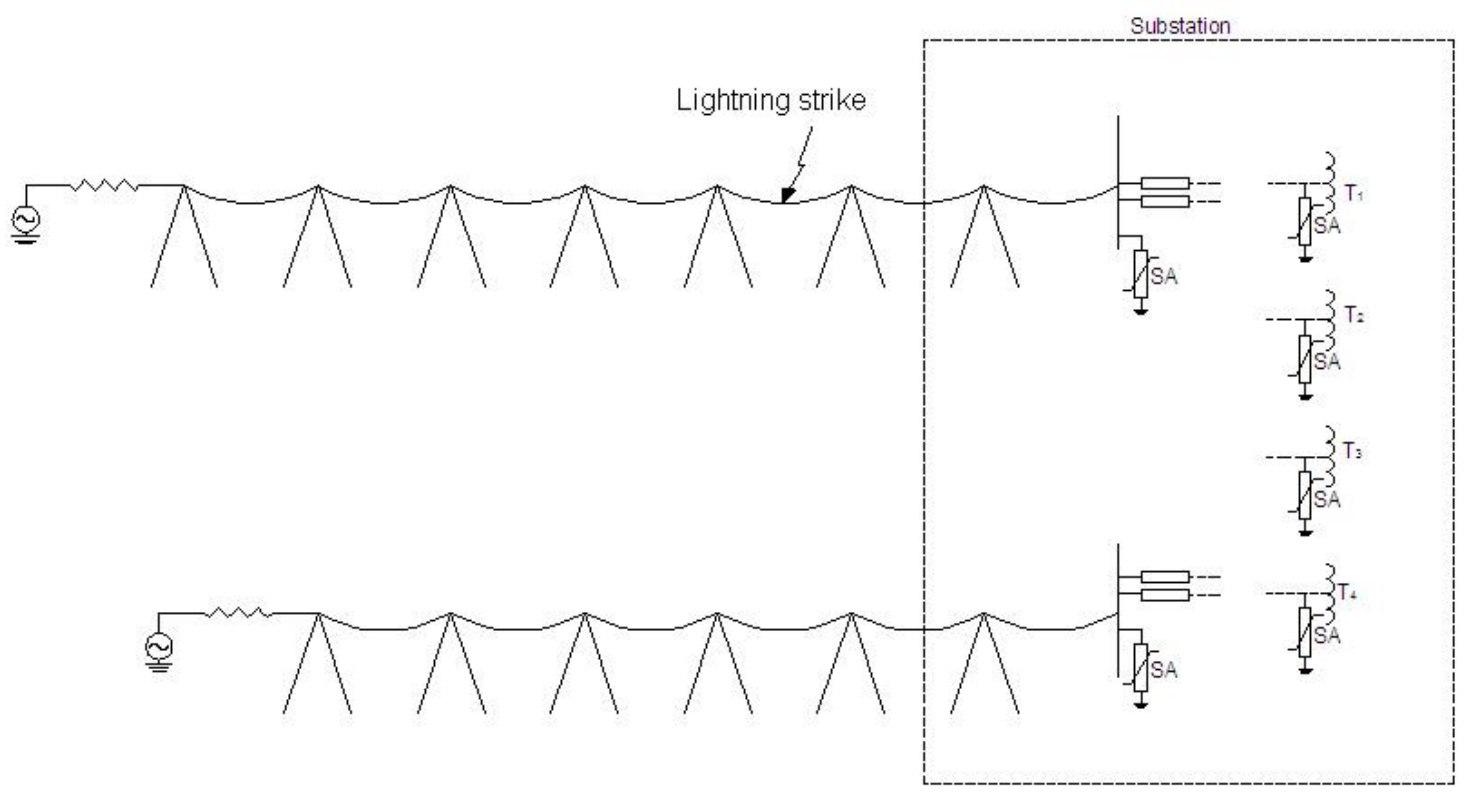

Figure 1.6. Transmission line EMTP model (parameters of each elements presented in [30], [31]).

\subsection{THE LIGHTNING CURRENT MEASURING EQUIPMENT}

\section{$\underline{\text { Shunt Resistors }}$}

The first method used to record the lightning current utilized shunt resistor, which have precise resistance values for a broad frequency band. The lightning current passing through this resistance produces a drop voltage which was recorded. In early years, a cathode-ray oscilloscope was used to display the resulting lightning current waveform. The cathode ray oscilograph have been used for lightning current measurements at the Empire State Building. With developement of electronic equipment, digitizers replaced cathode-ray oscilloscopes. 
Digitizers together with shunt resistors have been used at the $100 \mathrm{~m}$ tall radio transmission Gaisberg Tower for current measurement. A $0.25 \mathrm{~m} \Omega$ shunt resistor -T\&M Research Products Type W13.2K16-6.5s-00025 with a bandwidth of $0 \mathrm{~Hz}$ to $3.2 \mathrm{MHz}$ has been used (Figure 1.7). The most known database, obtained on Monte San Salvatore used two shunt resistances $0.8 \Omega$ and $50 \mathrm{~m} \Omega$. In order to avoid the splitting of the lightning current, the best installation location of shunt resistor should be on the top of the grounded tower just under the lightning rod (Figure 1.7) or the structure should be installed on insulators and grounding conductor connected directly to shunt resistor.

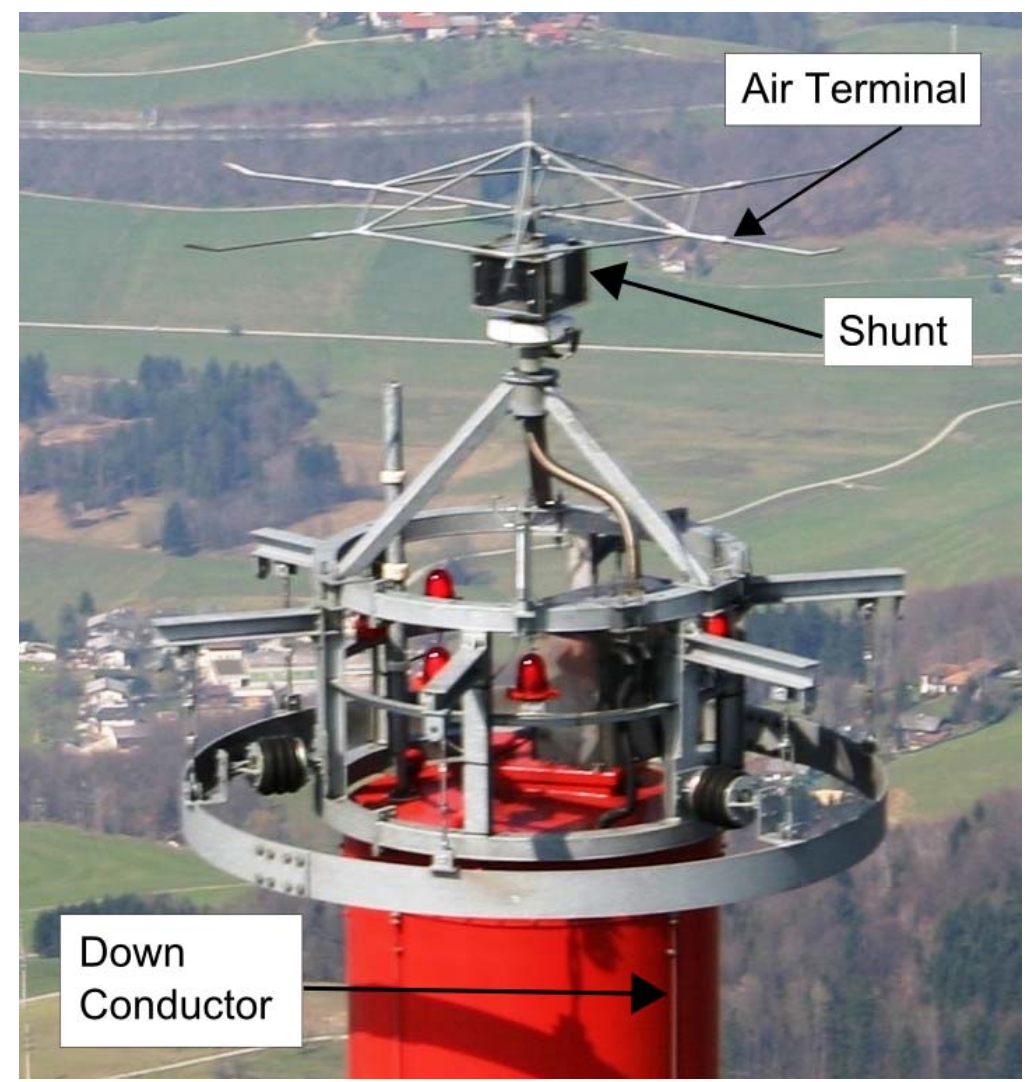

Figure 1.7 Lightning current measuring system at Gaisberg Tower Austria.

Shunt resistors were successfully used for the measurement of the continuing current and $\mathrm{M}$ - components. Also, it has to be mentioned that shunt resistors should be properly specified to 
withstand the highest lightning current (Berger recommended that shunt resistors must withstand positive lightning return strokes from positive or bipolar flashes). At San Salvatore, the shunt resistors were burned because they were not properly specified.

\section{$\underline{\text { Rogowski Coils }}$}

Rogowski coils were introduced for magnetic field measurements in 1912. The theory of the Rogowski coil illustrates how a coil can be considered as an application of Ampere's circuital law. Rogowski coils also became suitable for power system protection.

A Rogowski coil consists of a wire wound on an insulated core $\left(\mu_{r}=1\right)$. The coil is placed around the conductor whose current is to be measured as shown in Figure 1.8. The design criteria for the Rogowski coil include a core that has a constant cross-section area S and a wire that is wound perpendicular to the middle dashed line 1 with constant number of turns per unit length $n$. The induced voltage in the coil is defined by Faradey's law:

$$
e(t)=-N \frac{d \phi}{d t} ; \quad N=n l
$$

where $\Phi$ is the total magnetic flux within the Rogowski coil, which can be calculated from the following equations:

$$
\begin{aligned}
& N i=\oint_{l} \vec{H} d \vec{L} \\
& \vec{H}=n i \widehat{a}_{\varphi} \\
& \vec{B}=\mu_{0} n i \widehat{a}_{\varphi} \\
& \phi=\int_{S} \vec{B} d \vec{s}=\mu_{0} n i S
\end{aligned}
$$


the Rogowski output voltage is given by:

Therefore,

$e(t)=-\mu_{0} n l S \frac{d i}{d t}$

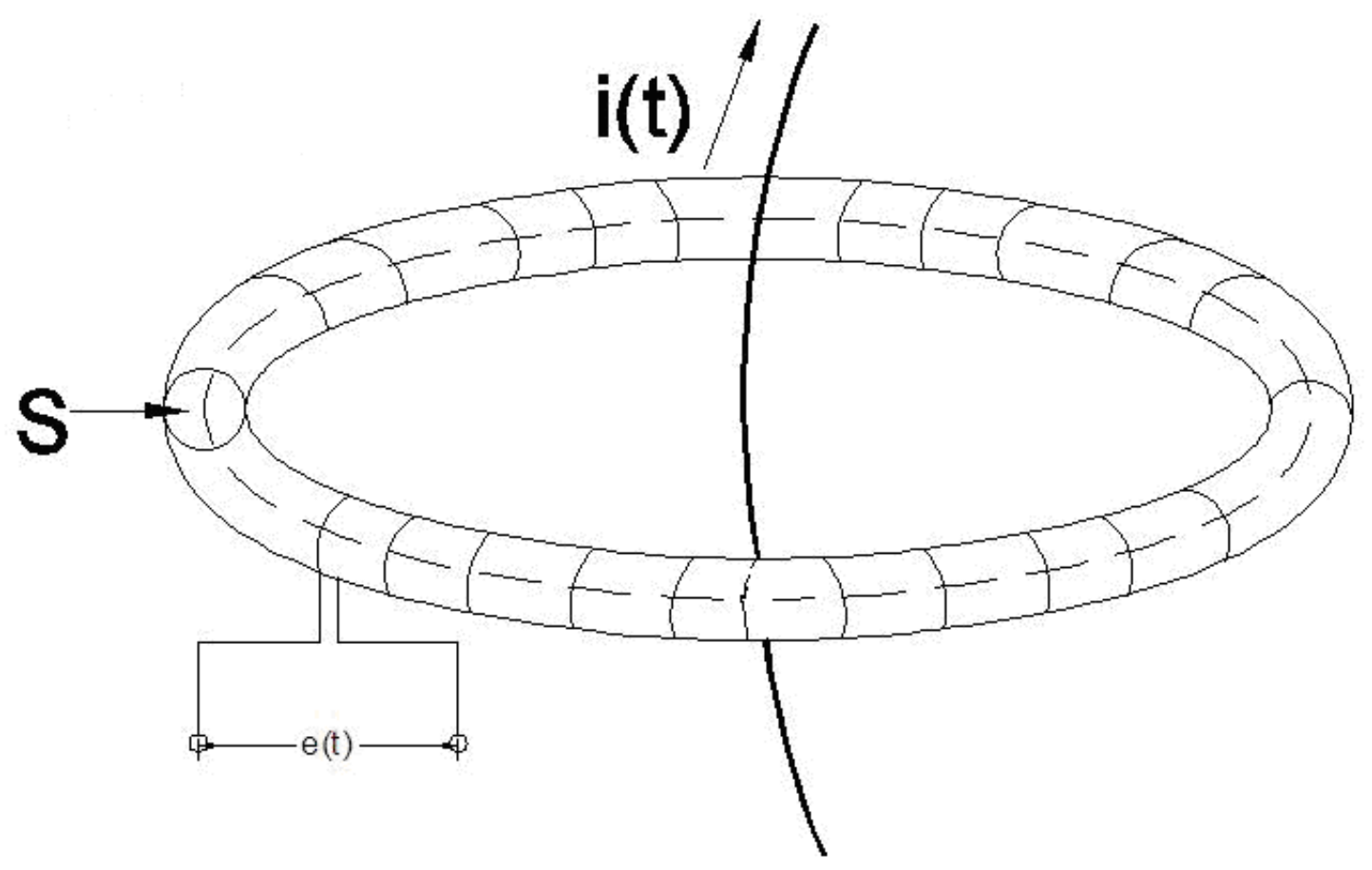

Figure 1.8. Rogowski coil principle.

For an ideal Rogowski coil the induced voltage is not dependent on the location of the conductor inside the coil loop. The Rogowski coil output voltage is proportional to the current derivative. To minimize the effect of nearby current carrying conductors, the Rogowski coil could be designed with two wire loops connected in electrically opposite direction Figure 1.9.

The accuracy of the Rogowski coil depends on its coil parameters $R_{s}, L_{s}$ and $C_{s}$, as well as the proper shielding of the connection wires. $C_{s}$ is due to coil shielding capacitance, connection cable capacitance and turn to turn capacitance. This capacitance should be minimized 
in order to reduce measurement error. The same rule is valid for Rogowski coil inductance and resistance.
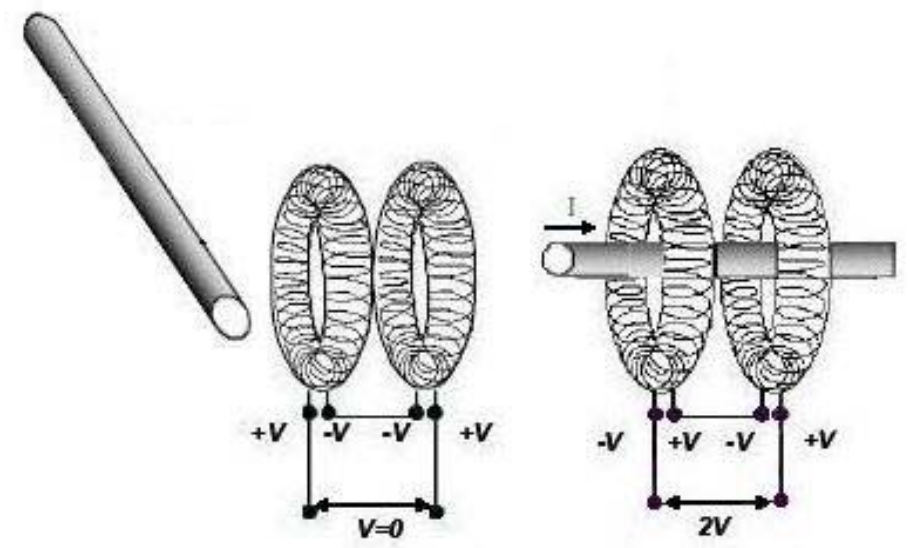

Figure 1.9 Minimization of impact of nearby current carrying conductors.

Rogowski coil design

A Rogowski coil is usually flexible and made by a coaxial cable with no outer shield. Then a wire is closely wound around the coaxial cable and the existing conductor through the cable core serves as the return conductor. It is shown in Figure 1.10.

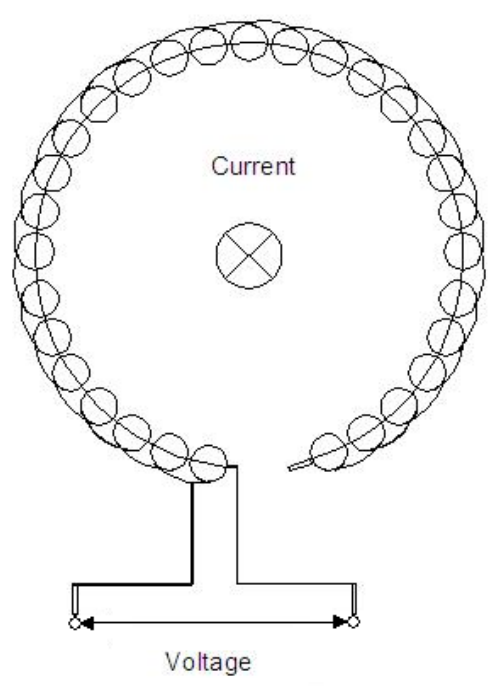

Figure 1.10. Flexible Rogowski coil. 
Since the Rogowski coil output voltage is proportional to the current derivative, in some application for lower frequencies $65 \mathrm{~Hz}$ measurement (e.g. station grounding measurements) the Rogowski coil is supplied together with an integrator (Figure 1.11). For lightning current measurement at the $\mathrm{CN}$ Tower, integrators have not been used.

Rogowski coils are usually connected to recording instruments through triaxial cables or fibre-optic links, which are more reliable in lightning environment.

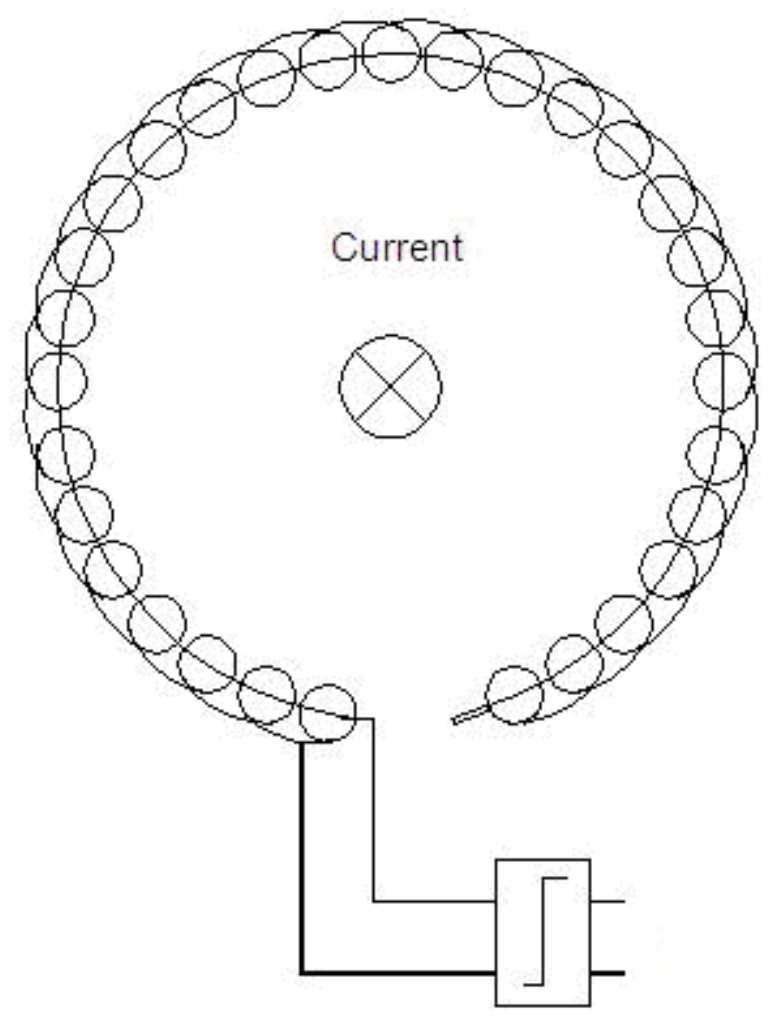

Figure 1.11. Rogowski coil with integrator.

Rogowski coils are designed to achieve good accuracy required for fast and slow di/dt changes. The absence of a magnetic material and its corresponding saturation, makes it possible to use the Rogowski coil sensor for lightning current measurements. The main factors that determine a Rogowski coil performance in comparison to other sensors are: 
- Easier installation - not connected to a conductor

- Temperature independence

- External electromagnetic field shielding

- Long lasting

- Linearity

- Frequency response and bandwidth

Easier installation: The current carrying conductor does not need to be centered or perpendicular to the Rogowski coil surface. Theoretically, the output voltage of a Rogowski coil is independent on how the current carrying conductor is located inside the coil, within a certain frequency bandwidth.

Temperature: The temperature is a problem for many sensors and in order to reduce this dependence, the coil core material should be made by materials having low temperature expansion coefficients. Rogowski coils are relatively insensitive to temperature increase of the current carrying conductor

External field shielding: A Rogowski coil output voltage depends on the magnetic field created by the current carrying conductor that passes through the area inside the coil. A careful design can minimize external field influences. Low-level current derivative signals (such as Mcomponents) measured by the Rogowski coil can be affected by the presence of strong electric fields. Such fields are often present before flashes, which make it necessary to provide coil 
shielding. Shielding is usually accomplished by adding a nonmagnetic grounded conducting surface (ground plane) in between the coil and the current carrying conductor, Figure 1.12.

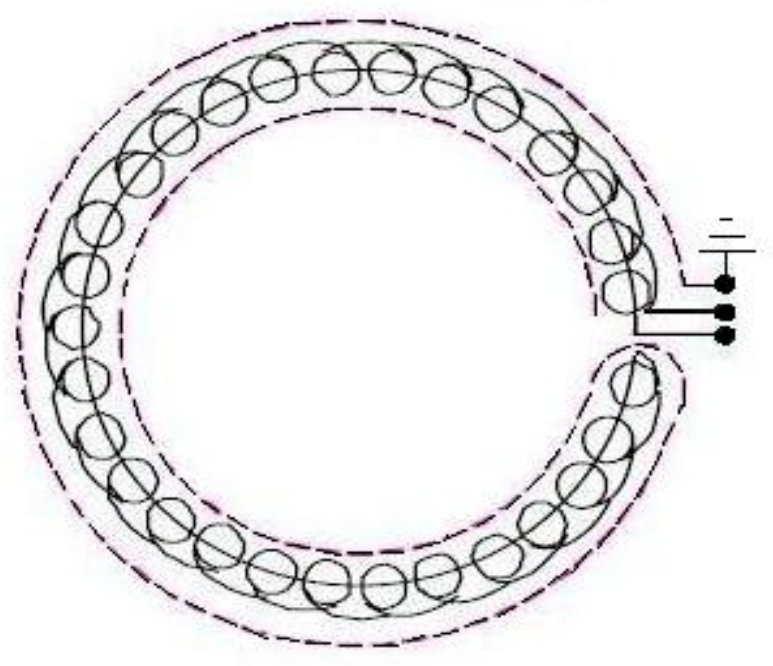

Figure 1.12. Rogowski coil external field shielding.

Although the signal is protected inside the Rogowski coil, it could be much affected by the medium through which that the signal is transported to the digitizer. In order to avoid electromagnetic interference from the outside field a double shielded cable shown in Figure 1.13. or an optical cable could be used to transfer the signal from the Rogowski coil to the digitizer. As explained before the Rogowski coil is an ideal sensor for current measurement for large current range and wide frequency bandwidth, but there is an issue if the measured current includes some unknown and unstable low frequency noise or if the time of the signal is limited.

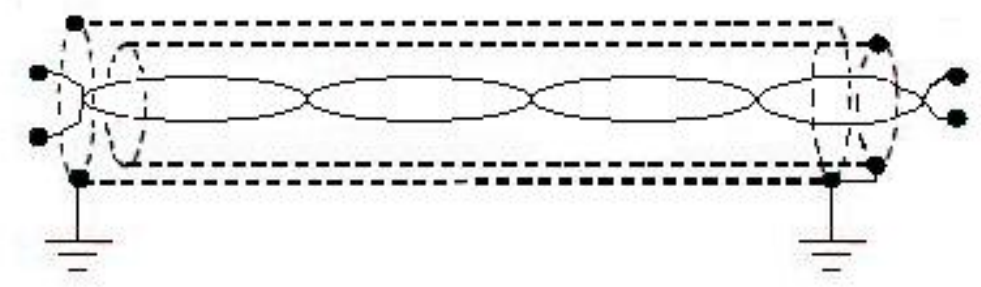

Figure 1.13 Double-shielded cable. 


\section{Chapter 2}

\section{CN Tower Lightning Measurement System}

Lightning characteristics can be determined with appropriate measuring and monitoring systems. The measurement systems of $\mathrm{CN}$ Tower lightning consist of a current measurement system and a system for the measurement of the associated electric and magnetic fields. The monitoring system serves for visual observation of the lightning channel, lightning development and characteristics.

The following sections provide a short description of the $\mathrm{CN}$ Tower lightning measurement and monitoring systems.

\section{$2.1 \quad$ INTRODUCTION}

The $\mathrm{CN}$ Tower lightning measurement and monitoring systems (Figure 2.1) provide measurement and observation of the following parameters:

- Lightning flash trajectory configuration

- Time variation of luminosity of flash trajectory

- Current derivative

- Azimuthal and radial components of the magnetic field

- Vertical component of the electric field. 


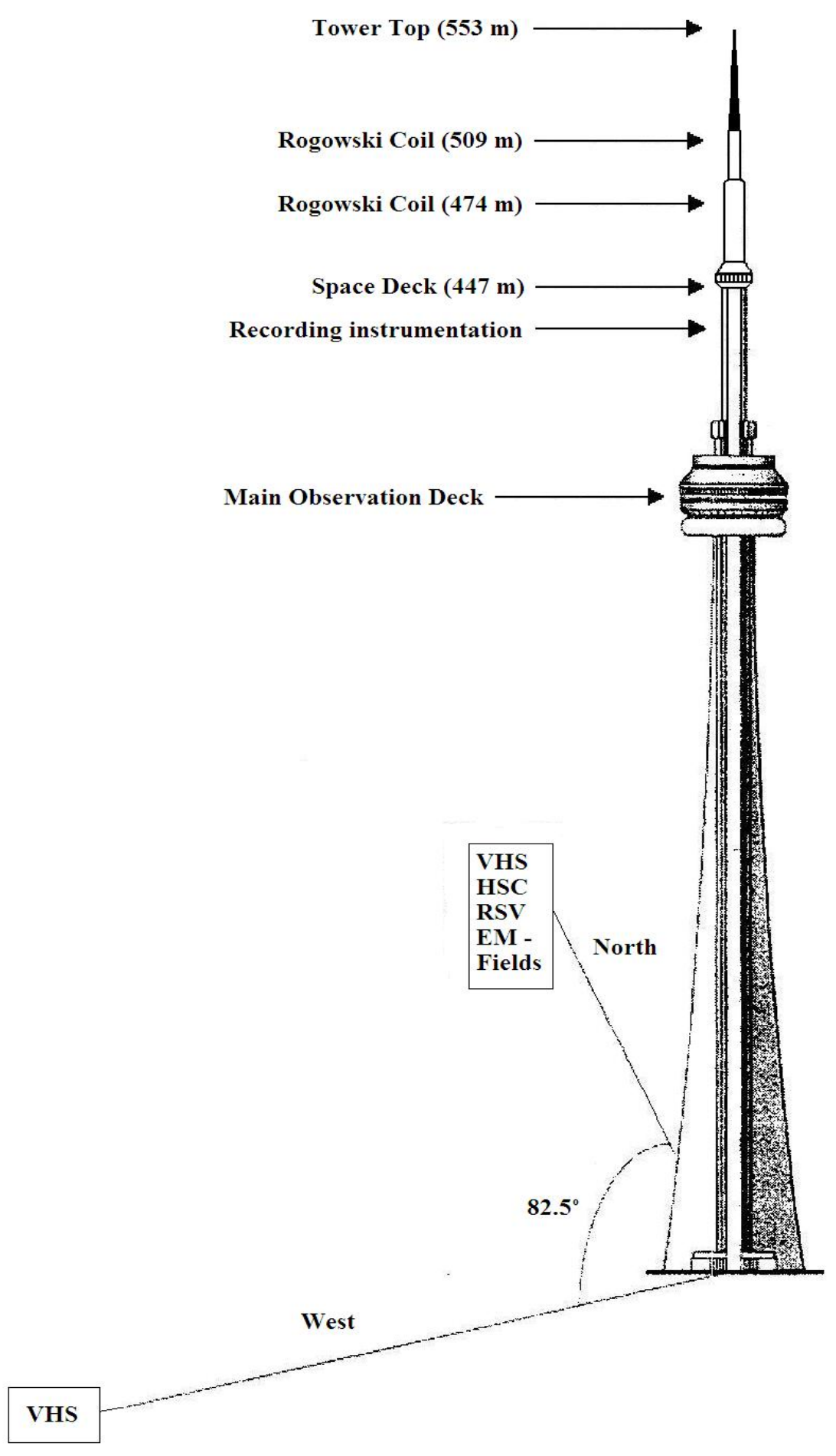

Figure 2.1. The CN Tower and locations of instruments. 


\subsection{CN TOWER VIDEO AND HIGH SPEED CAMERA MONITORING SYSTEM}

Lightning to the CN Tower has been monitored by a Video system since 1978. Since 1996, the video recording system consisted of a Vision Research Phantom v.2.0 high-speed digital camera and two Sanyo CCD cameras (model VCB-3424). One Sanyo CCD camera is located at Pratt Building of the University of Toronto (2.0 km north of the CN Tower) and the second Sanyo CCD camera is located at the Kinectrix Inc. building (formerly Ontario Hydro Technologies building), $11.8 \mathrm{~km}$ west of the $\mathrm{CN}$ Tower. The two locations provide almost perpendicular views (with an angle of $82.5^{\circ}$ between them), Figure 2.1. The two images from the two locations can be used to construct three dimensional lightning trajectories. The monitoring system helps in finding the initiation direction (downward or upward) of CN Tower lightning flashes, as well as their characteristics.

The disadvantage of the ordinary video monitoring system is the very long time interval between successive frames. At $33 \mathrm{~ms}$ resolution, this system may not allow the proper determination of the number of return-strokes in a flash or interstroke times. An example of a flash striking the tower is shown in Figure 2.2. Also, one of the rare cases when the tower is struck below its tip is presented in Figure 2.3. Video monitoring with resolution of 33ms could easily miss lightning return-strokes. 


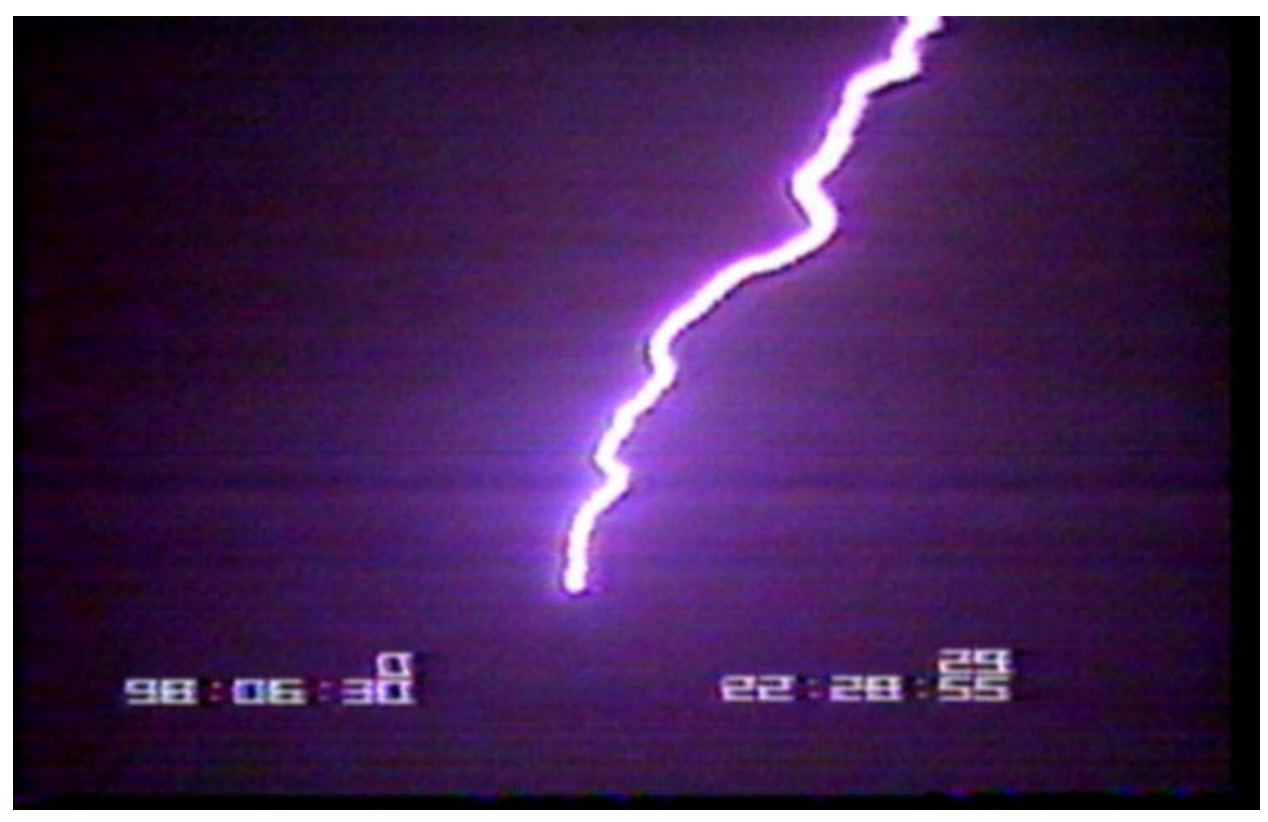

Figure 2.2. Typical video camera record of a flash striking the $\mathrm{CN}$ Tower at the tip.

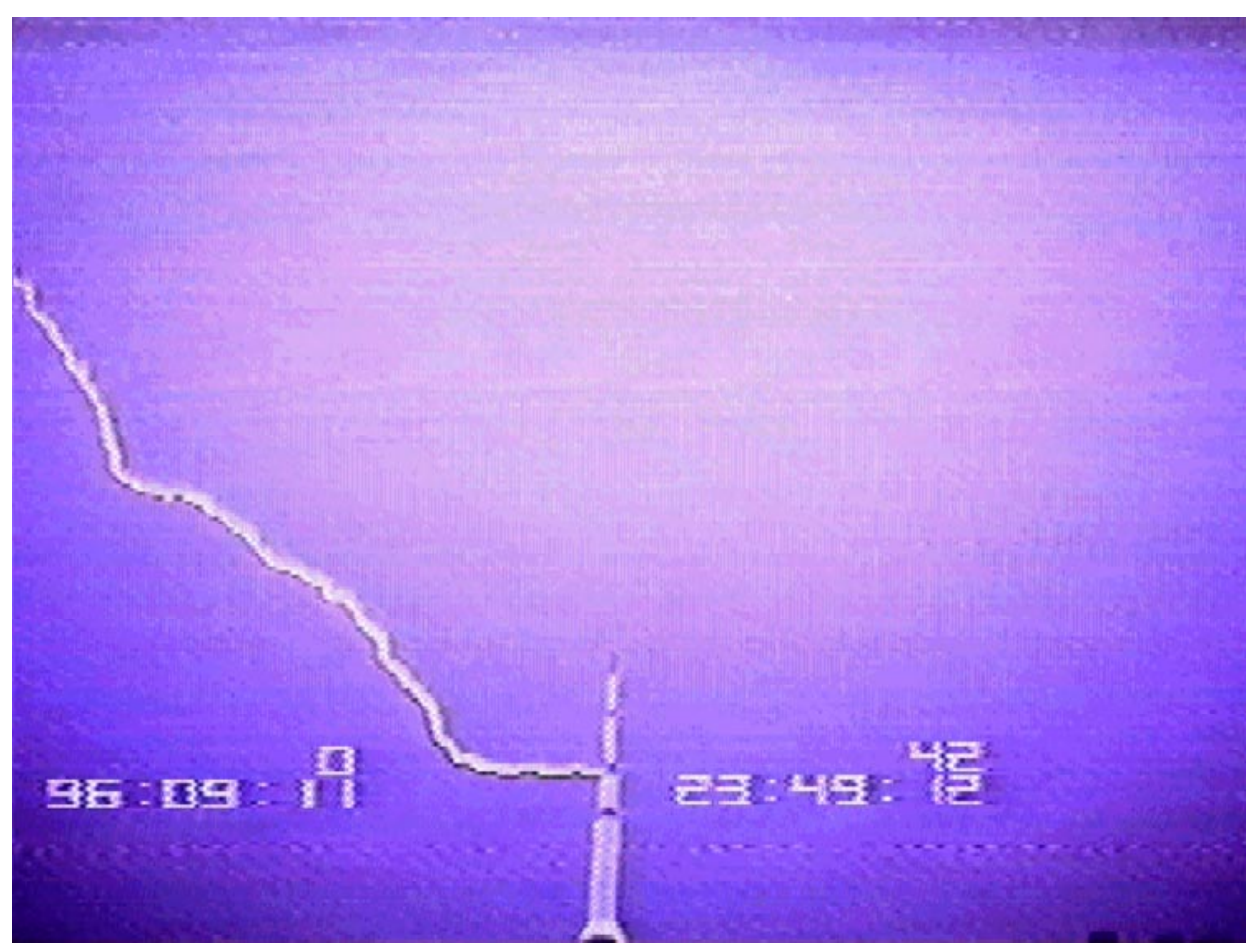

Figure 2.3. Lightning strike $45 \mathrm{~m}$ below the tip of the $\mathrm{CN}$ Tower.

This video monitoring system is substantially enhanced by the introduction of Phantom v2.0 digital high speed camera (HSC), with the capability of recording up to 1000 frames per second, 
which was installed $2 \mathrm{~km}$ north of the CN Tower in 1996. This HSC is automatically triggered by changes in light intensity.

The high speed camera provides substantially better determination of flash components and characteristics [6]. Figure 2.4 shows a HSC record of a CN Tower lightning lash.

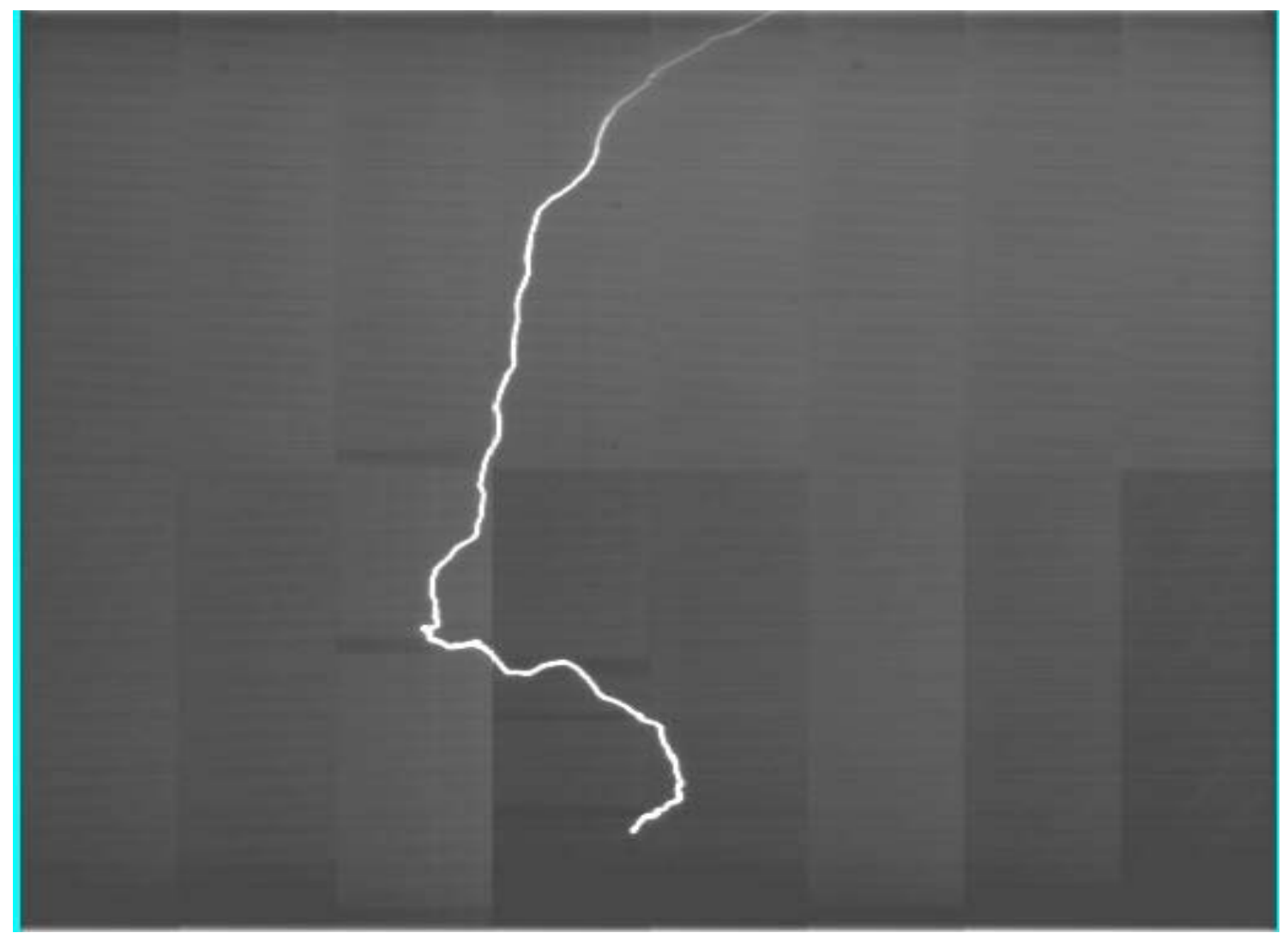

Figure 2.4. HSC record of a CN Tower lightning flash.

Detailed specification of each component of the $\mathrm{CN}$ Tower video recording system is given below:

\section{$\underline{\text { Sanyo VCB-3424 CCD Camera }}$}

Image Sensor:

Picture Elements:
1/2" CCD Sensor

811(horizontal) x 508 (vertical) 
Horizontal Resolution:

Vertical Resolution:

Signal-to-Noise Ratio:

Sensitivity:

Vision Research Phantom v2.0

Image Sensor:

Maximum Capture Rate:

Internal Memory:

Optional Memory:

Image Control:

Time Code Format:
570 TV lines

350 TV lines

more than $50 \mathrm{~dB}$

0.07 lux with F1.2 lens attached

1024x1024, SR-CMOS colour sensor

1000 picture per second (PPS) recording

$1024 \mathrm{MB}$ internal memory

$4096 \mathrm{MB}$

Fire Wire or RS422/232 serial interface

IRIG-B code, modulated or unmodulated input for timing 


\subsection{CN TOWER LIGHTNING CURRENT SENSORS}

As mentioned before, most damages caused by lightning are due to lightning currents. An essential part of the lightning research is the measurement of the lightning current. Two Rogowski coils have been used for the current derivative measurement at the $\mathrm{CN}$ Tower.

The first Rogowski coil (40MHz bandwidth and 3m long), usually known as the old Rogowski coil was installed in 1990 at the $474 \mathrm{~m}$ above ground level [AGL] of the CN Tower (Figure 2.1). This coil surrounds one fifth of the CN Tower steel structure and because of the symmetry shown in Figure 2.5, it is assumed to measure $20 \%$ of the total current derivative signal. This coil consists of two $1.5 \mathrm{~m}$ long coil segments, which are terminated with resistors at one end to absorb reflections and to damp oscillations, and then connected to an impedance matching box at the other end. The impedance matching box is connected through a $50 \mathrm{ohm}$ thriaxial cable (Belden RG-8/U), 165m long, to one channel of Sony-Tektronix RTD-710A real-time digitizer, located at the recording station, placed at 403m AGL. The impedance of the coil seen through the matching box is $50 \Omega$, in order to match it to the tri-axial cable.

\section{Technical Specifications of the old Rogowski Coil}

- $40 \mathrm{MHz}$ bandwidth

- 8.7 ns risetime

- $\quad 0.35 \mathrm{~V} /(\mathrm{A} / \mathrm{ns})$ sensitivity, $\pm 6 \%$ accuracy

- $50 \Omega$ impedance

- $3 \mathrm{~m}$ length (two sections of $1.5 \mathrm{~m}$ each) 

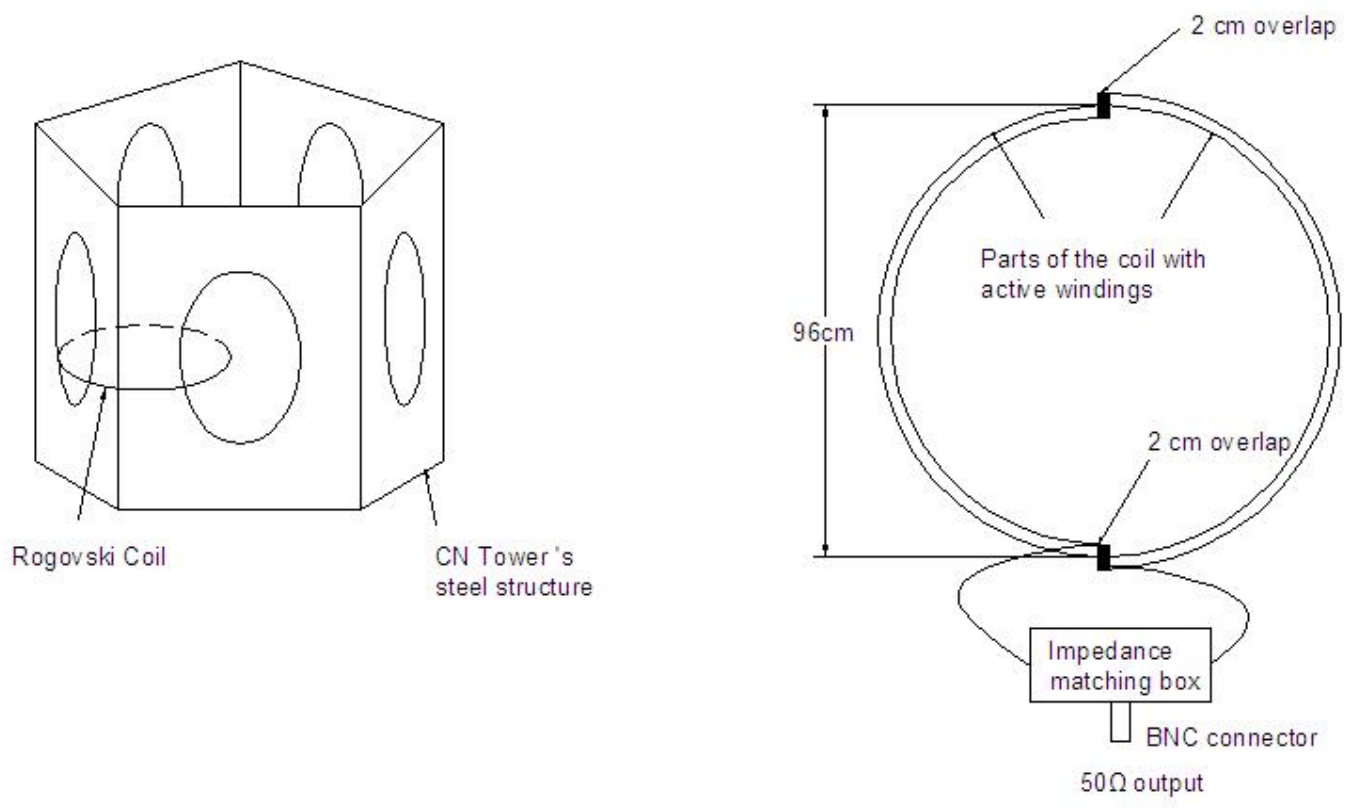

Figure 2.5. Old Rogowski coil connections and its installation at the CN Tower.

The new $20 \mathrm{MHz}, 6 \mathrm{~m}$ long, Rogowski coil was installed at the 509m AGL in 1997. The new Rogowski coil consists of four $1.5 \mathrm{~m}$ long segments for a total length of $6 \mathrm{~m}$. Since it encircles the whole steel structure of the $\mathrm{CN}$ Tower, it measures the whole lightning current derivative signal. The new Rogowski coil connection and installation at the CN Tower is shown in Figure 2.6. Each two segments of the new Rogowski coil are connected to a matching box, both matching boxes are connected to a third matching box in order to ensure that the output impedance of the third matching box is $50 \mathrm{ohms}$. A $30 \mathrm{~dB}$ attenuator is inserted between the third matching box and the fiber optic transmitter in order to avoid optical fibre link saturation.

\section{Technical Specifications of the new Rogowski Coil}

- $20 \mathrm{MHz}$ bandwidth 
- $\quad 17.4$ ns risetime

- $\quad 1.2862 \mathrm{~V} /(\mathrm{A} / \mathrm{ns})$ sensitivity, $\pm 6 \%$ accuracy

- $50 \Omega$ impedance

- $6 \mathrm{~m}$ length (four sections of $1.5 \mathrm{~m}$ each)
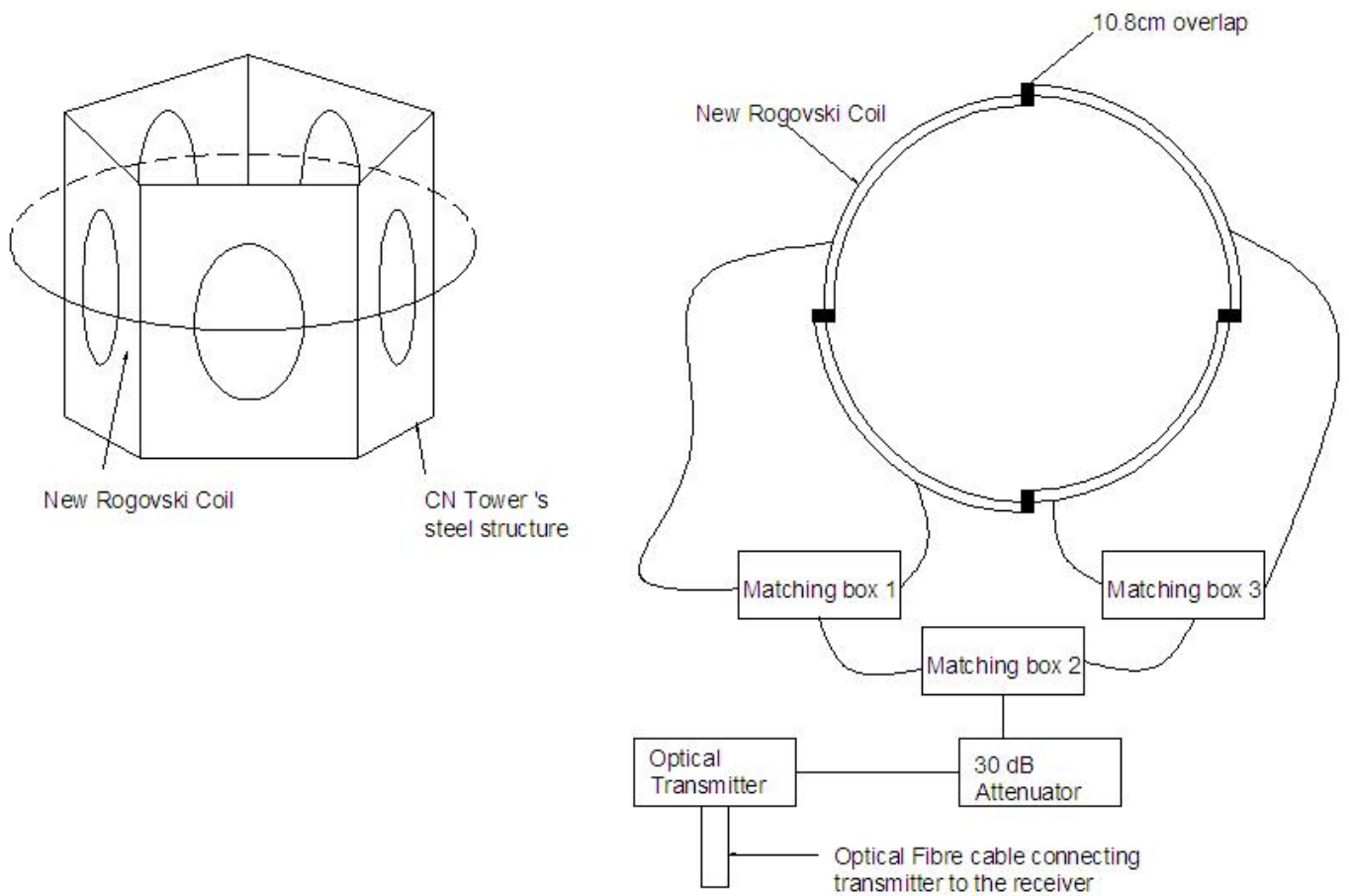

Figure 2.6. New Rogowski coil connection and its installation at the CN Tower.

\subsection{CN TOWER FIELD SENSORS}

The field measuring system consists of two magnetic field sensors and an electric field sensor. These sensors are located on the roof of Pratt Building of the University of Toronto, 2.0 $\mathrm{km}$ north of the $\mathrm{CN}$ Tower. As mentioned before, these sensors provide measurements of:

- Azimuthal component of the magnetic field

- Radial component of the magnetic field 
- Vertical component of the electric field.

One magnetic field sensors is oriented towards the $\mathrm{CN}$ Tower in such a way in order to measure the azimuthal component and the other is oriented to measure the radial component. The measured azimuthal component of the magnetic field is expected to be substantially much higher than the radial component, especially for vertical lightning trajectories (Figure 2.2).

Technical specifications of the magnetic field sensors

Type: $\quad$ active single loop antenna

Sensitivity: $\quad 0.166 \mathrm{~V} /(\mathrm{A} / \mathrm{m})$

3-dB low roll-off frequency $\quad 697 \mathrm{~Hz}$

3-dB high roll-off frequency $\quad 150 \mathrm{MHz}$

Maximum linear output: $\quad 0.62 \mathrm{~V}(\mathrm{rms})$

Technical specifications of the electric field sensor

Type: active hemispherical antenna

Sensitivity: $\quad 1.44 \mathrm{~V} /(\mathrm{kV} / \mathrm{m})$

3-dB low roll-off frequency $\quad 47 \mathrm{~Hz}$

3-dB high roll-off frequency $\quad 100 \mathrm{MHz}$

Maximum linear output: $\quad 0.62 \mathrm{~V}(\mathrm{rms})$ 


\subsection{RECORDING EQUIPMENT}

The CN Tower lightning current derivative as well as its associated electric and magnetic fields, measured $2 \mathrm{~km}$ north of the tower, were recorded by three real-time digitizers. The SonyTektronix RTD-710A double channel real-time digitizers were purchased in 1990. One of the RTD-710A digitizers was installed at the $\mathrm{CN}$ Tower for recording the lightning current derivative. The other two Sony-Tektronix RTD-710 digitizers (Figure 2.7) were used for recording one electric and two magnetic field signals. The setup allowed the recording of up to 8 strokes per flash due to memory limitations of the digitizers. In fact, according to reference [2] some of the lightning flashes could have more than 8 strokes per flash.

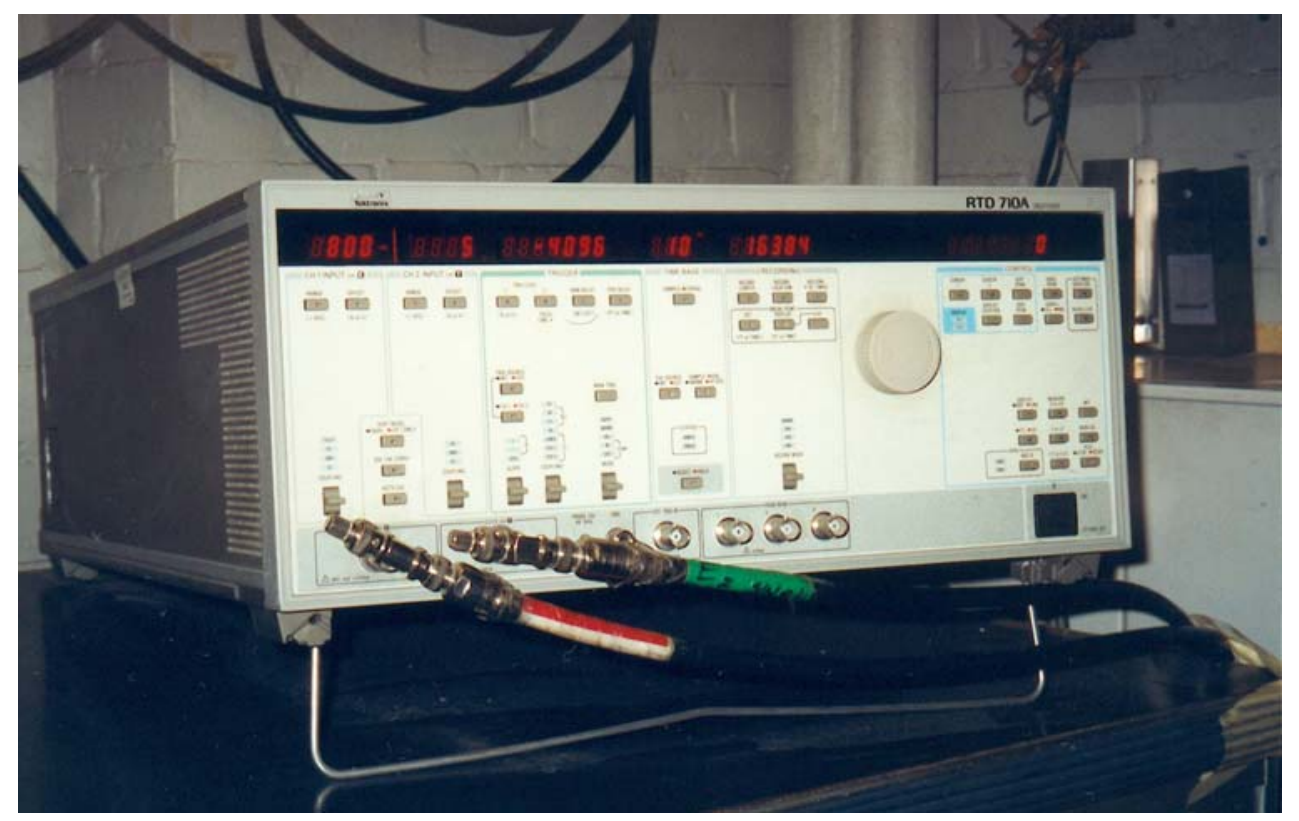

Figure 2.7. Sony-Tektronix RTD-710A digitizer. 
Technical specifications of Sony-Tektronix RTD-710A real-time digitizer

- number of channels: 2

- 68000,16 bit microprocessor is used to control programmable functions of the digitizer

- segmented memory per channel: $128 \mathrm{~K}$ points in dual channel mode and $256 \mathrm{~K}$ points in single channel mode

- bandwidth: $100 \mathrm{MHz}$

- vertical resolution: 10 bits

- minimum sampling interval: $10 \mathrm{~ns}$

- trigger mode: single or bi-slope 


\section{Chapter 3}

\section{The Lightning Current}

\subsection{RELEVANT CURRENT PARAMETERS}

The current parameters are very important in the area of lightning protection. As mentioned earlier, the lightning current peak is the primary source for thermal and mechanical damages. Also, the current rate of rise is an important parameter because its increase elevates the induced overvoltages which could cause failures in electrical and electronic devices/systems. The lightning current impact parameters are:

- Current peak

Ipeak

- Charge

$Q=\int i d t$

- Joule's energy

$$
W=R \int i^{2} d t
$$


- Maximum current derivative

$$
\left(\frac{d i}{d t}\right)_{\max }
$$

The current peak $\left(\mathrm{I}_{\text {peak }}\right)$ is crucial for the design of protection means from direct lightning strikes to objects. When the lightning current flows through the ground, which has resistivity that is dependent on the electrical field (ionisation point), it produces drop voltage in the earth that could destroy buried cables.

The charge $\mathrm{Q}$ is responsible for the melting effects at lightning striking points. The energy transferred at arc root is given by arc voltage multiplied by the charge Q [32].

Joule's energy is responsible for the heating effects, when the lightning current flows through metallic objects.

The induced voltage increases as the lightning current maximum rate of rise increases, which could damage electrical and electronic devices as well as cause flashover in power substation and failure in power equipment insulation.

A schematic representation of the lightning return-stroke current is shown in Figure 3.1. It is characterized by its peak, front time $T_{1}$ and decay time $T_{2}$. 


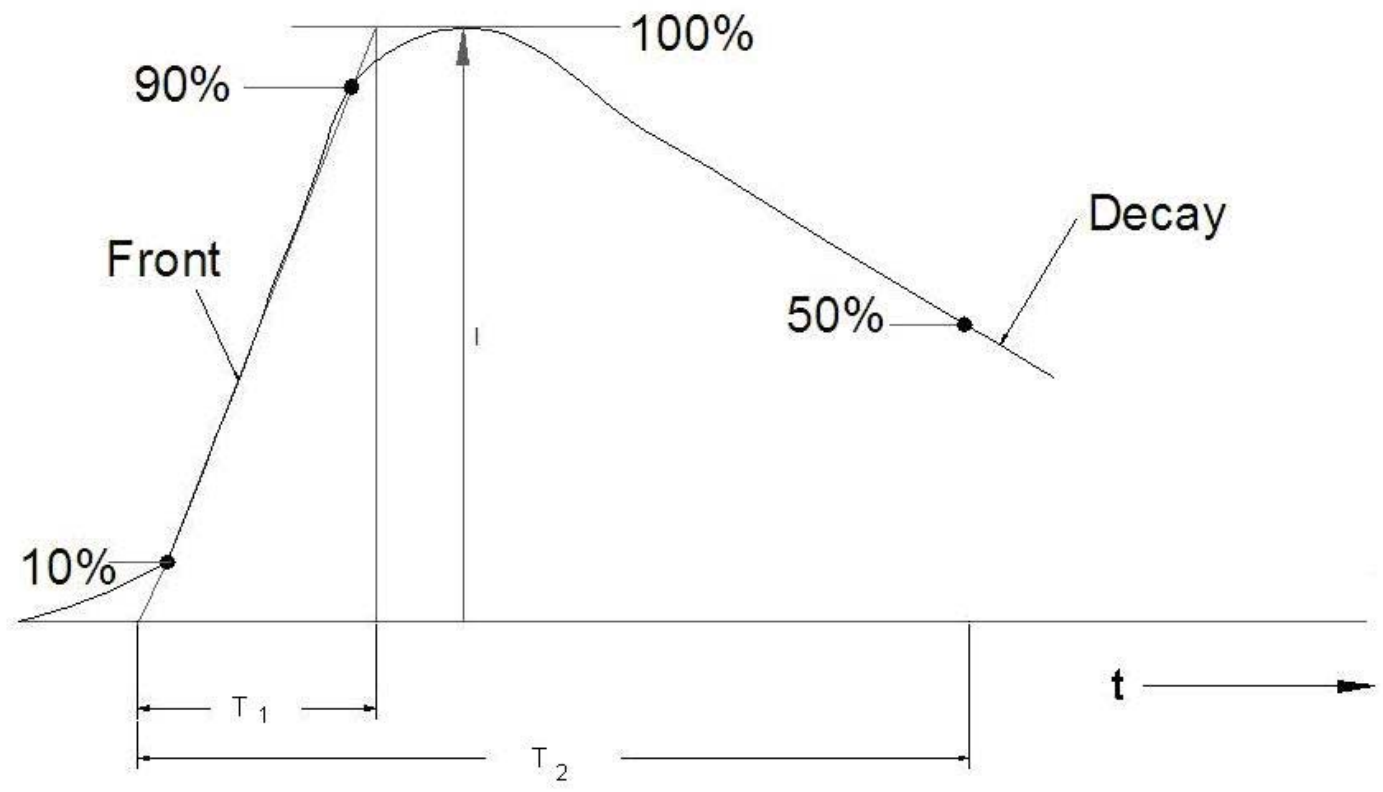

Figure 3.1. A schematic representation of the lightning return-stroke current.

The risetime $t_{r}$ is defined as the time range during which the current rises from $10 \%$ to $90 \%$ of its peak. The front time $\mathrm{T}_{1}$ is derived from the current risetime and it is $25 \%$ larger than the current risetime as it is shown in Figure 3.1. The decay time $T_{1}$ is the time between derived "zero" point and the time when current falls to $50 \%$ of the current peak after it passed the current peak (Figure 3.1).

The current waveform is commonly presented by a double exponential function (3.5) in power engineering modelling (Figure 3.2a).

$$
\begin{aligned}
& i=\frac{I_{\text {peak }}}{\eta}\left(e^{-t / \tau_{2}}-e^{-t / \tau_{1}}\right) \\
& \mathrm{I}_{\text {peak }} \quad \text { - current peak }
\end{aligned}
$$


$\eta \quad$ - correction factor

$\tau_{1} \quad$ - front time constant

$\tau_{2} \quad$ - decay time constant

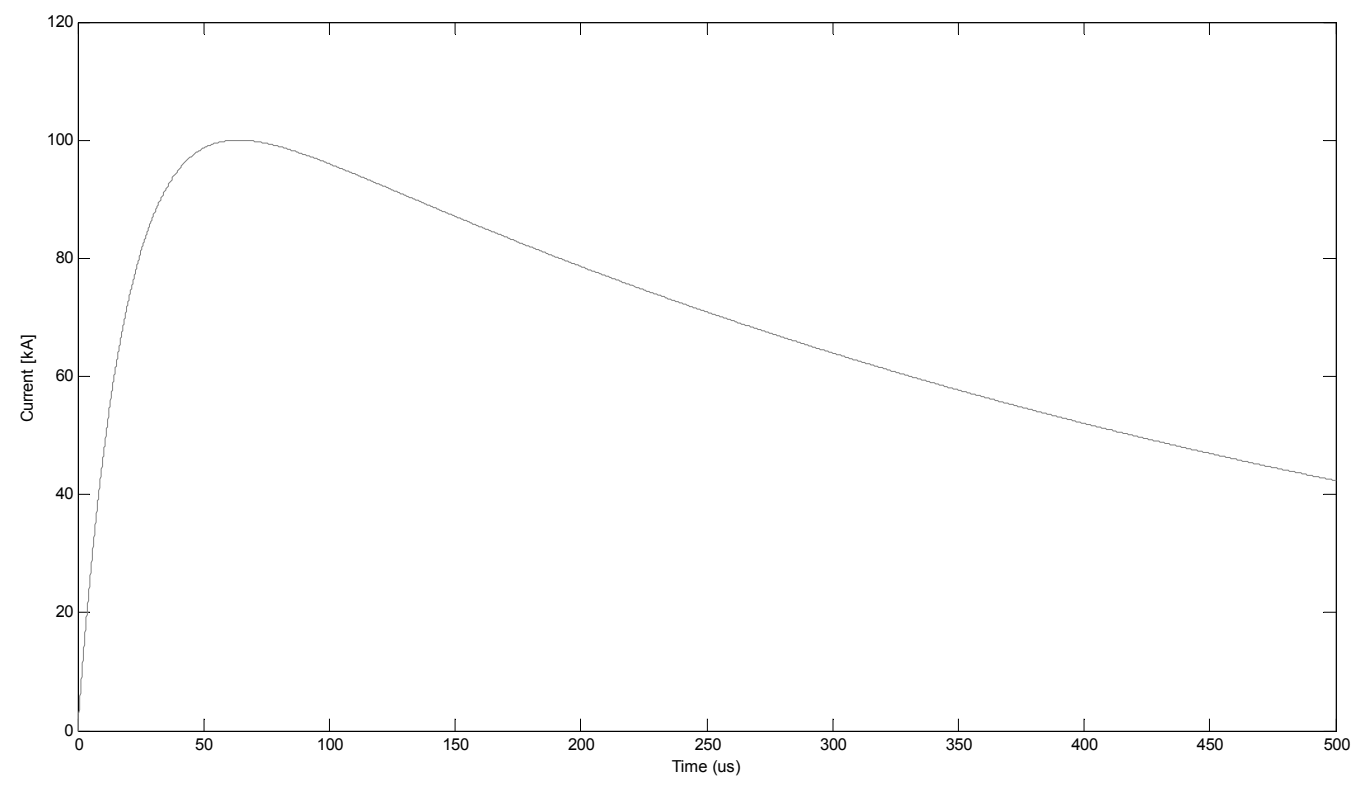

Figure 3.2a. Double exponential presentation of lightning return-stroke current.

Equation (3.5) has a problem because of the current derivative discontinuity at $t=0$ [33]. However, Heidler function (3.6) is much more suitable to simulate fast and slow current wavefronts.

$i=\frac{I_{\text {peak }}}{\eta} \frac{\left(t / \tau_{1}\right)^{n}}{1+\left(t / \tau_{1}\right)^{n}} e^{-t / \tau_{2}}$

where 
$\eta=\exp \left[-\left(\frac{\tau_{1}}{\tau_{2}}\right)\left(\frac{n \tau_{2}}{\tau_{1}}\right)^{\frac{1}{n}}\right]$

and $\mathrm{n}$ is an exponent having values between 2 and 10

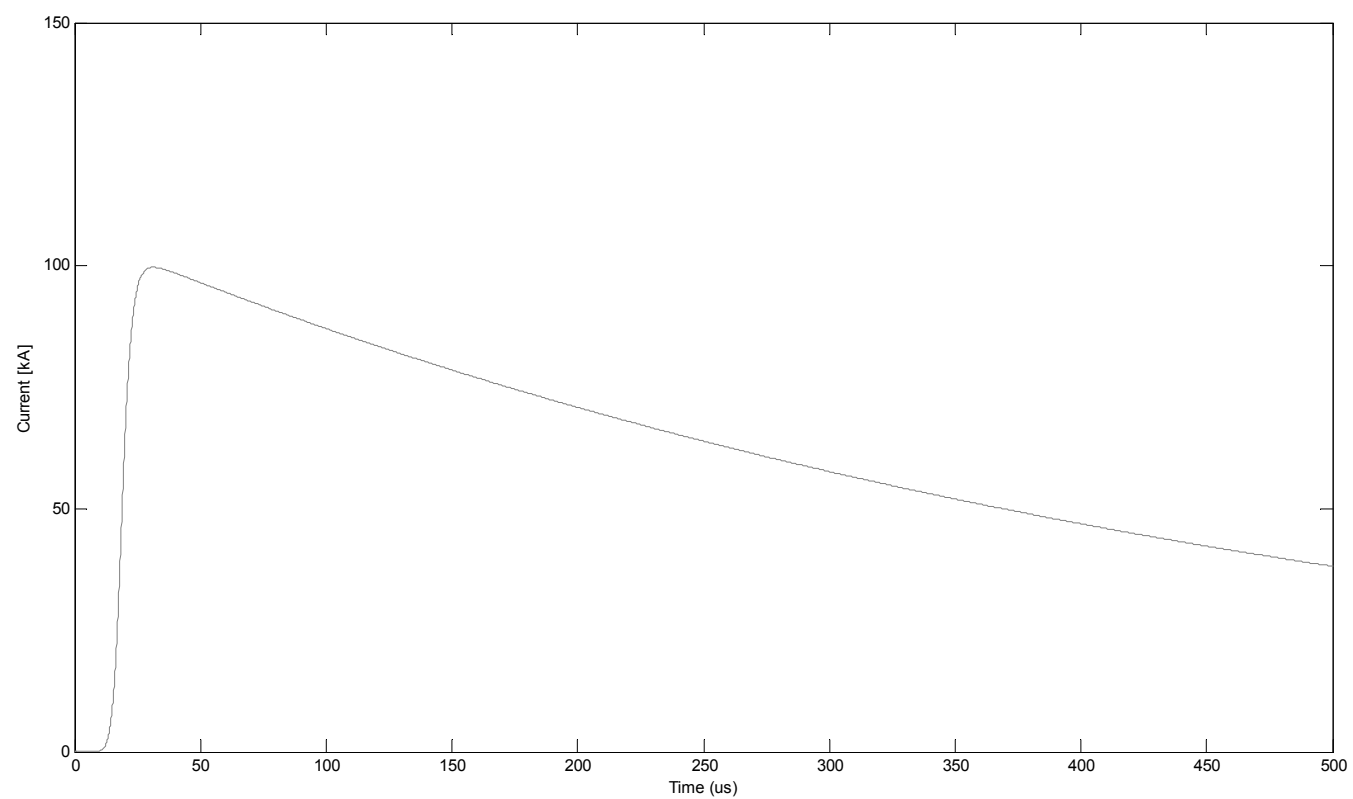

Figure 3.2b. Heidler function from IEC 62305 - Table B1 - first return-stroke.

In lightning protection standard IEC 62305 part, the Heidler function, shown in Figure $3.2 b$, is used with exponent $n=10$ to simulate lightning current, for a return - stroke impulse $10 \mu \mathrm{s}$ /350 $\mu \mathrm{s}, \tau_{1}=10 \mu \mathrm{s}, \tau_{2}=485 \mu \mathrm{s}, \eta=0.93$ [34]. For simulating the lightning current, Nucci et al. proposed the sum of the Heidler function and the double-exponential function [35], whereas Diendorfer and Uman used the sum of two Heidler functions [36]. 


\subsection{MEASUREMENT OF CN TOWER RETURN-STROKE CURRENT DERIVATIVE}

\subsubsection{ASSOCIATED NOISE IN THE LIGHTNING RETURN-STROKE CURRENT DERIVATIVE SIGNAL}

The CN Tower lightning return-stroke current derivative is measured at the $\mathrm{CN}$ Tower. The old Rogowski coil is located at $474 \mathrm{~m}$ AGL, whereas the new Rogowski coil is at $509 \mathrm{~m}$ AGL. The recording station is located at 403m AGL. The old Rogowski current derivative measure signal is associated with the following types of noise:

- DC offset

- Low frequency noise in the vicinity of $100 \mathrm{kHz}$

- High frequency noise

$\underline{\text { DC Offset }}$

A typical CN Tower lightning return-stroke current derivative signal is shown in Figure 3.3. This DC offset produced the ramp shown in the return-stroke current waveform obtained by numerical integration and shown in Figure 3.4. 


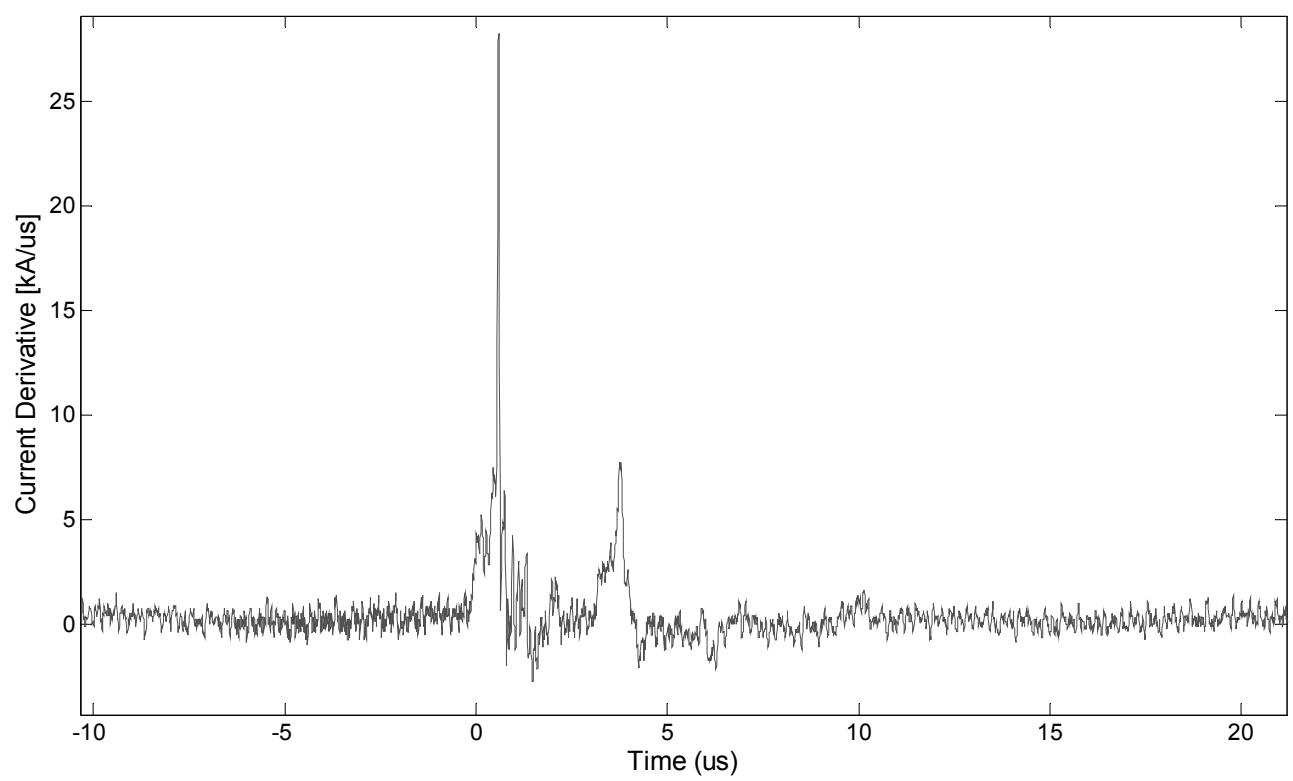

Figure 3.3. A lightning current derivative signal recorded at the CN Tower in 1996.

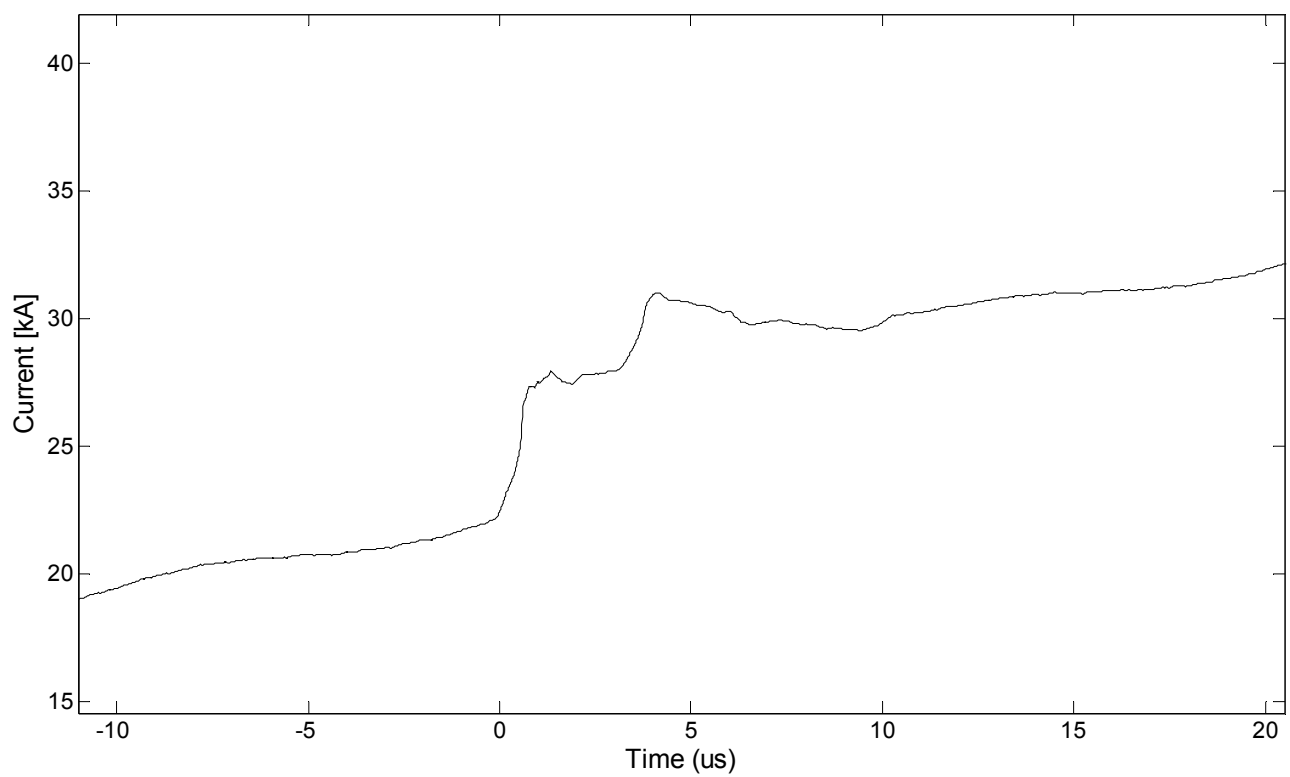

Figure 3.4. The current waveform obtained by numerical integration of the current derivative signal shown in Figure 3.3.

In order to get the proper current waveform, the DC offset must be removed from the current derivative signal. This DC offset could be calculated by averaging the pre-lightning portion of the signal. This portion must be properly chosen in order to accurately determine the 
return-stroke current peak and risetime. The removal of the DC offset from the measured returnstroke current derivative signal (Figure 3.3) before the integration process produced the current waveform shown in Figure 3.5.

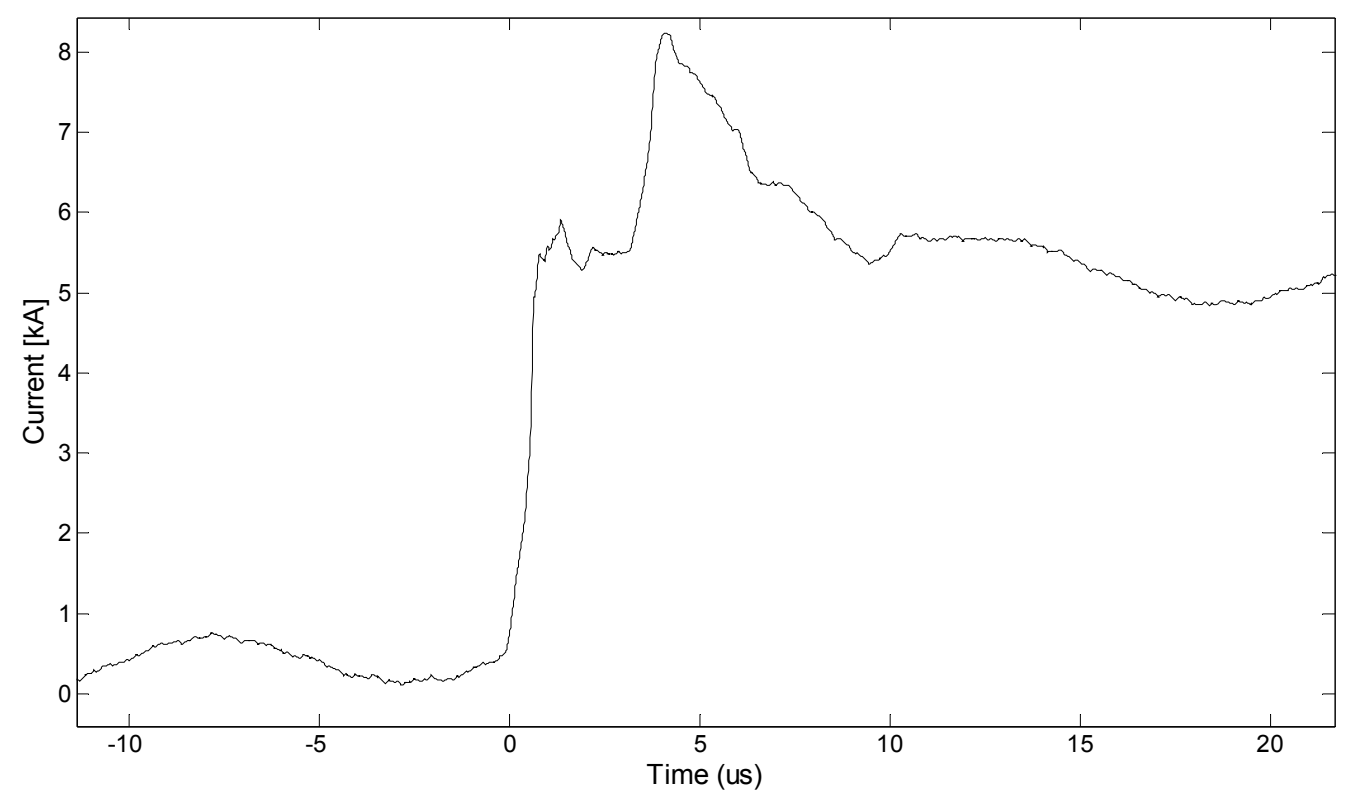

Figure 3.5. CN Tower current waveform resulted after the removal of the DC offset.

$100 \mathrm{kHz}$ noise (low frequency noise)

This noise is clearly visible at the beginning and at the end of the current waveform shown in Figure 3.5. The existence of this noise makes the calculation of waveform parameters difficult, especially for lower peak currents. Previous investigations proved that this low frequency noise is actually LORAN-C (Long Range Navigation) signal, a radio navigating signal, at its centre frequency the $\mathrm{CN}$ Tower represents an efficient receiving monopole antenna. 


\section{$\underline{\text { High frequency noise }}$}

High frequency is generated by $\mathrm{CN}$ Tower transmitting antennas. This noise almost disappears after numerical integration of the recorded current derivative signal.

\section{$\underline{\text { Lightning current wave reflections }}$}

If we compare the simulated return-stroke waveform in Figure 3.2 and the real returnstroke current waveform in Figure 3.5, we can see several current reflections from the CN Tower structural discontinuities and from ground. Analysing numerous signals captured by the old Rogowski coil, it is confirmed that the ground reflections occurs always at $3.16 \mu$ s after the first peak. The lightning current wave travels through the tower's structure at approximately the speed of light in free space. The distance between the old coil and ground is $474 \mathrm{~m}$, that means that current wave travels $948 \mathrm{~m}$, from coil to ground and back, in $3.16 \mu \mathrm{s}$. Other minor reflections usually have lower effect on fast wavefront lightning return-stroke impulses and in these cases we assume that the first peak is the actual initial peak. For the slow wavefront lightning current impulses, ground reflections may considerably influence the calculation of the current initial peak.

\subsection{CN TOWER RETURN-STROKE CURRENT WAVEFORMS}

Negative lightning

Through the duration of this work, it was noticed that $\mathrm{CN}$ Tower negative lightning current impulses can be divided into two considerably different categories, which was a major 
discovery that lead to the characterization of two very distinguished current impulses: impulses with fast wavefronts, representing the overwhelming majority of $\mathrm{CN}$ Tower negative lightning current impulses and impulses with relatively much lower rate of rise of the current. Figures 3.63.9 present a comparison between the current waveshapes and parameters of fast wavefront pulses (Figures 3.6, 3.7) and slow wavefront impulses (Figures 3.8, 3.9).

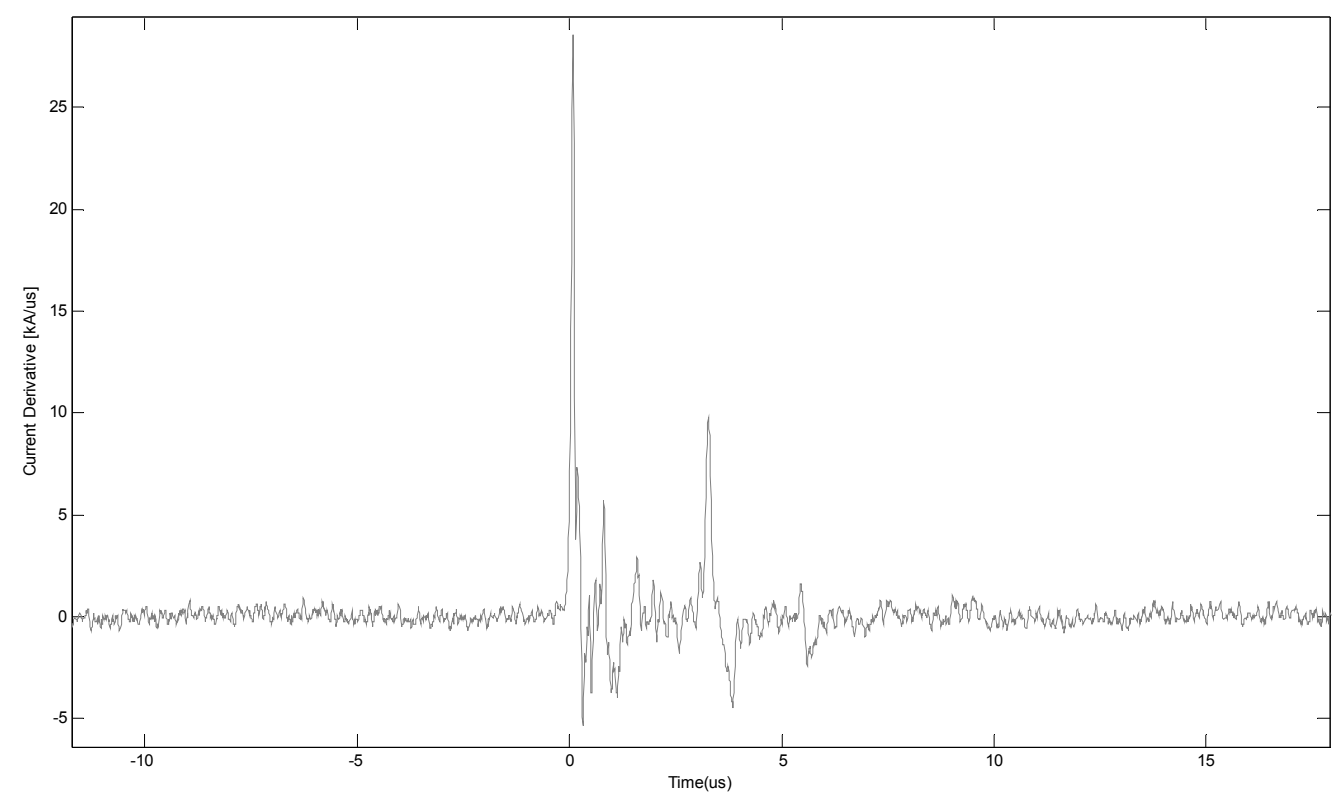

Figure 3.6 A typical negative lightning return-stroke current derivative signal measured at the $\mathrm{CN}$ Tower. It belongs to fast current rising impulses.

A typical negative lightning return-stroke current derivative recorded at the $\mathrm{CN}$ tower is shown in Figure 3.6. The figure shows two high current derivatives' peaks where the first one (maximum current derivative) represents the signal maximum wavefront steepness and the second one represents the ground reflected current derivative wave. The reflection is a result of different characteristic impedances of different $\mathrm{CN}$ Tower sections. The reflection factor for current waves is defined by equation (3.8) 


$$
\beta_{I}=\frac{Z_{B}-Z_{G}}{Z_{B}+Z_{G}}
$$

where

$Z_{B} \quad$ - characteristic impedance of the bottom part of $\mathrm{CN}$ Tower (multistory model in EMTP [37])

$Z_{G} \quad-$ CN Tower grounding impedance

For the transmission line (TL) modelling $Z_{\mathrm{B}}$ is assumed to be a constant whereas $Z_{\mathrm{G}}$ is not [38]. The effective grounding impedance is initially equal to impedance of buried wires, and in a few microseconds, it reduces to a level which corresponds to the leakage resistance. The wave impedance rises fast in less than $1 \mu$ s and then increases at slow rate after, but the leakage resistance initially has very high value and it decreases as the reflections build up the voltage along the conductor and getting final value equal to low frequency value [39], [40], [41].

As mentioned before, for this fast impulse category, the ground reflected wave that comes after the current wave reaches its own natural peak. This means that first lightning current peak, in the Figure 3.7. presents real lightning current peak, that arrives about $3.2 \mu$ s after the initial peak. The waveform of Figure 3.8 presents a current derivative signal of a negative lightning return-stroke, which belongs to the slow impulse category. It is not easy to detect the reflected wave and it is not possible to differentiate between initial peak and absolute peak. That is because the current impulse risetime is larger than the travel time from the Rogowski coil to ground and back. 


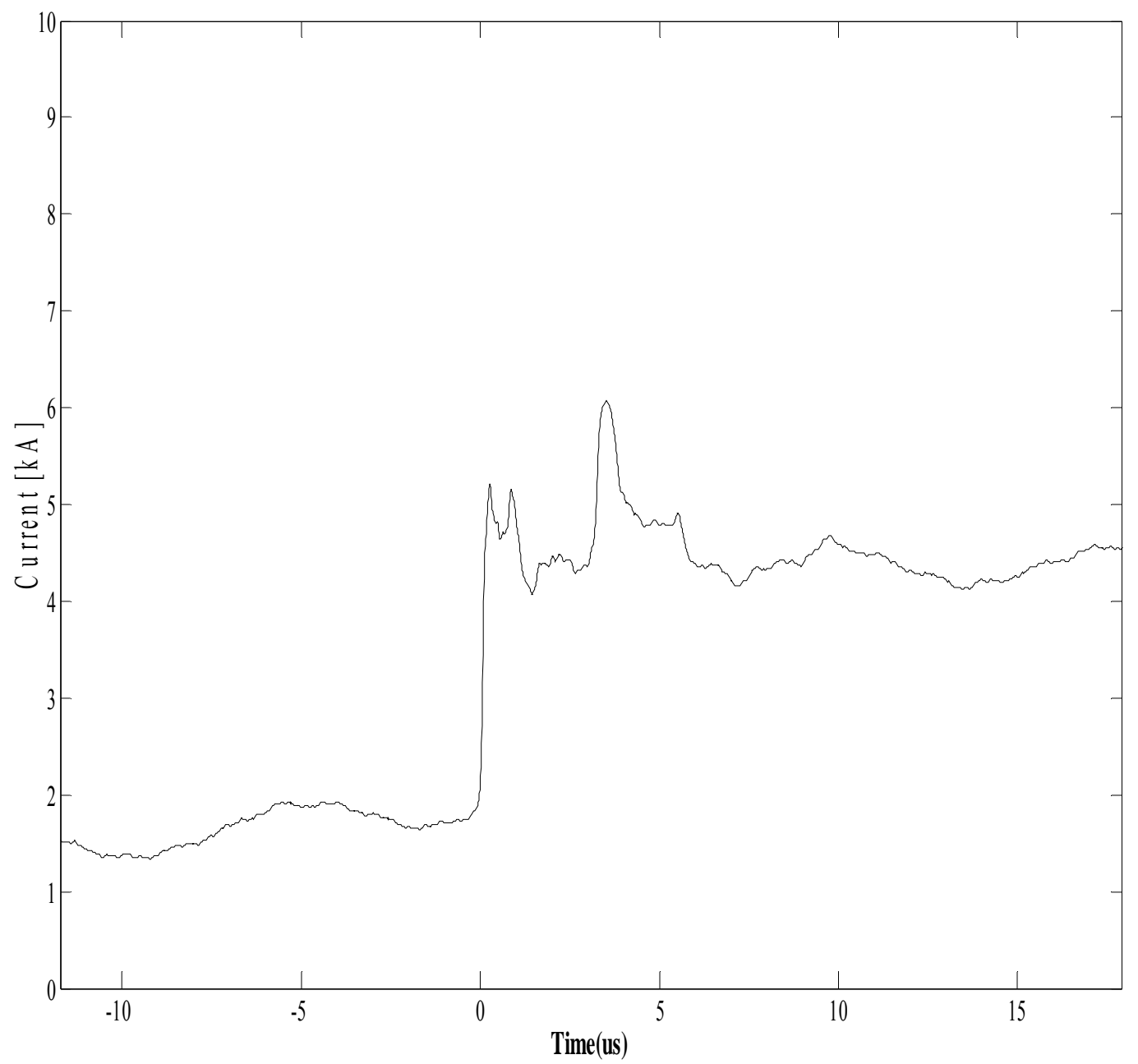

Figure 3.7. The lightning return-stroke current obtained by numerically integrating the measured current derivative signal shown in Figure 3.6. 


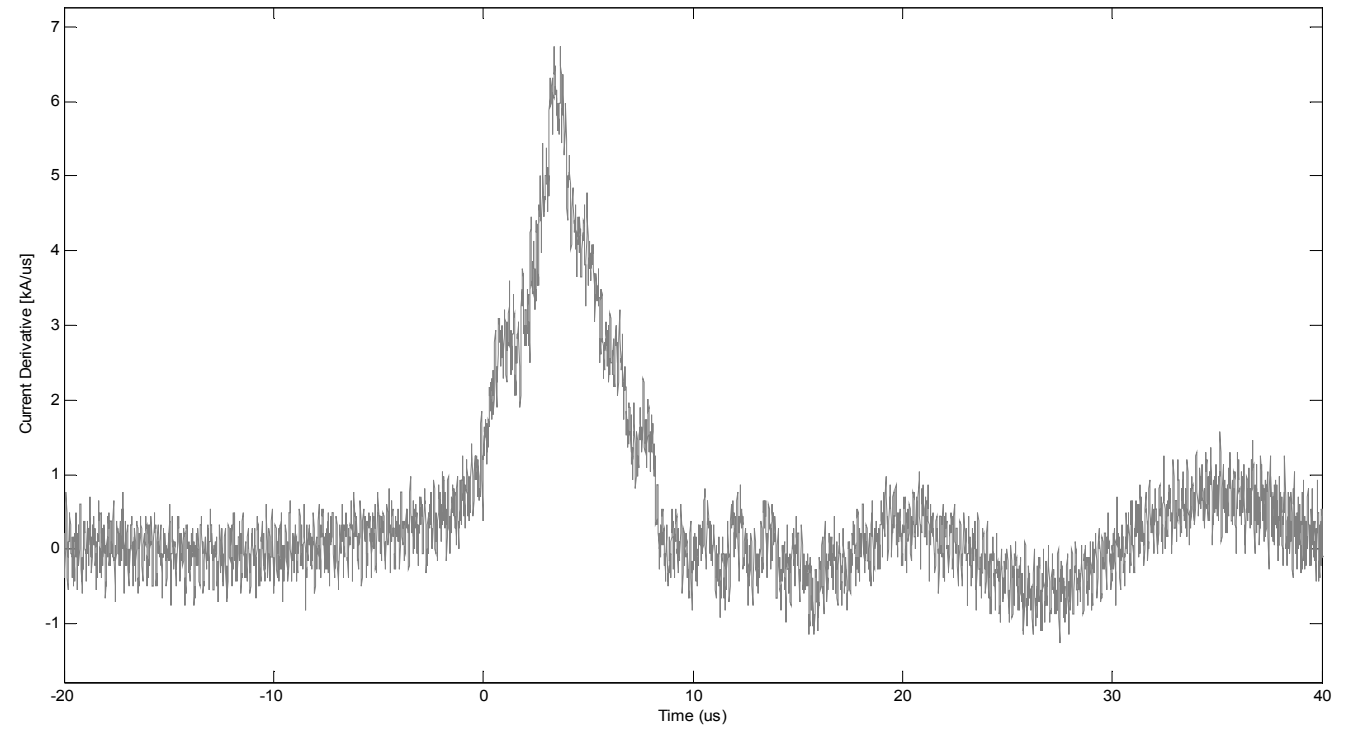

Figure 3.8. A negative lightning return-stroke current derivative signal measured at the $\mathrm{CN}$ Tower. It belongs to slow current rising impulses.

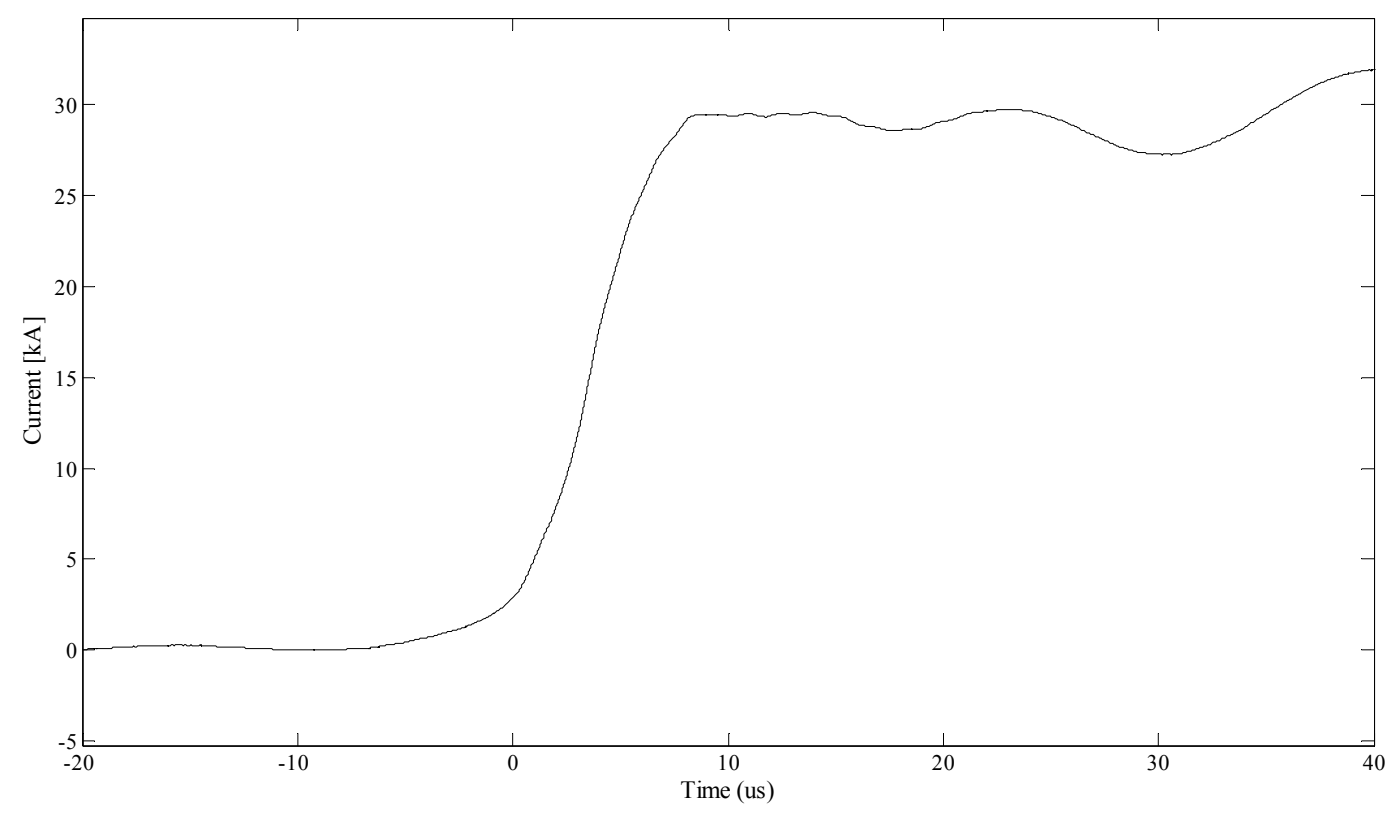

Figure 3.9. The lightning return-stroke current obtained by numerically integrating the measured current derivative signal shown in Figure 3.8.

Comparing waveforms of Figures 3.10 and Figure 3.11 with Figure 3.12 and Figure 3.13 the substantial differences are clearly noticed. Impulses with fast wavefronts do not distinguished 
between themselves whether they are first or subsequent return-strokes, what is known for ordinary return-strokes on tall structures. The impulses with slow rise time look like first returnstroke in downward initiated lightning, what has been proved for some of them by Video recordings [3]. Figure 3.10 presents current derivatives' signals recorded at the $\mathrm{CN}$ Tower for a lightning flash with all fast wavefront return-stroke current impulses, and figure 3.11 presents current impulses obtained by numerical integration of current derivatives from figure 3.10. Figure 3.12 presents current derivatives' signals for a lightning flash with a first slow wavefront return-stroke current impulse and with all subsequent fast wavefront return-stroke current impulses, and figure 3.13 presents current impulses obtained by numerical integration of current derivatives from figure 3.12 .

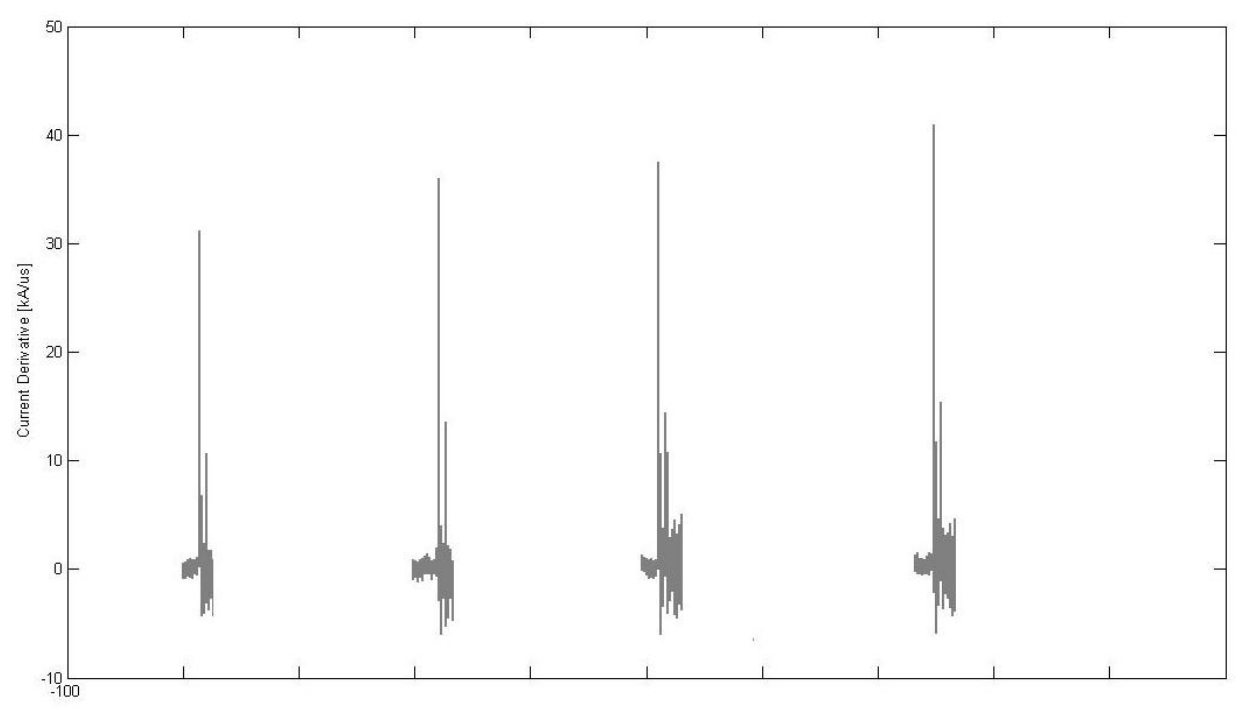

Figure 3.10. The current derivatives of a CN Tower flash containing 4 return-strokes. All return-strokes current derivative signals are of the fast current rise category. 


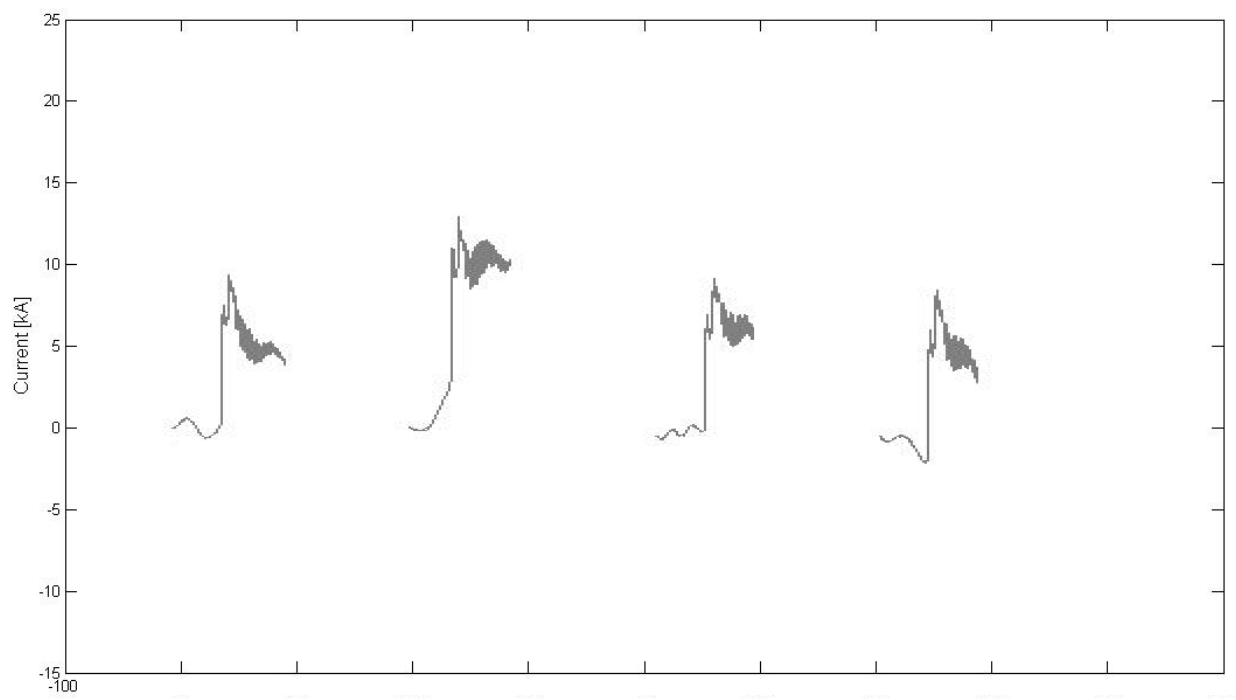

Figure 3.11. Return-stroke currents obtained by numerical integration of currents derivative signals shown in Figure 3.10.

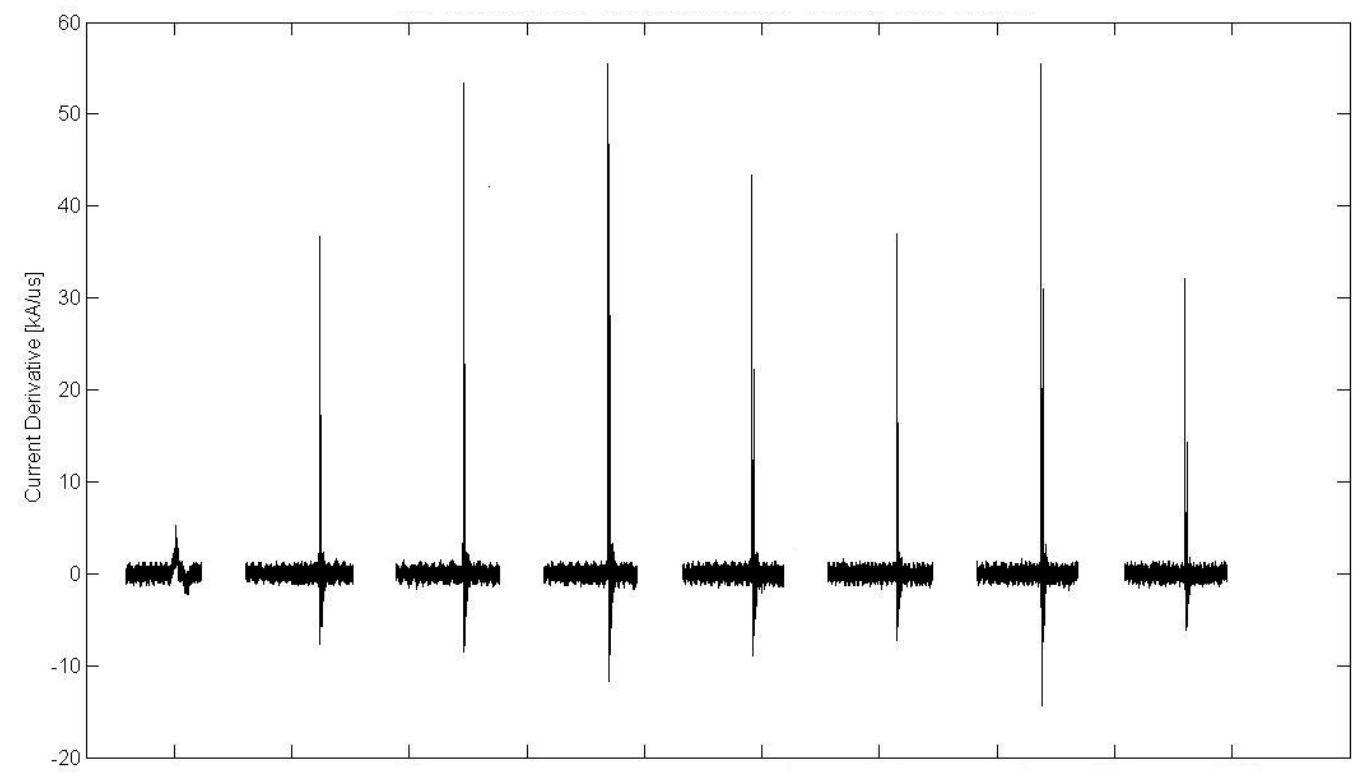

Figure 3.12 Current derivatives of a $\mathrm{CN}$ Tower flash containing 8 return-strokes. The first return-stroke has a much lower current rate of rise. 


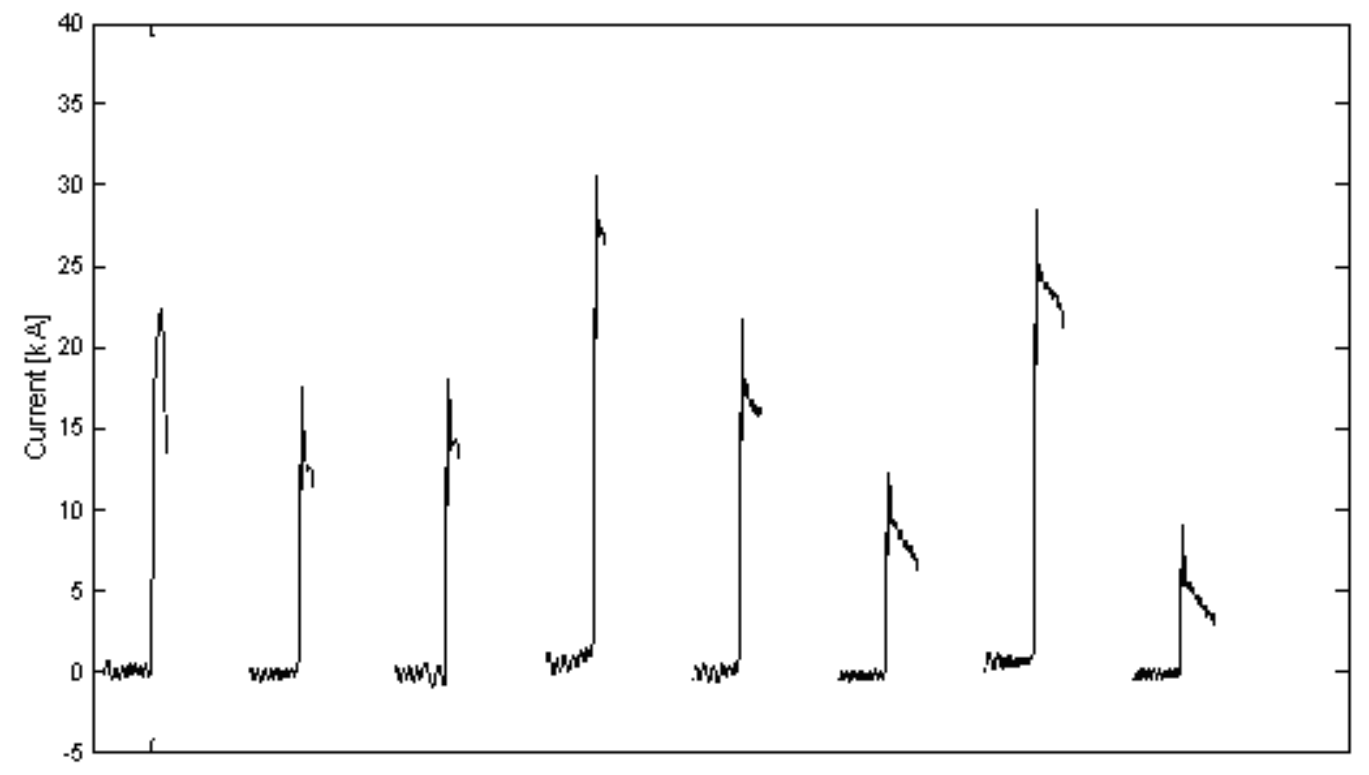

Figure 3.13 Return-strokes currents obtained by numerical integration of derivative signals shown in Figure 3.12.

\section{Positive lightning}

A positive flash consists of only one positive return-stroke. During measurements in period 1992-1996, two positive flashes were recorded. Figure 3.14 presents current derivative signal for one of rarely recorded positive lightnings. The lightning current impulse that corresponds to integral of current derivative signal on Figure 3.14 is shown in Figure 3.15. 


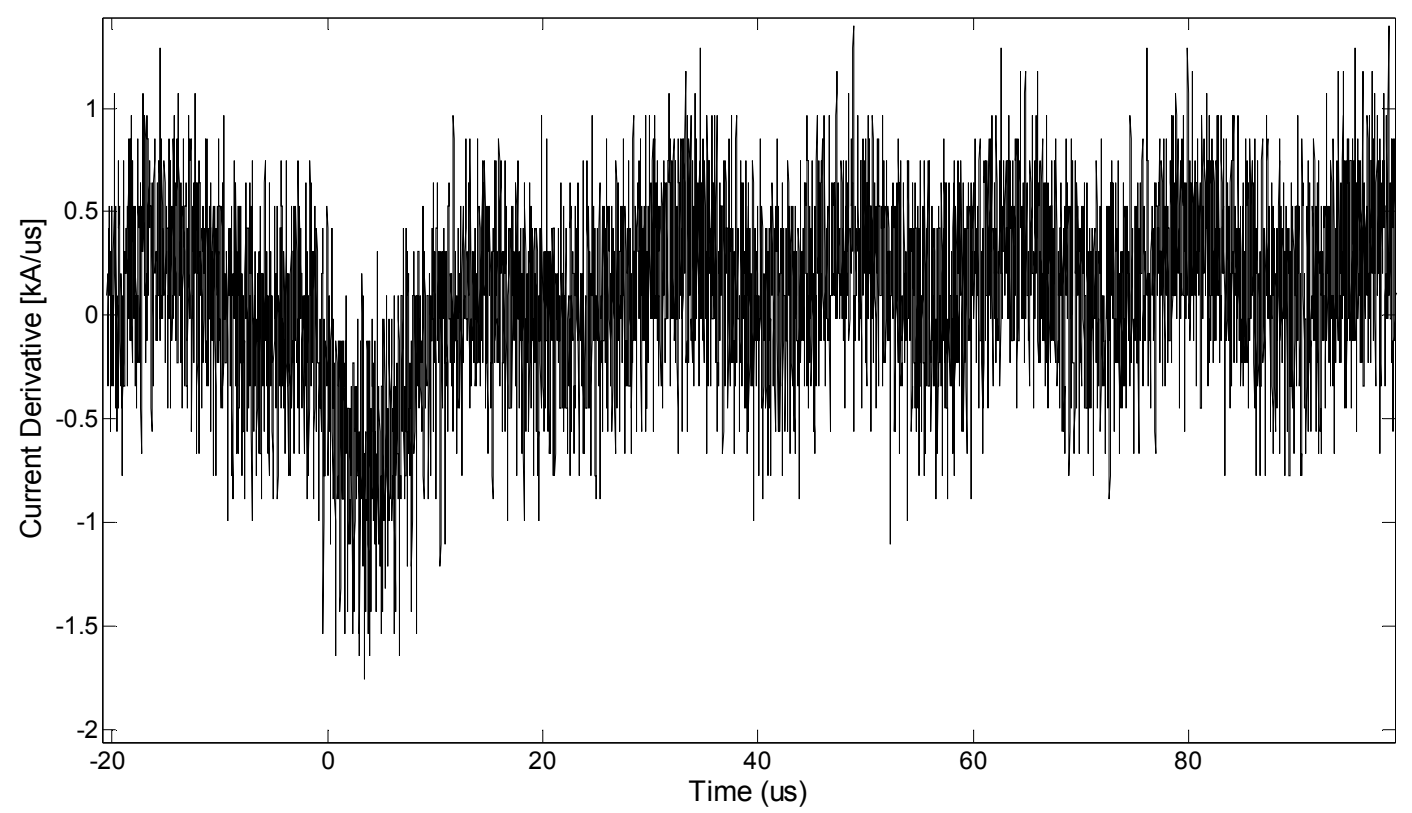

Figure. 3.14 A positive lightning return-stroke current derivative signal recorded at the $\mathrm{CN}$ Tower.

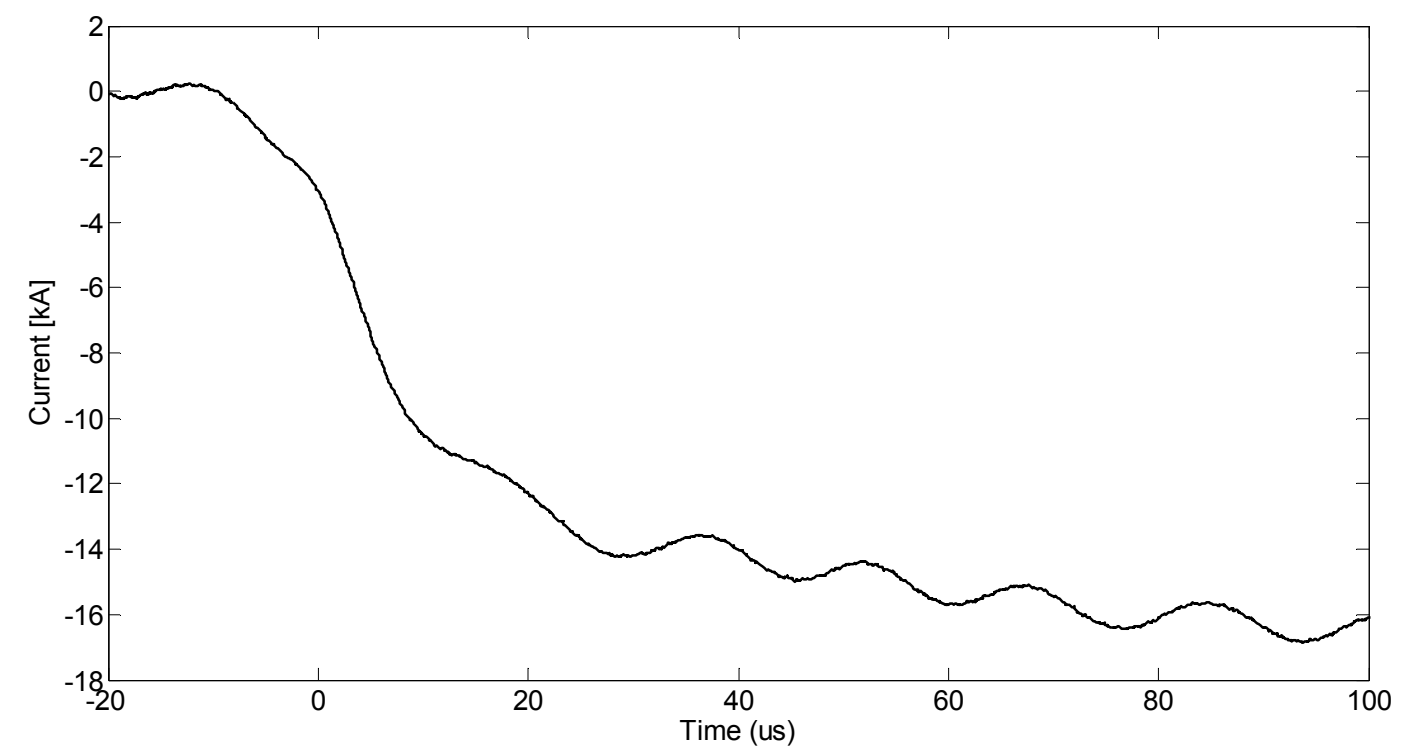

Figure 3.15 The $\mathrm{CN}$ Tower positive lightning return-stroke current obtained by numerical integration of the measured current derivative signal shown in 3.14. 


\section{Bipolar lightning}

During measurements in period 1992-1996, in 1994 a bipolar flash was recorded. The bipolar flash consisted of one positive and two negative return-strokes. Figure 3.16 shows the positive return-stroke current derivative signal, and Figure 3.17 corresponds to the return-stroke current impulse (integral of the current derivative Figure 3.16). Figure 3.18 presents current derivative signals in the bipolar flash with first positive return-stroke current followed by two negative return-strokes. Figure 3.19 presents bipolar flash with first positive return-stroke current impulse and two subsequent negative return-stroke current impulses.

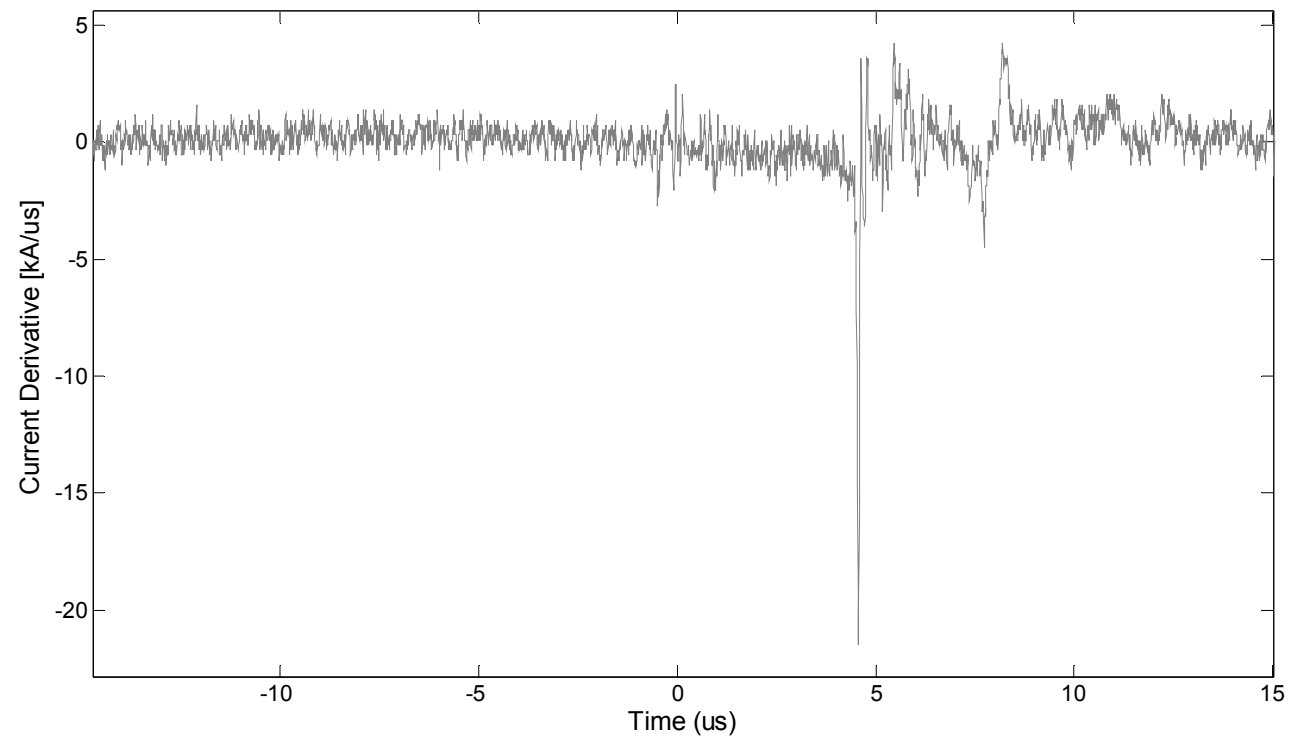

Figure 3.16 A positive lightning current derivative signal measured at the $\mathrm{CN}$ Tower. It belongs to positive impulse in a bipolar flash. 


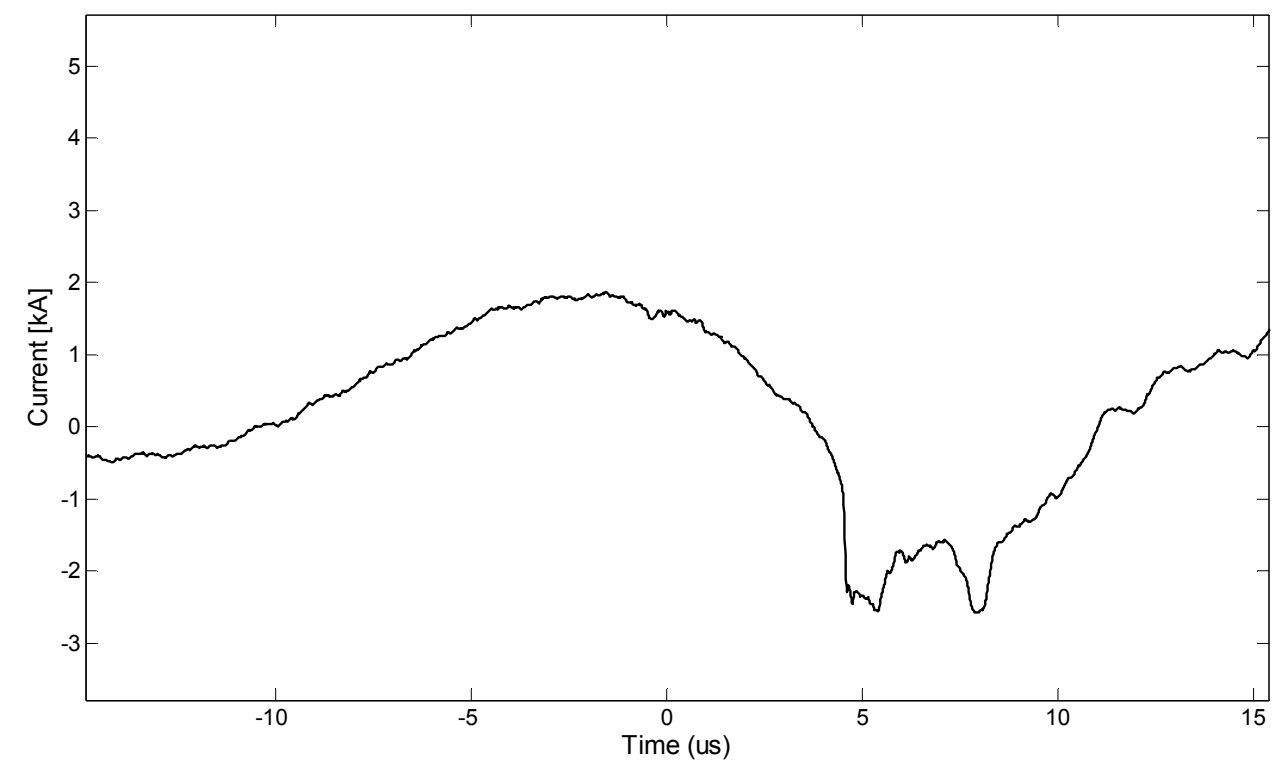

Figure 3.17 A positive lightning return-stroke current obtained by numerical integration of derivative signal shown in Figure 3.16.

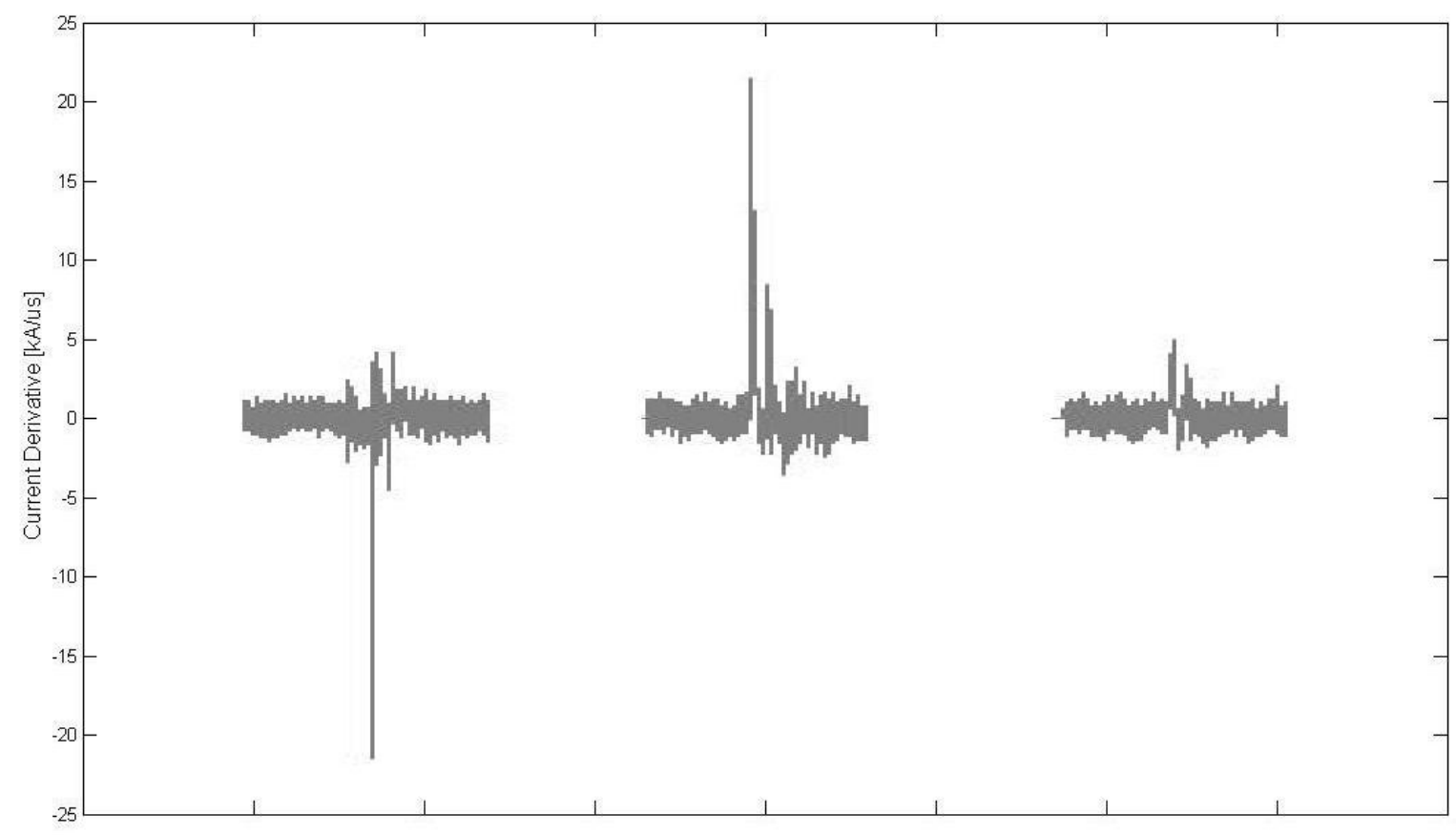

Figure 3.18 The current derivative signals of a $\mathrm{CN}$ Tower flash containing one positive and two negative return-strokes 


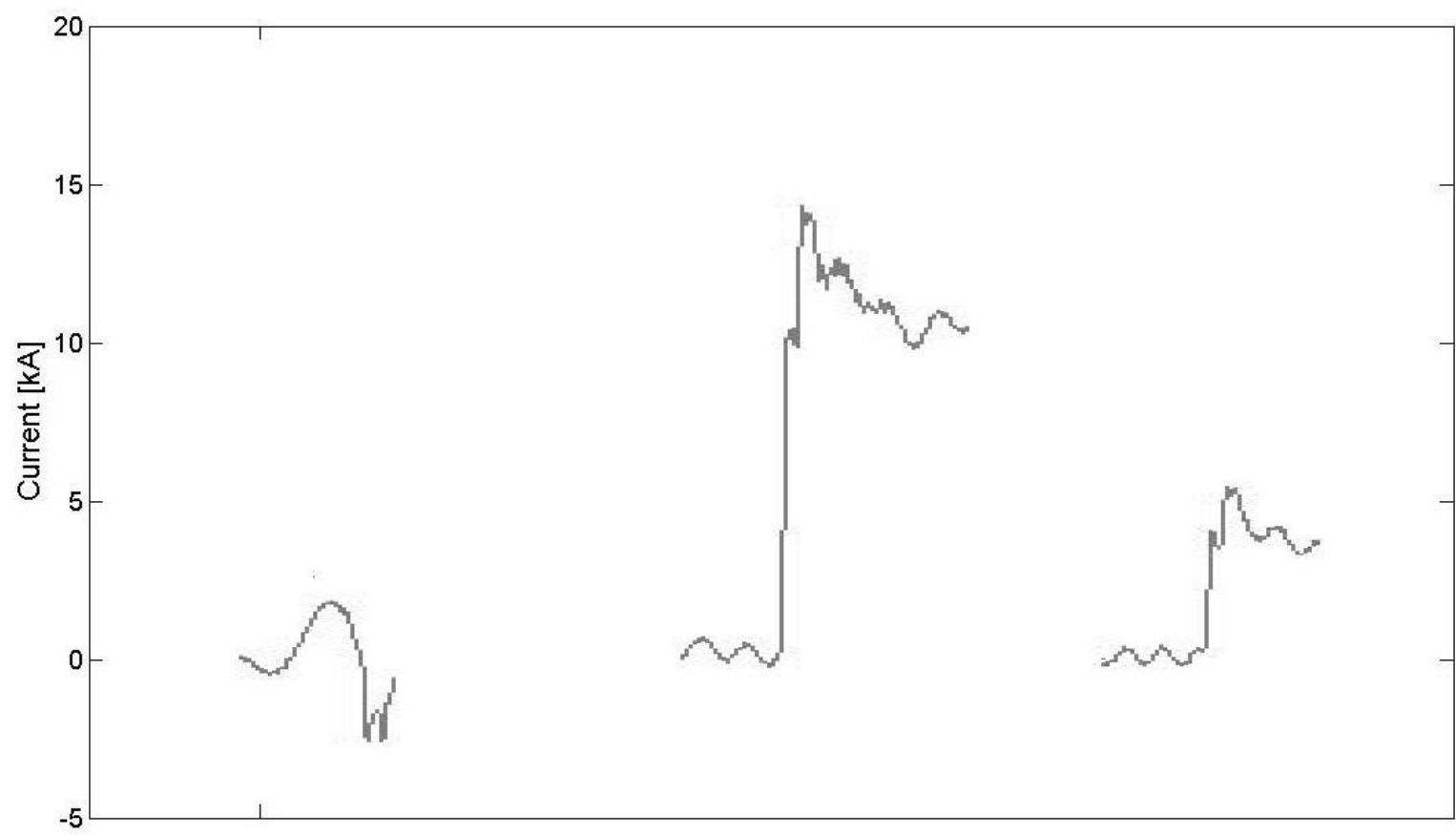

Figure 3.19 Return-strokes currents obtained by numerical integration of derivative signals shown in Figure 3.18. 


\section{CHAPTER 4}

\section{Flash Characteristics}

The measurement of the CN Tower lightning current derivative signal started in 1991 . Previous analysis of recorded $\mathrm{CN}$ Tower current signals did not distinguish between different impulses and thus produced mixed results and problematic conclusions. Also, since the number of slow wavefront pulses is substantially lower than the number of fast impulses, the distinguished characteristics of slow impulses was impeded by the majority impulses. As a result was that the subsequent lightning return-strokes had risetimes similar to the first return-strokes' risetime. That is applicable to all fast wavefront current impulses, but not to slow wavefront current impulses. In this study the following parameters have been analysed: the current peak, the current derivative peak, the current risetime, the current derivative risetime, the inter-stroke time and the flash duration.

\subsection{DETERMINATION OF RETURN-STROKE CURRENT WAVEFRONT PARAMETERS}

\subsubsection{DETERMINATION OF CURRENT DERIVATIVE PARAMETERS}

The signals recorded using Rogowski represent the current derivatives. The wavefront parameters of the current derivative signal are: current derivative peak and current derivative risetime. After removing DC offset from the current derivative signal, the wavefront current derivative parameters, such as the current derivative peak and current derivative risetime, were 
determined. The determination of current derivative peak is shown in Figure 4.1. When the current derivative peak was calculated, the current derivative risetime is defined as time within which current derivative impulse rises from $10 \%$ to $90 \%$ of the current derivative peak value.

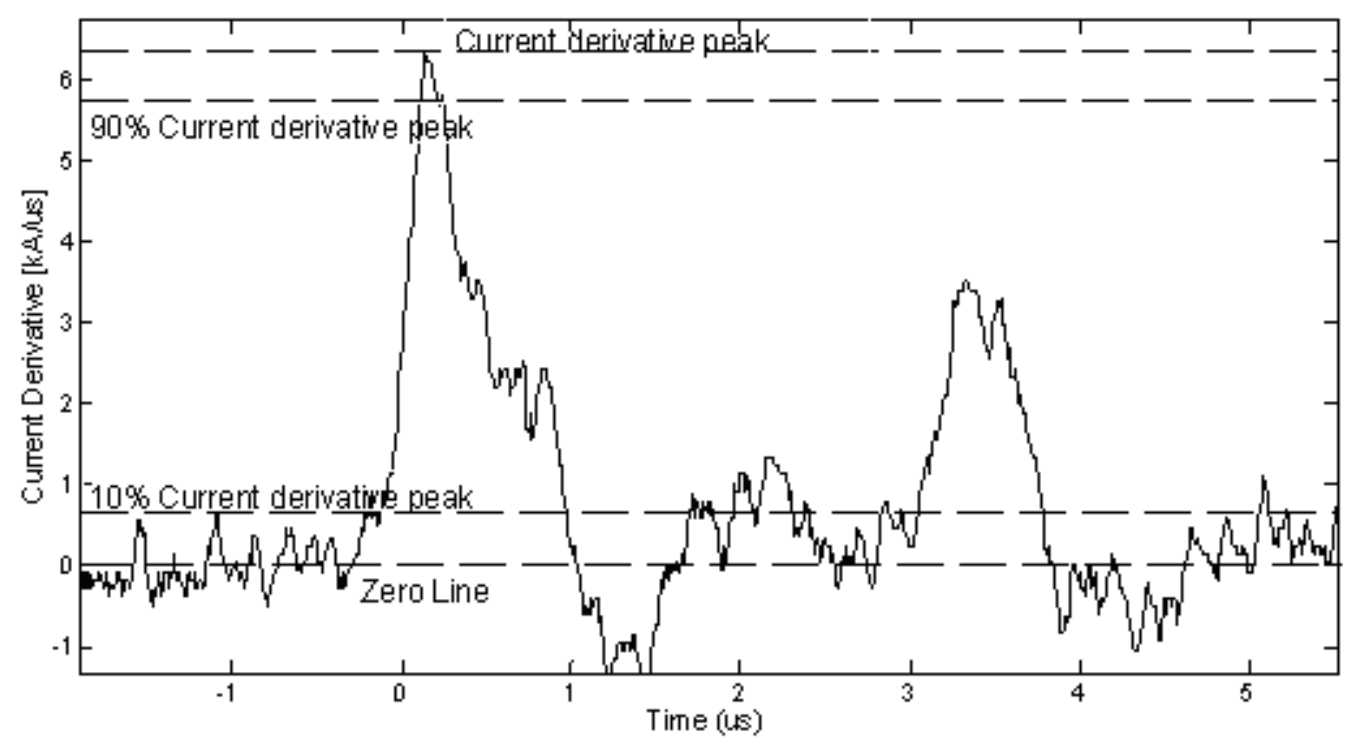

Figure 4.1. Determination of lightning current derivative peak and current derivative risetime

\subsubsection{DETERMINATION OF CURRENT PARAMETERS}

The lightning current impulse waveform (Figure 4.2) is obtained after numerical integration of the current derivative signal from Figure 4.1. Before the determination of the lightning current impulse peak, the current impulse baseline should be defined (Figure 4.2). The initial current impulse peak is determined as the difference between the measured current peak value and the baseline value (Figure 4.2). The second current impulse parameter is current risetime. It is defined as a time needed for the current to rise from $10 \%$ to $90 \%$ of current impulse peak (Figure 4.2). 


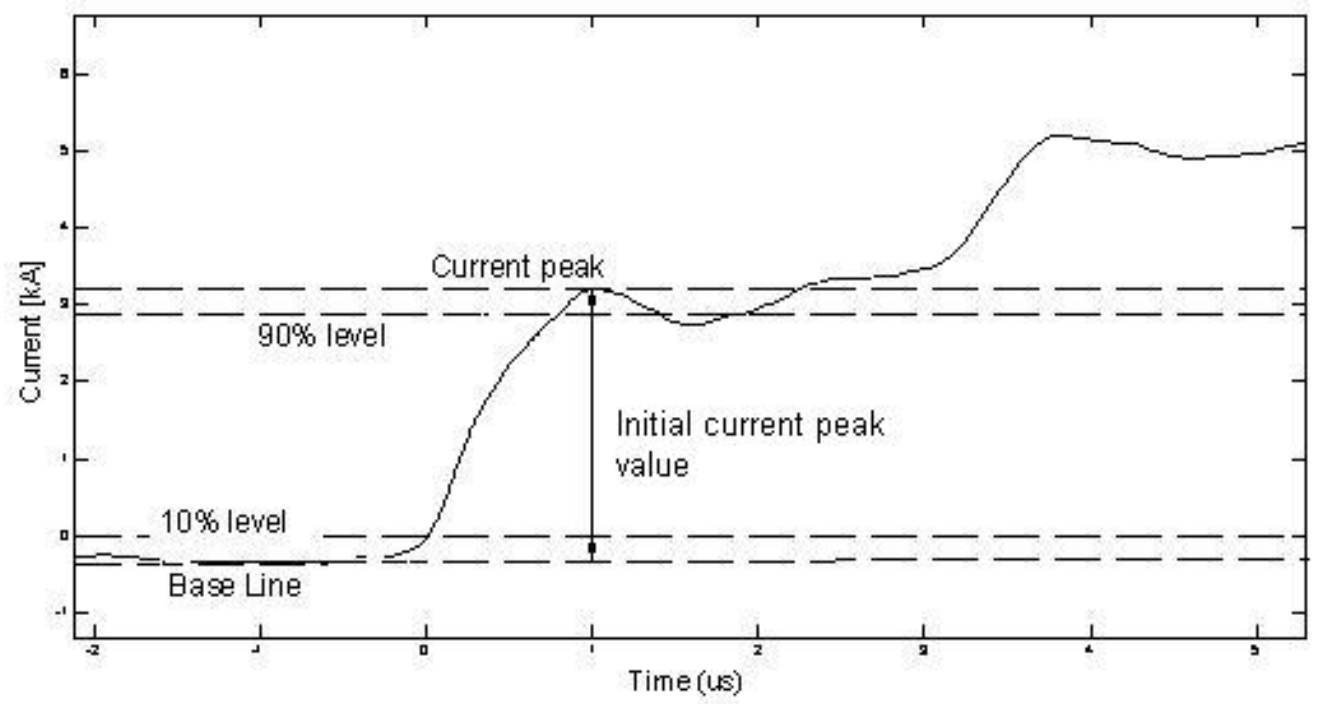

Figure 4.2. Determination of lightning current impulse peak and current impulse risetime

\subsection{STATISTICAL ANALYSIS OF RETURN-STROKE CURRENT WAVEFRONT PARAMETERS 1992-1996}

\subsubsection{STATISTICAL ANALYSIS OF LIGHTNING FLASH PARAMETERS}

The statistical analysis presented in this study is based on the 1992-1996 CN Tower lightning current derivative data, measured by the old Rogowski coil. In this 5-year period, the $\mathrm{CN}$ Tower current recording system recorded 82 lightning flashes, containing 269 current impulses (current impulses with current peak lower than $2 \mathrm{kA}$ have not been usually used because they likely belong to initial discharges [2]). The overwhelming majority of recorded flashes contain negative return-strokes $(96.34 \%)$, only two single stroke flashes were positive $(2.44 \%)$ 
and one three stroke flash was bipolar, first positive stroke and 2 subsequent negative strokes, $(1.22 \%)$

Statistical analysis of the CN Tower negative lightning discharges recognizes two very distinguished current impulses: impulses with fast wavefronts representing the majority of the CN Tower lightning, and impulses with slower wavefronts. These slower wavefronts impulses always occured either as the first strokes in multiple-stroke flashes or the only strokes in singlestroke flashes, which suggest that they occur in downward initiated lightning. During the period 1992-1996, flashes having slow wavefront current impulse (return-stroke) occurred in 18 flashes out of a total of 79 negative flashes $(22 \%)$.

Frequency and cumulative flash are presented in Figures 4.3-4.9. Figure 4.3. shows that overwhelming majority 61 of all 82 flashes in period 1992-1996 were ordinary flashes, e.g. negative flashes with all strokes with short risetimes; (74.4\%), 18 slow-stroke flashes; (25\%), positive flashes; $(2.44 \%)$, bipolar flashes $(1.22 \%)$ 


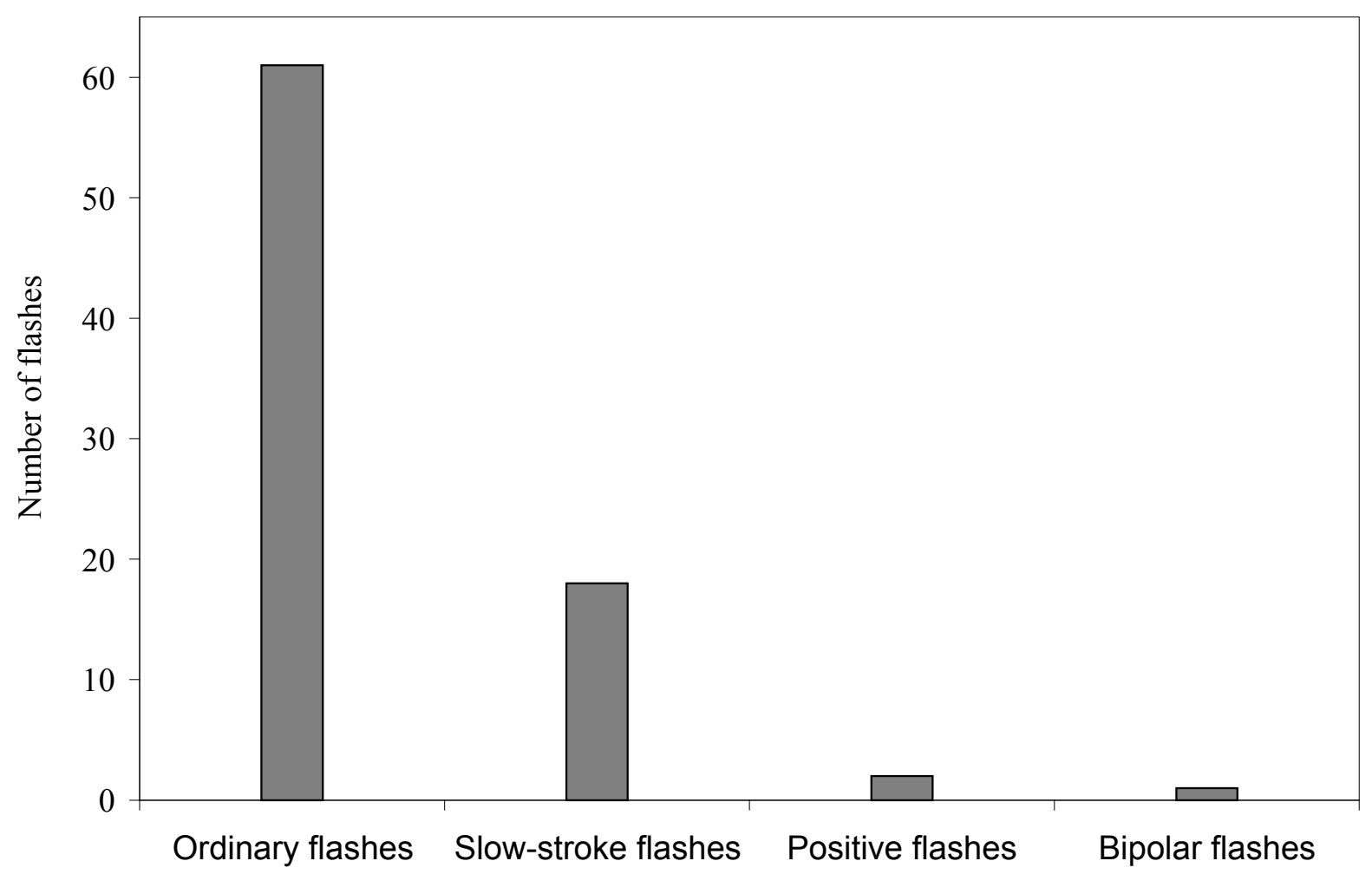

Figure 4.3. Frequency distribution of 82 CN Tower flashes (1992-1996).

Figure 4.4. presents the cumulative statistics for different flash categories. The figure shows that only $30 \%$ of flashes that start with a slow rising wavefront current are called 'slowstroke' flashes have more than one return-stroke. 


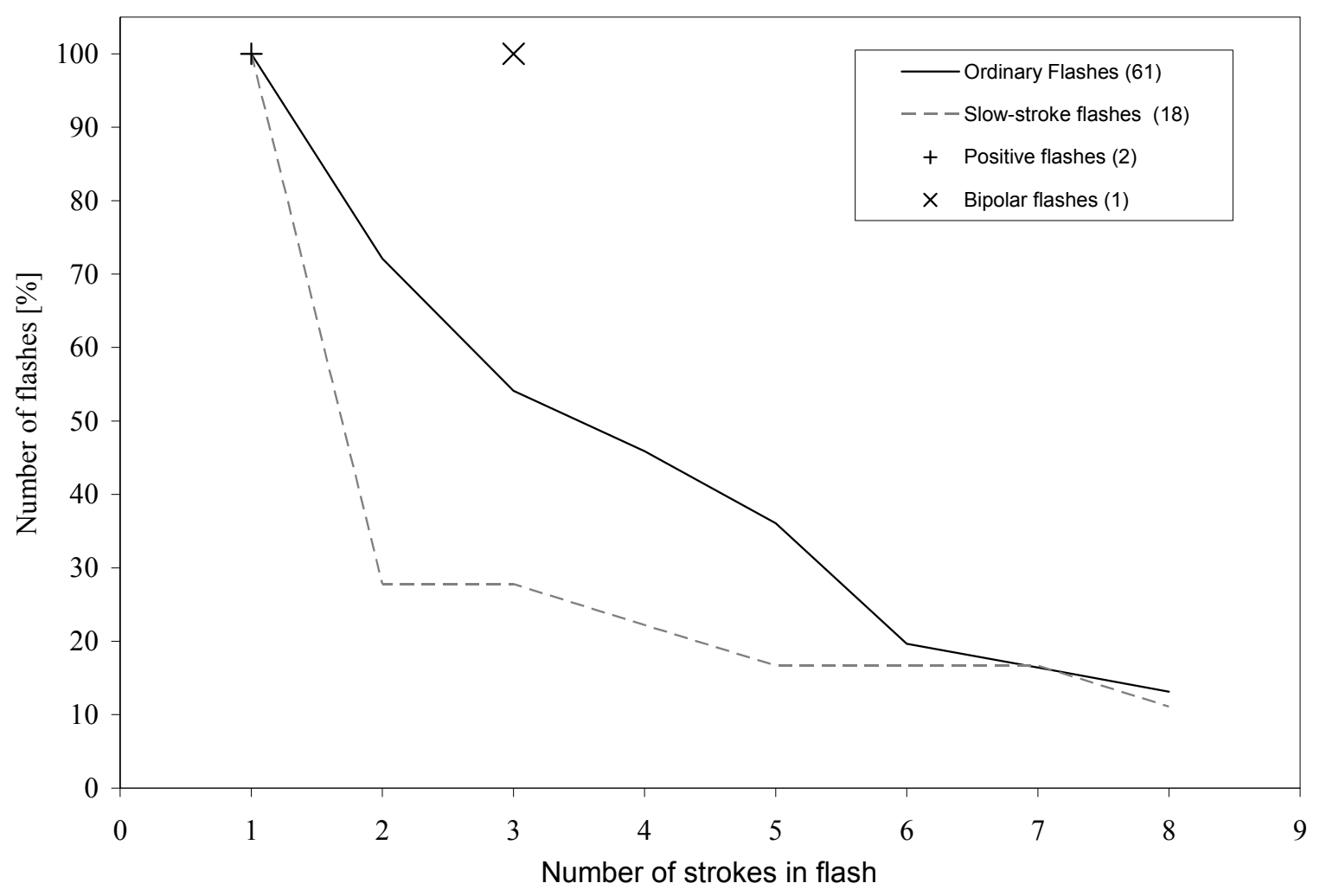

Figure 4.4. Cumulative statistics of number of strokes per flash (1992-1996).

Figures 4.5 shows flash duration for all flashes in periods 1992-1994. During two period 1992-1994 and 1995-1996 inter-stroke time have been measured with different accuracy. In that Figure dashed line shows lower duration for slow-stroke flashes and 70\% of slow-stroke flashes were single-stroke flashes. 


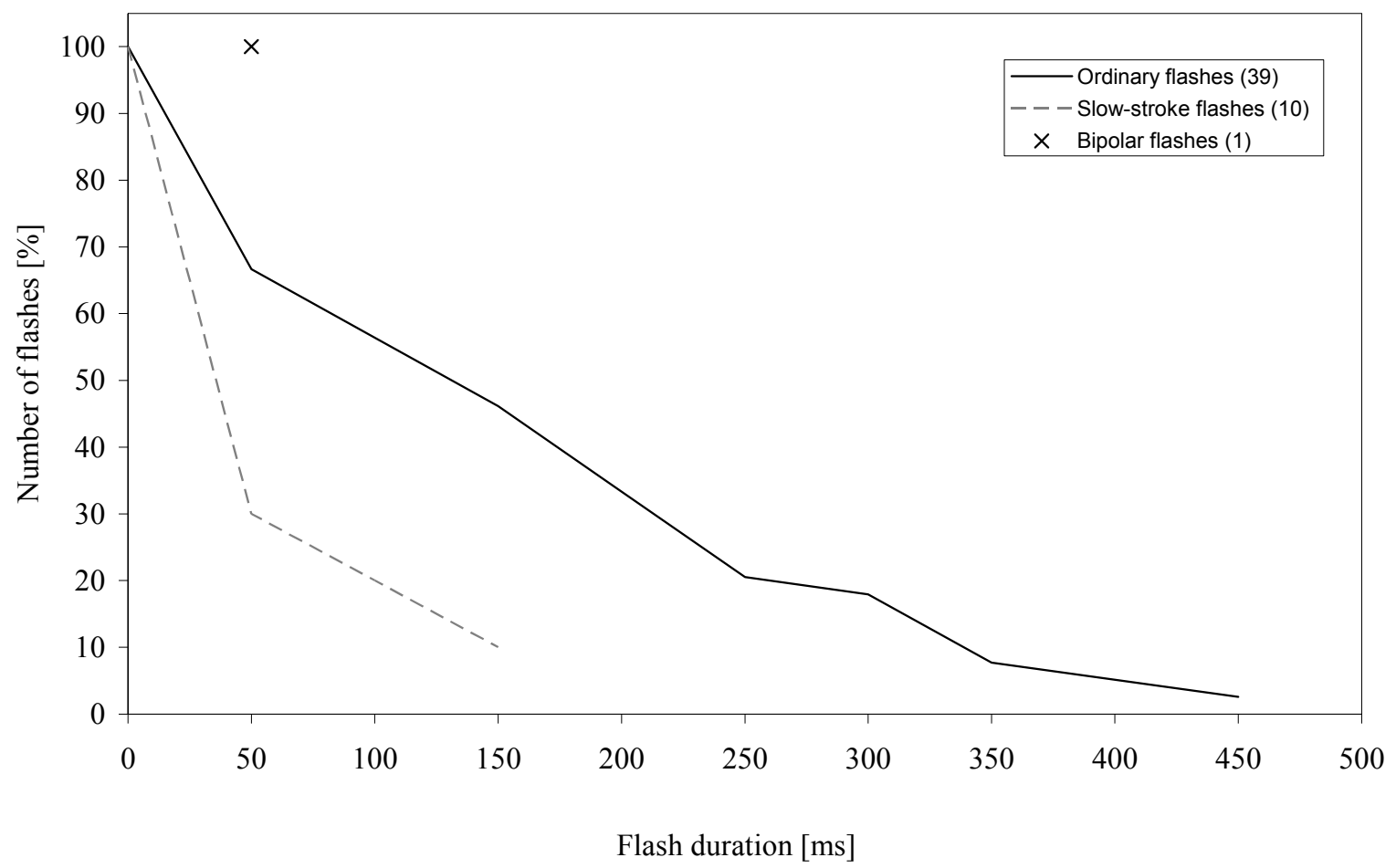

Figure 4.5 Cumulative statistics of flash duration (1992-1994)

The smallest measured interstroke time for strokes in flashes in period (1992-1994) was $50 \mathrm{~ms}$ and the rest of inter-stroke time is got as a multiplication of $50 \mathrm{~ms}$. The ordinary flashes in comparison with other flashes have largest number of strokes and durations, but lower interstroke time than flashes with the first slow current wavefront stroke. 


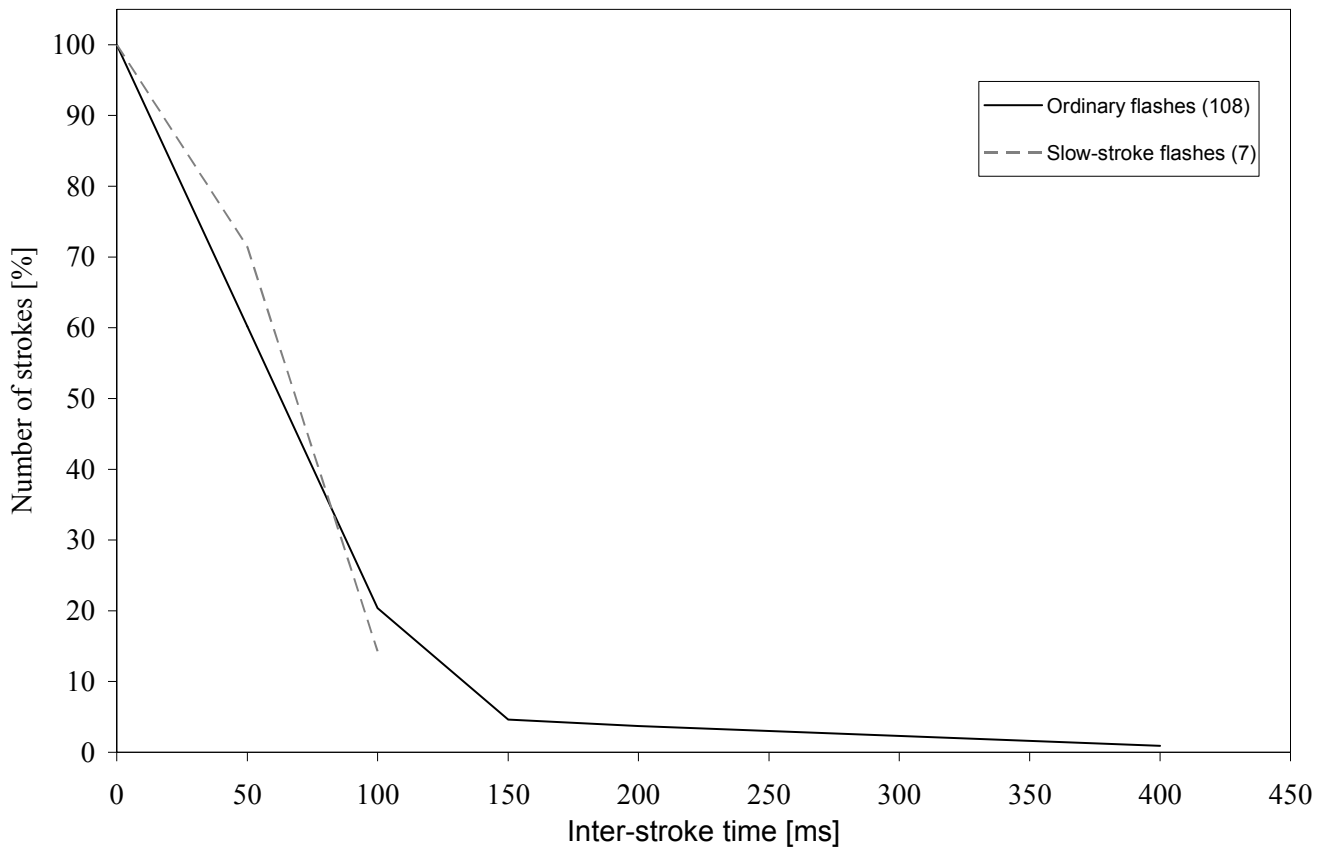

Figure 4.6 Cumulative statistics of inter-stroke time (1992-1994).

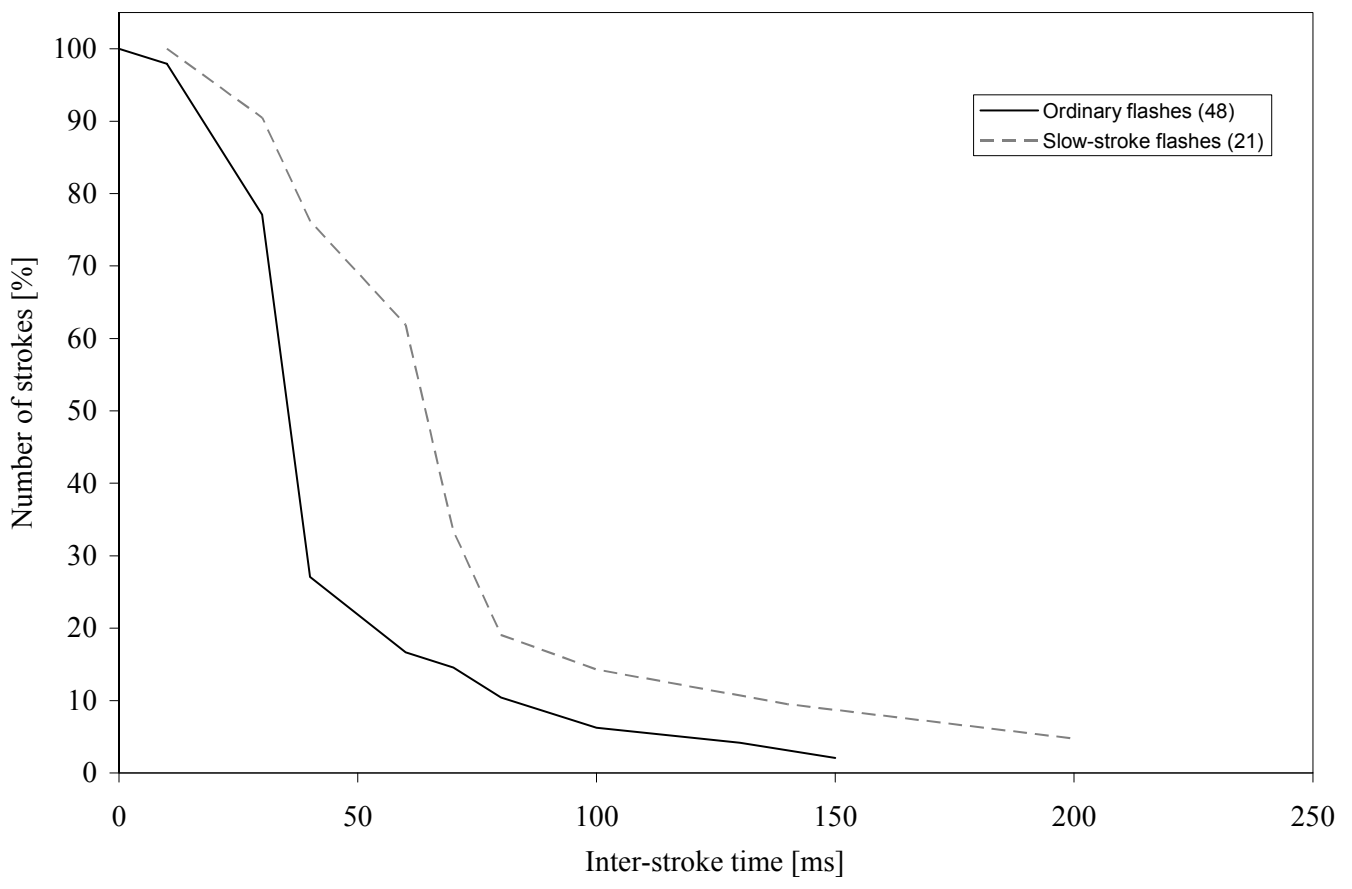

Figure 4.7 Cumulative statistics of inter-stroke time (1995-1996). 
Table 4.1 presents the summary of the statistical results for strokes/flash, flash duration and inter-stroke time shown in Figures 4.3 - 4.7 for distinguished type of flashes. The ordinary flashes, in comparison with other flashes, have largest number of strokes and durations and lower inter-stroke time than flashes with the first slow current wavefront stroke.

Table 4.1 Strokes in a flash for distinguished flash types

\begin{tabular}{|c|c|c|c|c|c|}
\hline & Min. & Max. & Mean & Median & $50 \%$ \\
\hline Strokes/Flash & & & & & \\
\hline Ordinary & 1 & 8 & 3.5737 & 1 & 3.5 \\
\hline Slow & 1 & 8 & 2.3889 & 1 & 2.077 \\
\hline Positive & 1 & 1 & 1 & 1 & 1 \\
\hline Bipolar & 3 & 3 & 3 & 3 & 3 \\
\hline Flash Duration [ms] & & & & & 100.83 \\
\hline Ordinary & - & 450 & 110.66 & 100 & 8.18 \\
\hline Slow & - & 570 & 89.45 & - & - \\
\hline Positive & - & - & - & - & 50 \\
\hline Bipolar & 50 & 50 & 50 & 50 & \\
\hline Inter-Stroke Time [ms] & & & & & \\
\hline Ordinary & - & 400 & 43.33 & 35 & 40 \\
\hline Slow & - & 200 & 57.86 & 200 & 60 \\
\hline Positive & - & - & - & - & - \\
\hline Bipolar & - & 50 & 25 & 25 & 50 \\
\hline & & & & & \\
\hline
\end{tabular}




\subsubsection{STATISTICAL ANALYSIS OF CURRENT WAVEFRONT PARAMETERS}

Comprehensive statistics concerning the current derivative and current wavefront parameters are presented in this section. These parameters are: the current derivative peak (maximum current wavefront steepness), current derivative risetime10\%-90\%, current peak and current risetime $10 \%-90 \%$. Statistical data consists of current parameters of 269 lightning returnstrokes (248 negative return-strokes with fast wavefronts, 18 negative return-strokes with slow wavefronts, 2 positive return-strokes and 1 bipolar positive return-stroke). In cumulative statistics diagrams, ordinary current impulses were presented with solid lines, slow wavefront current impulses with dashed lines, single positive current impulses with"+" and positive current impulses in bipolar flashes with " $\mathrm{X}$ ".

Figure 4.8. presents frequency distribution of number of strokes belonging to different flash categories. It shows that for majority of all 269 strokes are the ordinary negative strokes $(92.2 \%)$. Slow wavefront return-strokes occurred 18 times $(6.7 \%)$, positive return-strokes in positive flashes twice $(0.74 \%)$ and positive return strokes in bipolar flashes once $(0.37 \%)$. 


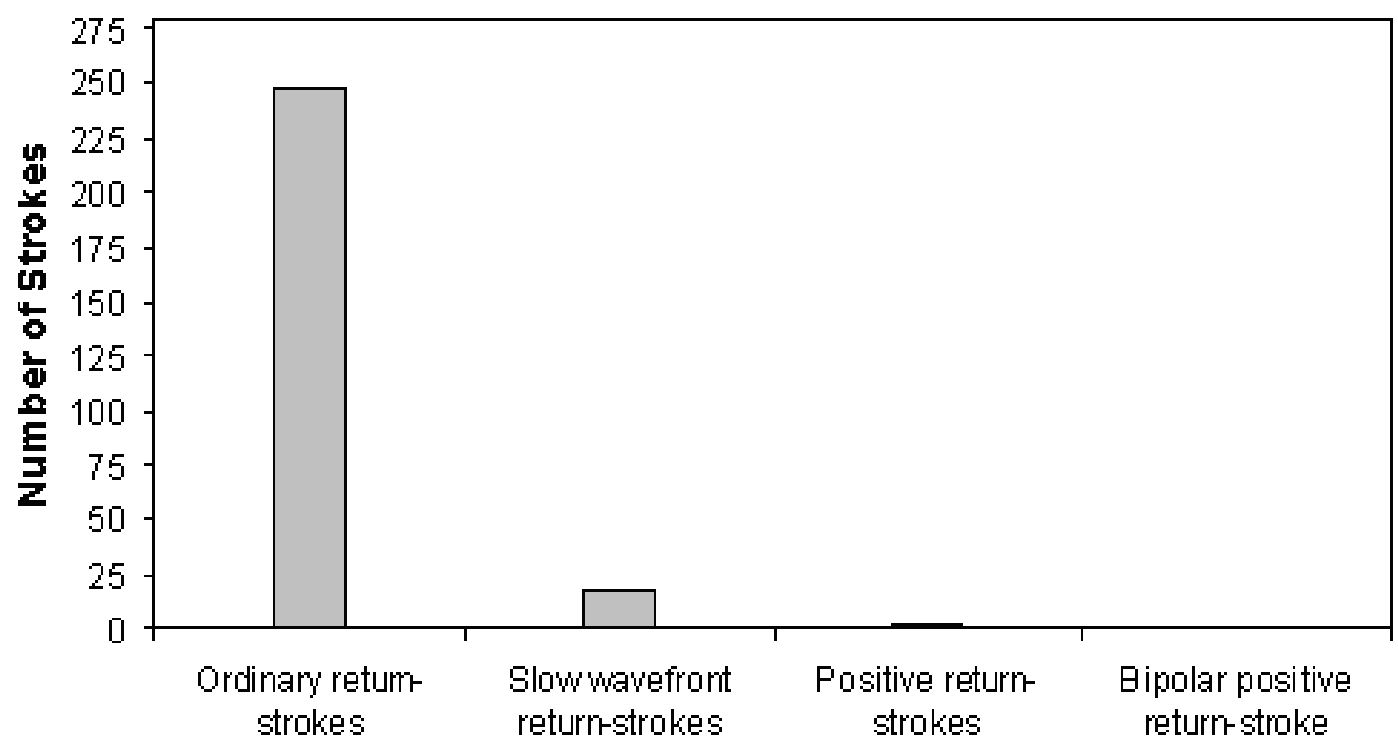

Figure 4.8 Frequency distribution of the number of strokes belonging to different categories distinguished return-strokes (1992-1996).

\subsubsection{The Current Impulse Derivative Parameters' Analysis}

The CN Tower recorded 269 return-stroke current derivative data was analyzed. The current impulse derivative peak together with the current derivative impulse rise was determined and these two values are presented in the following statistical figures. Figure 4.9 shows a substantial decrease in current maximum steepness for negative current impulses with slow wavefronts in comparison with that for ordinary negative current impulses, indicating different physical processes for these two categories. For a few flashes having slow first strokes, it was proved to be down-initiated flashes due to existing downward branches [3]. The figure also shows that positive return-strokes in positive flashes had the lowest current maximum steepness, although a larger statistical set of data is needed to confirm this result. On the other hand, the 
positive stroke in the bipolar flash had larger current maximum steepness, a larger statistical set is also needed to confirm this result.

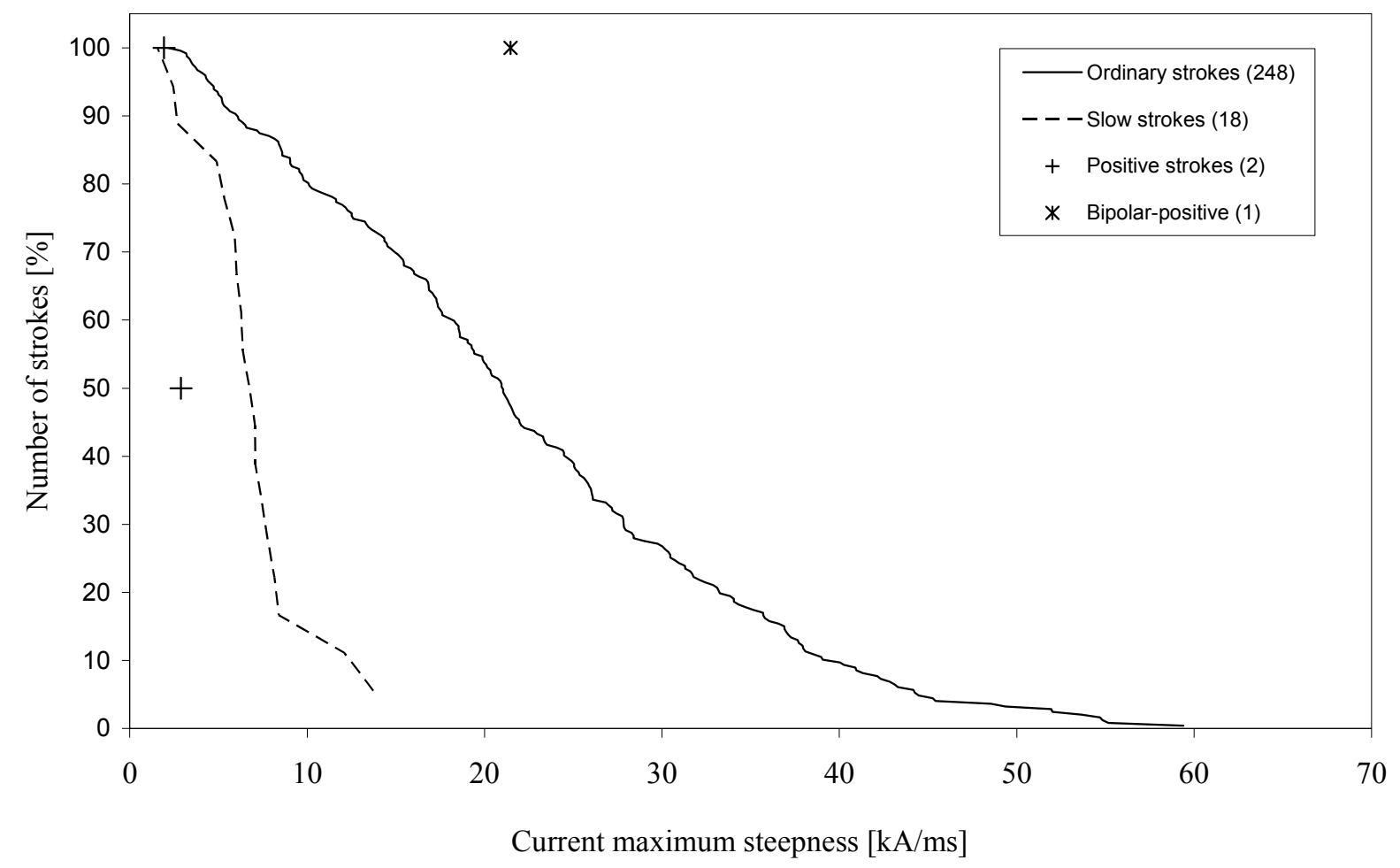

Figure 4.9 Cumulative statistics of current maximum steepness for 269 return-strokes in 82 Flashes.

Figures 4.10 and 4.11 show frequency distribution of current derivative risetime for the determined intervals of time (e.g. $0.25 \mu \mathrm{s}$ - presents, time interval from $0-0.5 \mu \mathrm{s}, 0.5 \mu \mathrm{s}$ presents time interval $0.25 \mu \mathrm{s}-0.75 \mu \mathrm{s}$ etc.) and cumulative statistics of current derivative rise-time for all 269 return-strokes occurred in period 1992-1996. 


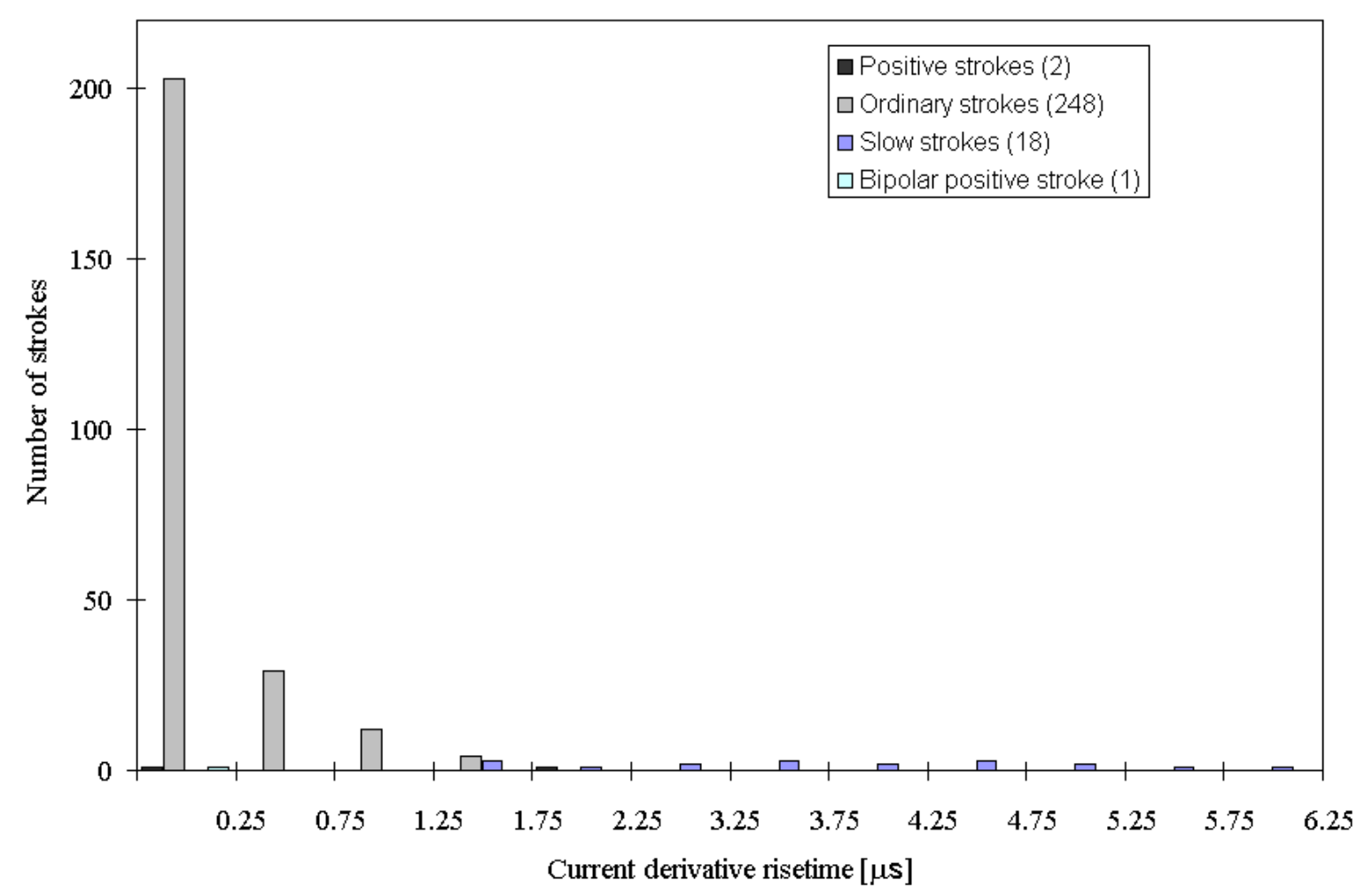

Figure 4.10. Frequency distribution of current derivative risetime for the determined Intervals of time (e.g. $0.25 \mu \mathrm{s}-$ presents, time interval from $0-0.5 \mu \mathrm{s}$ etc.).

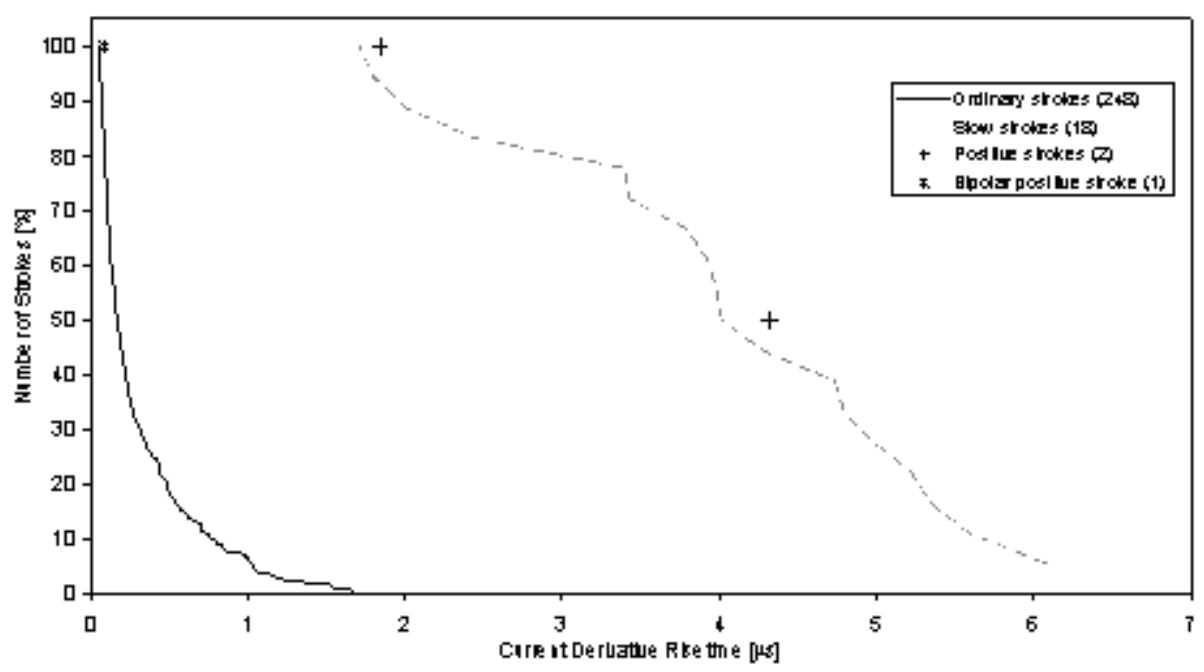

Figure 4.11. Cumulative statistics of current derivative rise-time (10\%-90\%) for all 269 return-strokes (1992-1996). 


\subsubsection{The Current Impulse Parameters’ Analysis}

Figures 4.12 and 4.13 present frequency distribution of current impulse peak for slow and ordinary strokes and cumulative statistics of current peak for four distinguished return-strokes.

Figure 4.13 indicates a substantial difference in the current peak value between negative current-impulses with slower wavefronts and ordinary negative return-strokes. The current peaks of slow wavefront strokes (dashed line) are larger than those for ordinary return strokes. The figure also shows that the positive return-strokes in positive flashes have on average higher current peaks than those for ordinary negative return-strokes, although more data is needed to confirm this result.

Figure 4.18 shows that on average positive return-strokes in positive flashes have much higher current wavefront risetime than those for other return-strokes. The figure also shows that on average current risetime for slow negative return-strokes is substantially higher than that from ordinary negative return-strokes, which suggests again that the slow wavefront current returnstrokes belong to different category. Tables 4.2 and 4.3 present summary of cumulative statistics for current derivative and current waveforms parameters. 


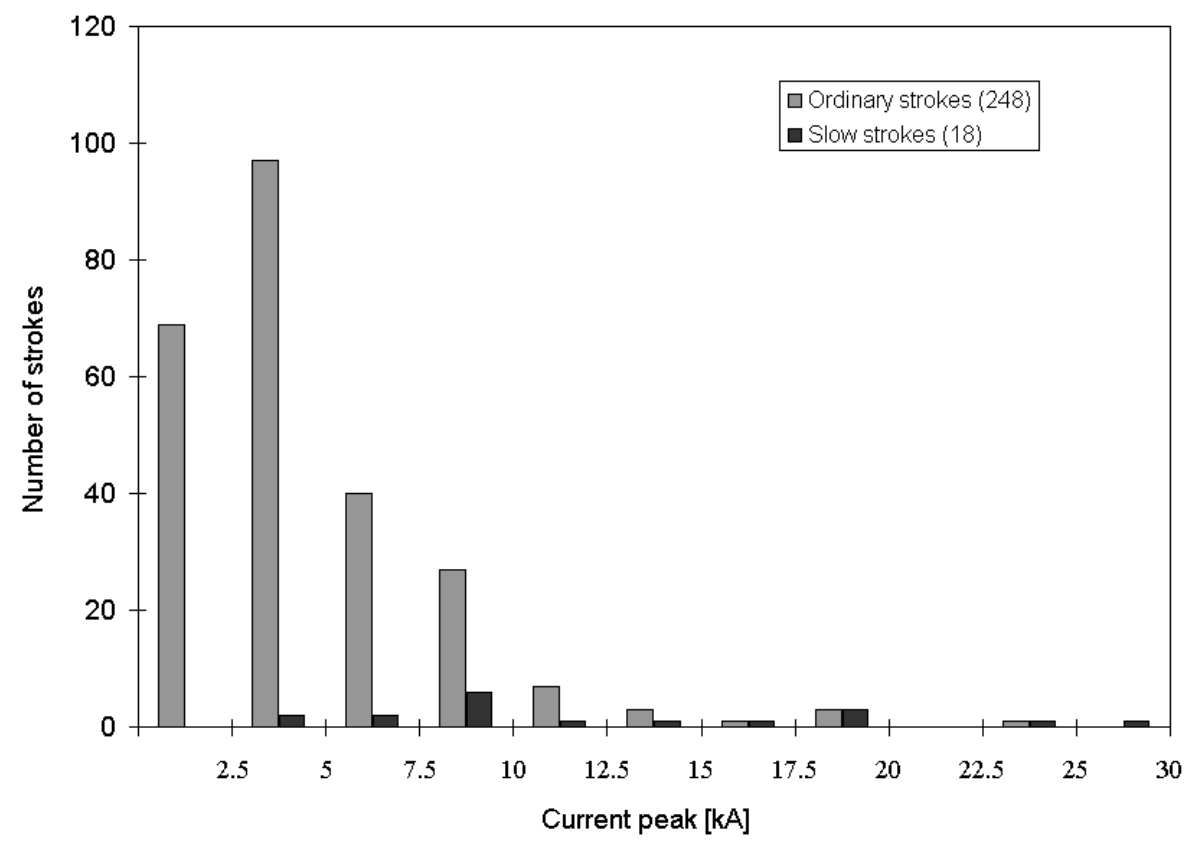

Figure 4.12. Frequency distribution of current peak for ordinary strokes and strokes with slow current wavefront.

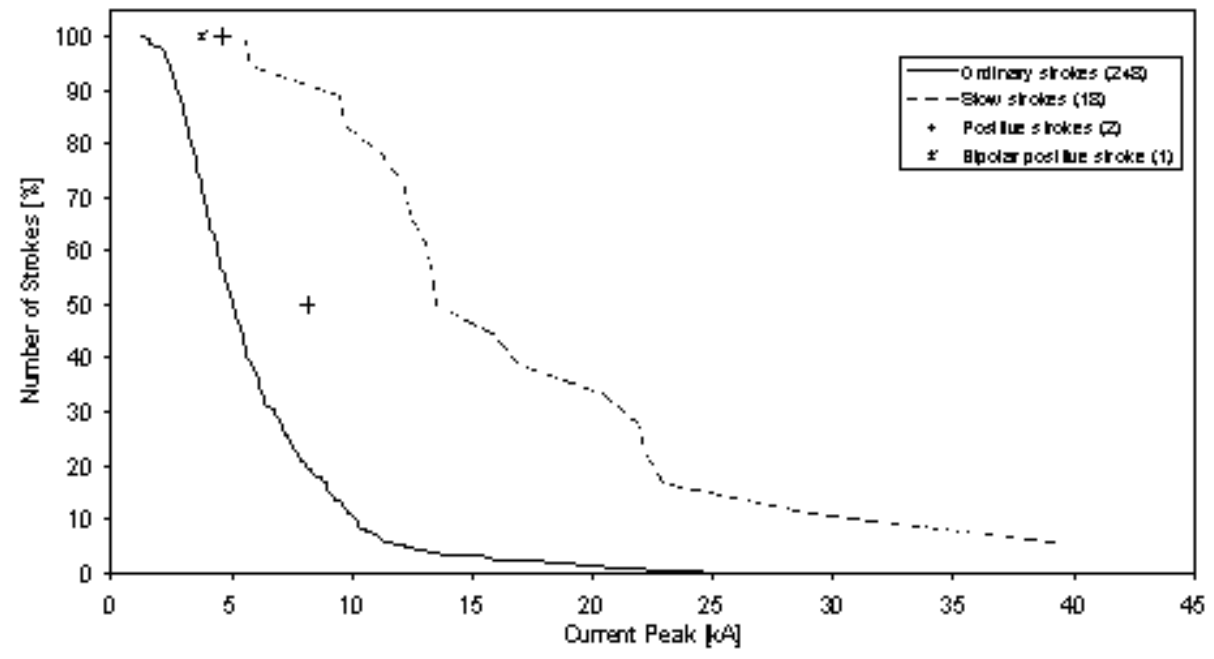

Figure 4.13. Cumulative statistics of current (1992 - 1996).

Figures 4.14 and 4.15 present frequency distribution of current wavefront risetime of the ordinary negative return-strokes and of the slow wavefront strokes. 


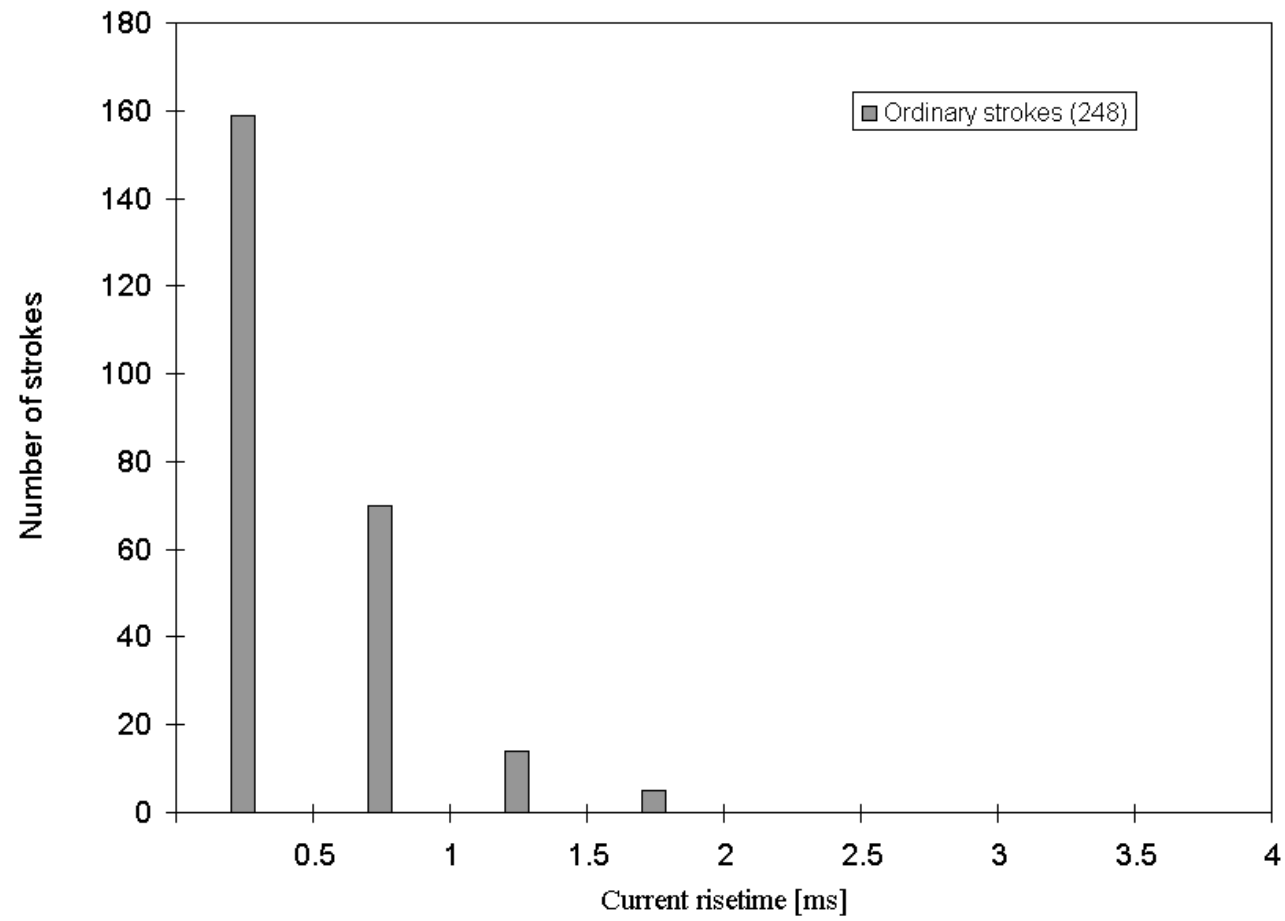

Figure 4.14 Frequency distribution of current risetime of ordinary strokes (1992-1996, 248 ordinary negative strokes).

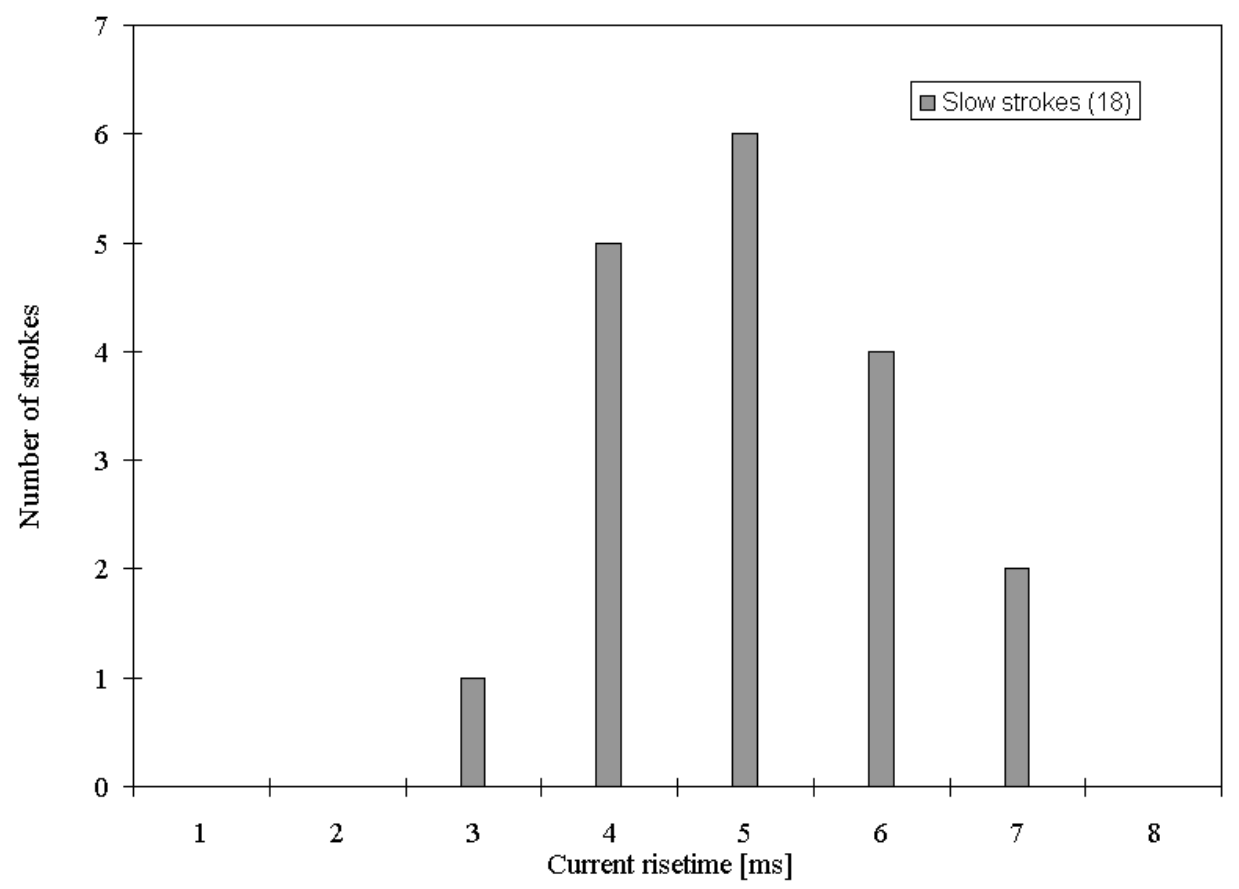

Figure 4.15 Frequency distribution of current risetime of slow wavefront strokes 


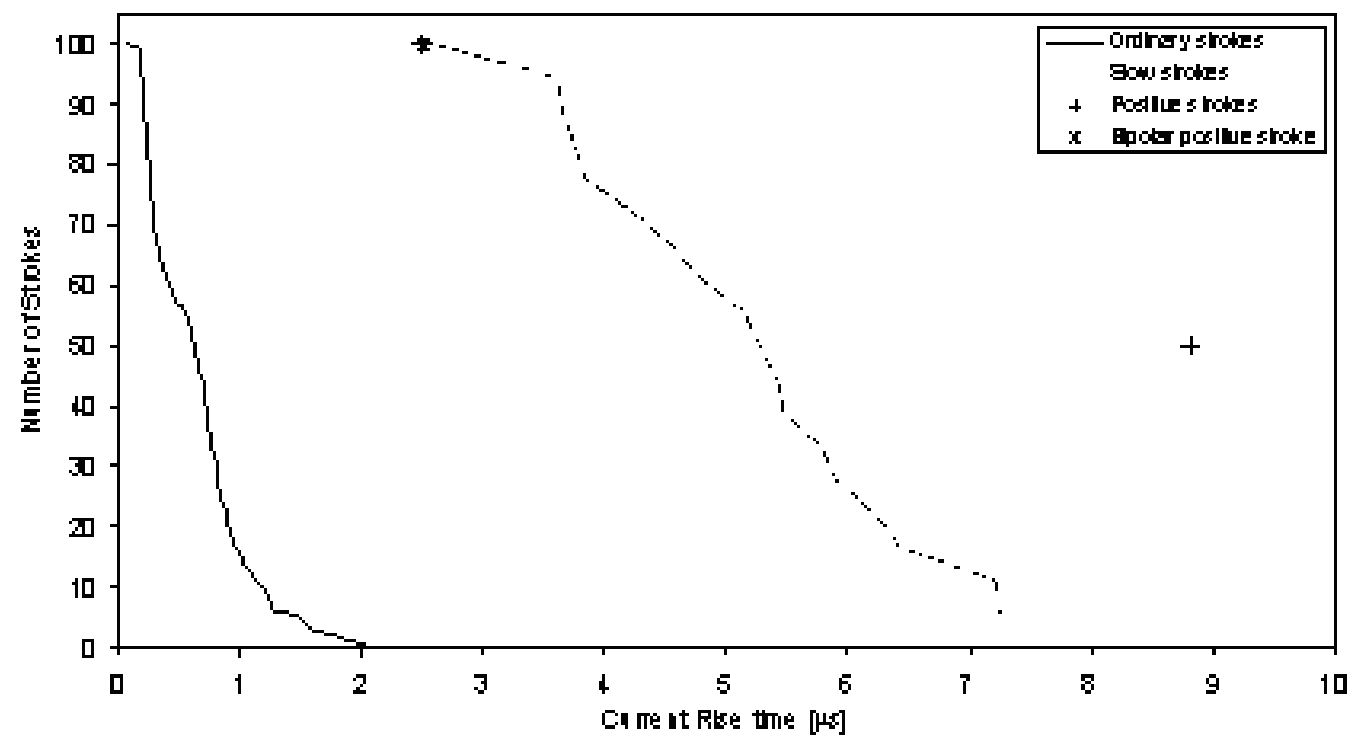

Figure 4.16 Cumulative statistics of current risetime (1992-1996, 269 strokes).

The cumulative distribution of return-stroke current peak shows that average current peak value to be much larger than average value of current peak for the ordinary $\mathrm{CN}$ Tower returnstrokes. Summary of statistical data for return-stroke current parameters without subsequent strokes is given in Table 4.2 and 4.3 . 
Table 4.2 Summary of current derivative characteristic

\begin{tabular}{|c|c|c|c|c|c|}
\hline & Min. & Max. & Mean & Median & Cumul.50\% \\
\hline $\mathrm{di} / \mathrm{dt}[\mathrm{kA} / \mu \mathrm{s}]$ & & & & & \\
\hline Ordinary & 2.164 & 59.38 & 22.289 & 20.95 & 21 \\
\hline Slow & 1.572 & 13.73 & 6.671 & 6.5595 & 6.748 \\
\hline Positive & 1.938 & 2.881 & 2.4085 & 2.4085 & - \\
\hline Bipolar & 21.467 & 21.467 & 21.467 & 21.467 & - \\
\hline di/dt risetime $[\mu \mathrm{s}]$ & & & & & \\
\hline Ordinary & 0.049 & 1.674 & 0.305993 & 0.1675 & 0.168 \\
\hline Slow & 1.713 & 6.082 & 3.972 & 3.997 & 4.013 \\
\hline Positive & 1.840 & 4.315 & 3.0775 & 3.0775 & - \\
\hline Bipolar & 0.083 & 0.083 & 0.083 & 0.083 & - \\
\hline
\end{tabular}


Table 4.3 Summary of return-stroke current characteristics

\begin{tabular}{|c|c|c|c|c|c|}
\hline & Min. & Max. & Mean & Median & Cumul.50\% \\
\hline Current Peak [kA] & & & & & \\
\hline Ordinary & 1.522 & 24.56 & 5.93 & 5.015 & 5.018 \\
\hline Slow & 5.518 & 39.315 & 16.381 & 13.4065 & 13.491 \\
\hline Positive & 4.611 & 8.148 & 6.3795 & 6.3795 & - \\
\hline Bipolar & 3.751 & 3.751 & 3.751 & 3.751 & - \\
\hline $\begin{array}{c}\text { Current Risetime } \\
{[\mu \mathrm{s}]}\end{array}$ & & & & & \\
\hline $\begin{array}{c}\text { Ordinary } \\
\text { Slow }\end{array}$ & 0.078 & 2.045 & 0.640 & 0.629 & 0.631 \\
\hline Positive & 2.493 & 8.8142 & 5.6536 & 5.6536 & - \\
\hline Bipolar & 2.512 & 2.512 & 2.512 & 2.512 & - \\
\hline
\end{tabular}

\subsection{FIRST AND SUBSEQUENT RETURN-STROKES FOR TWO DISTINGUISHED FLASH CATEGORIES}

Figure 4.17 shows cumulative statistics of return-stroke current impulse, derivative peak for slow wavefront current impulse and Figure 4.18 the same of fast wavefront current impulse. Figure 4.19 shows current derivative risetime of return-stroke current impulse derivative peak for slow wavefront current impulse and Figure 4.20 the same of fast wavefront current impulse. Figure 4.21 shows current peak of return-stroke current impulse derivative peak for slow wavefront current impulse and Figure 4.22 the same of fast wavefront current impulse. Figure 
4.23 shows current risetime return-stroke current impulse derivative peak for slow wavefront current impulse and Figure 4.24 the same of fast wavefront current impulse.

Analysing of $4.17-4.24$ Figures we can see that cumulative statistics for fast first wavefront is congruous with cumulative statistics of subsequent return-strokes and cumulative statistics for first slow wavefront first strokes is different from the cumulative statistics of its subsequent return-strokes.

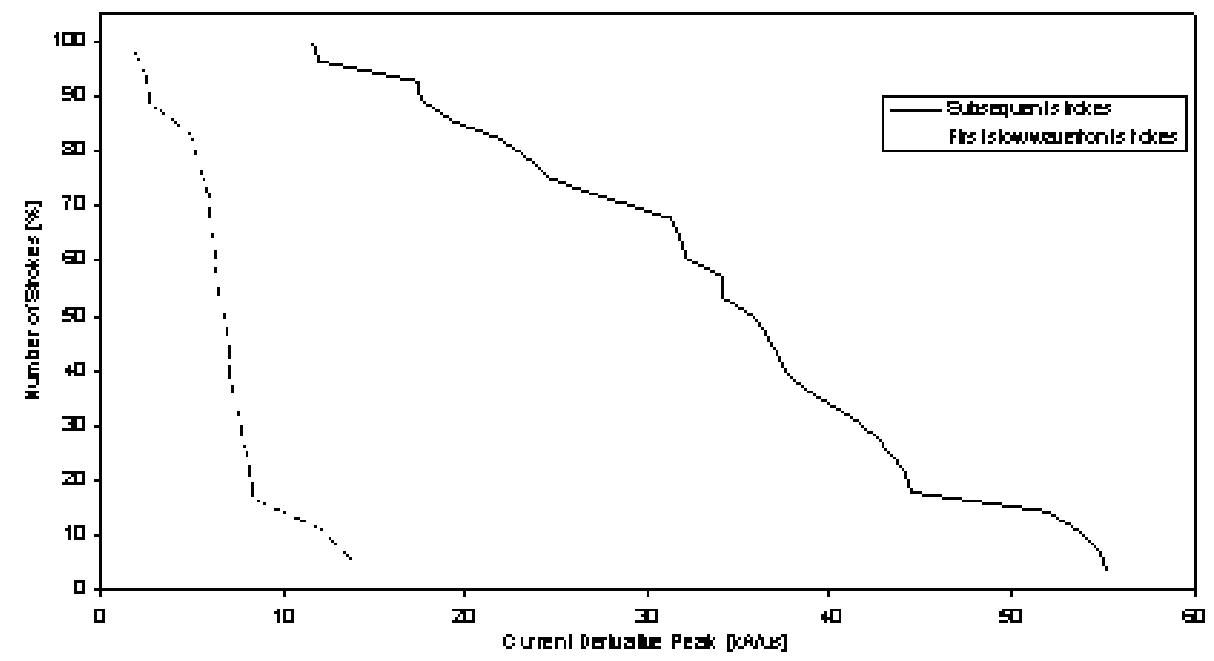

Figure 4.17 Cumulative statistics of return-stroke current derivative peak for slow wavefront current impulse. 


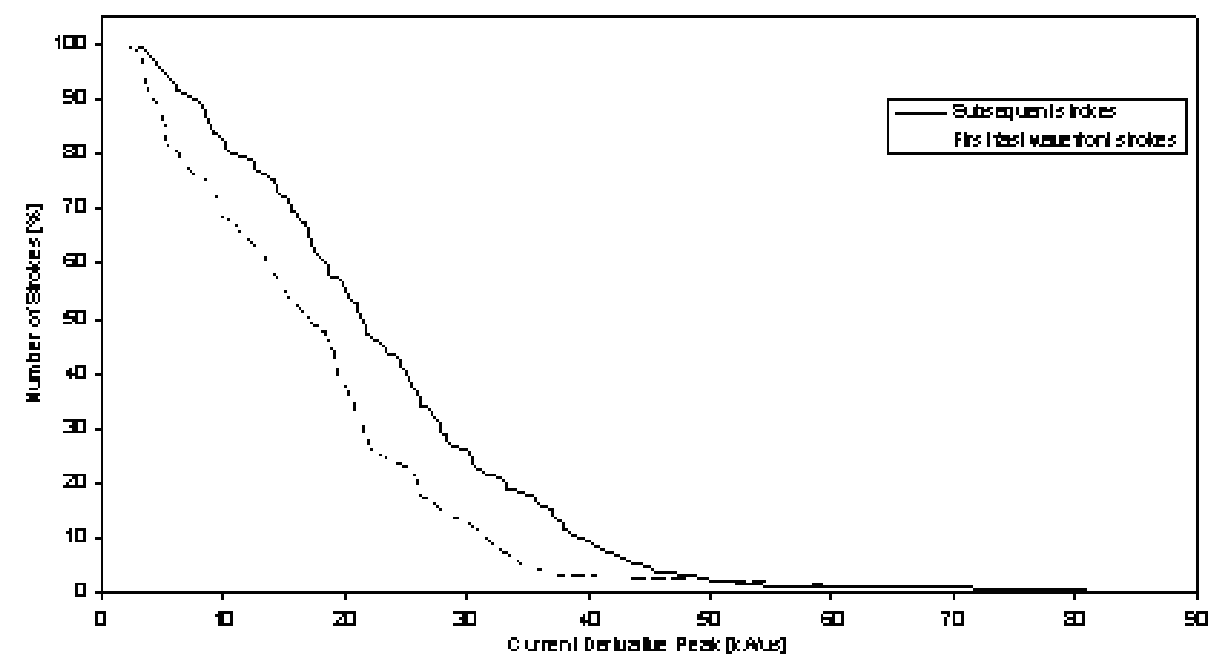

Figure 4.18 Cumulative statistics of return-stroke current derivative peak for fast wavefront current impulse.

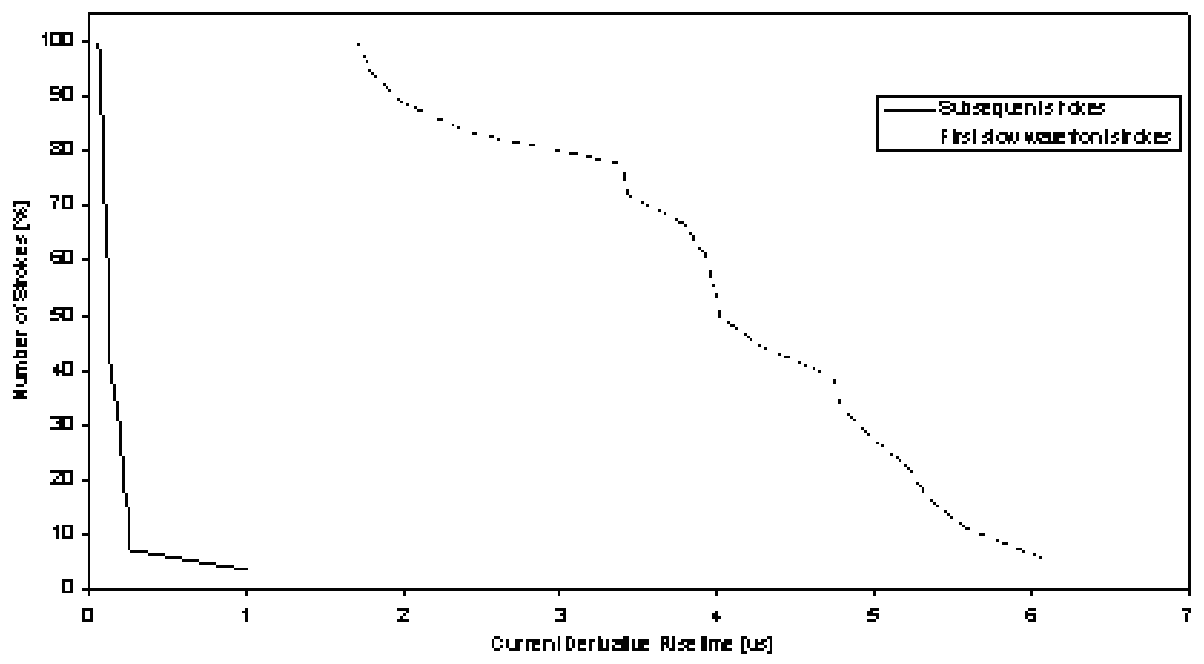

Figure 4.19 Cumulative statistics of return-stroke current derivative risetime for slow wavefront current impulse. 


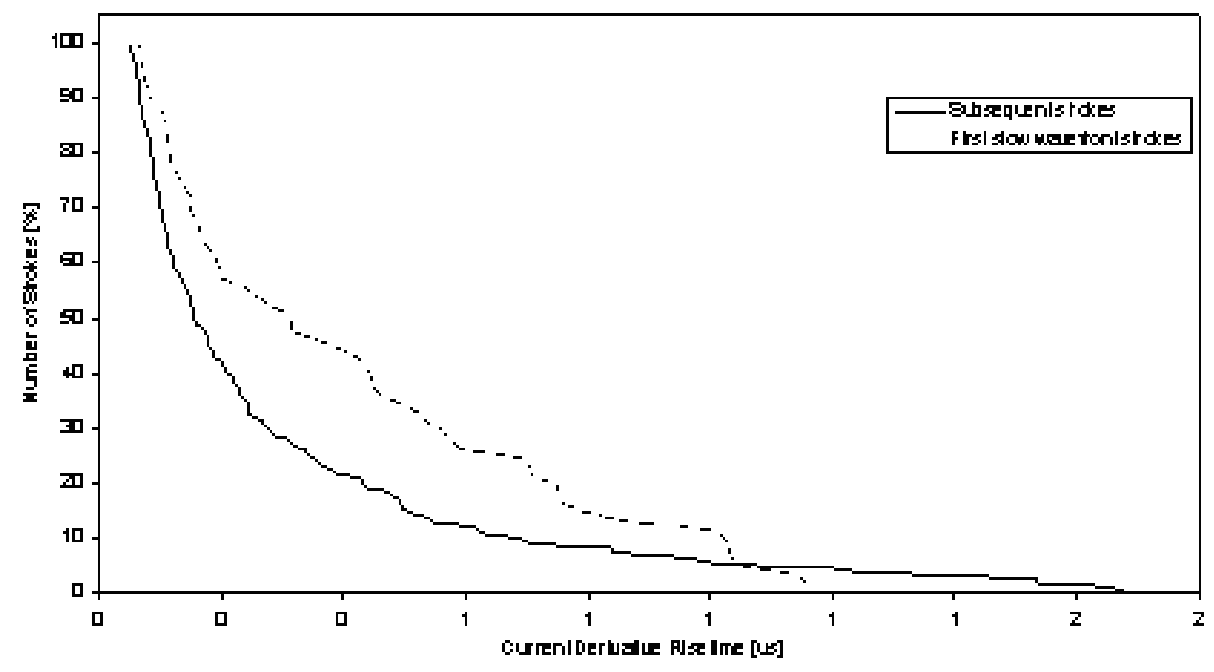

Figure 4.20 Cumulative statistics of return-stroke current derivative risetime for fast wavefront current impulse

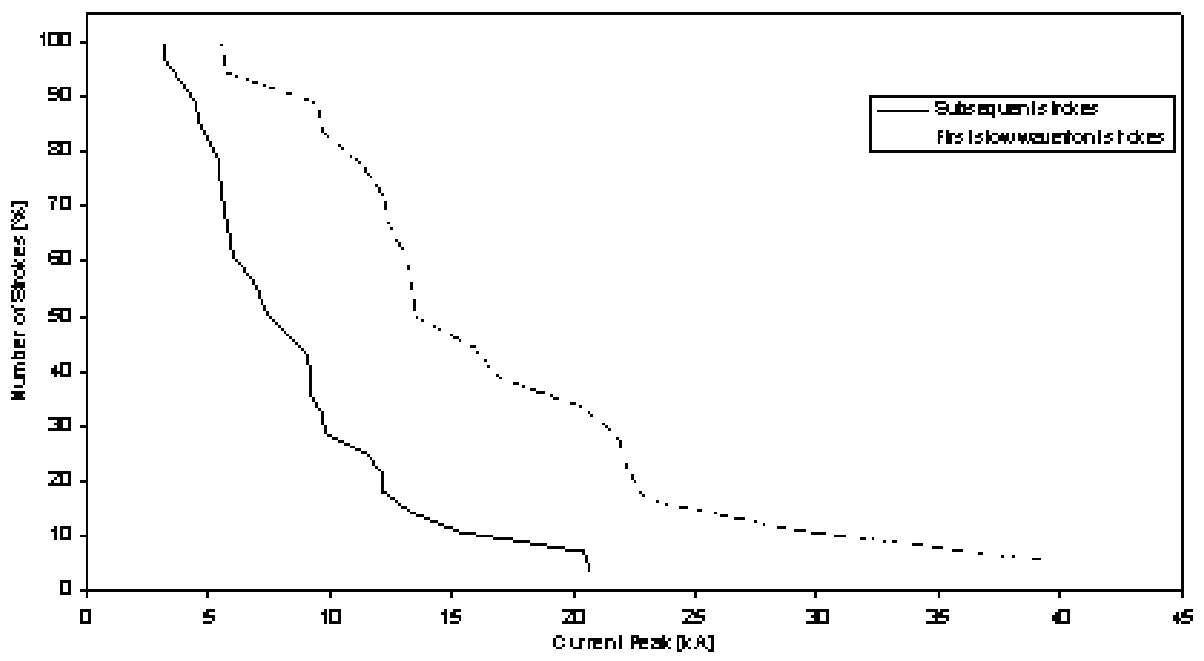

Figure 4.21 Cumulative statistics of return-stroke current peak for slow wavefront current impulse 


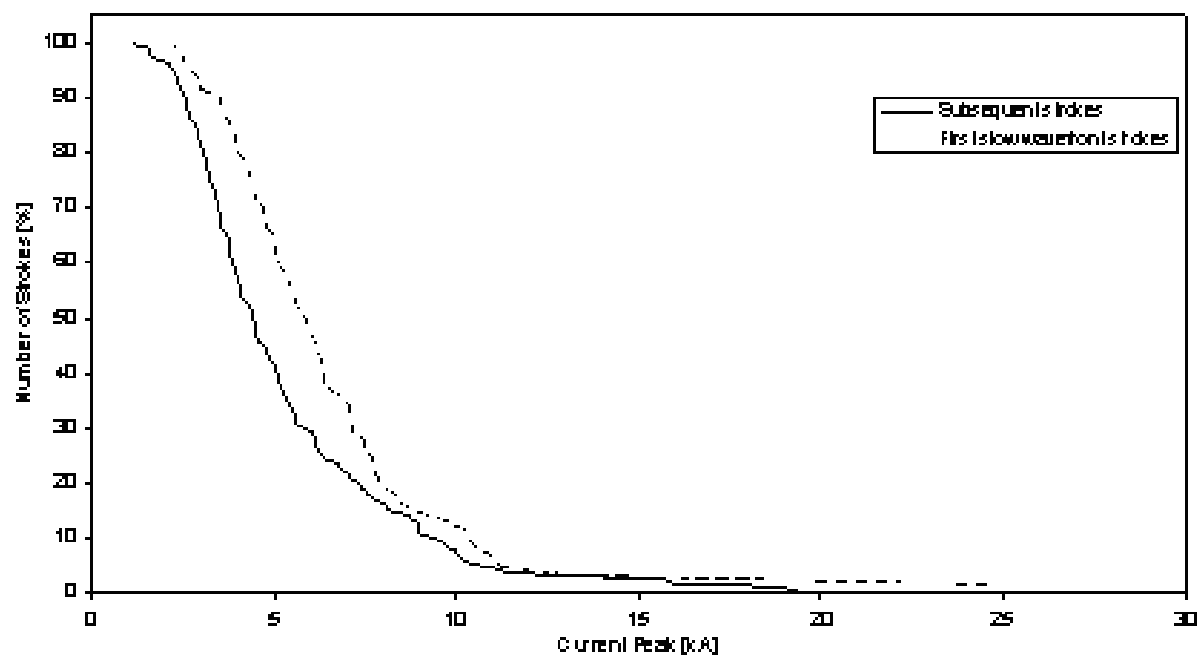

Figure 4.22 Cumulative statistics of return-stroke current peak for fast wavefront current impulse

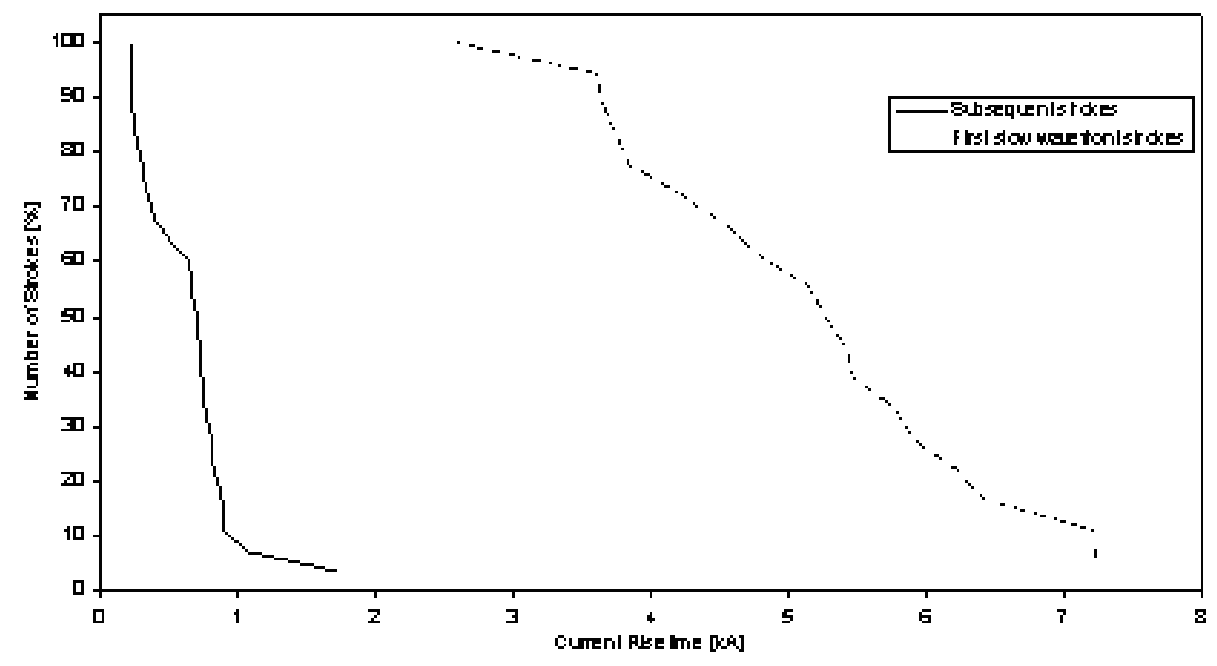

Figure 4.23 Cumulative statistics of return-stroke current risetime for slow wavefront current impulse 


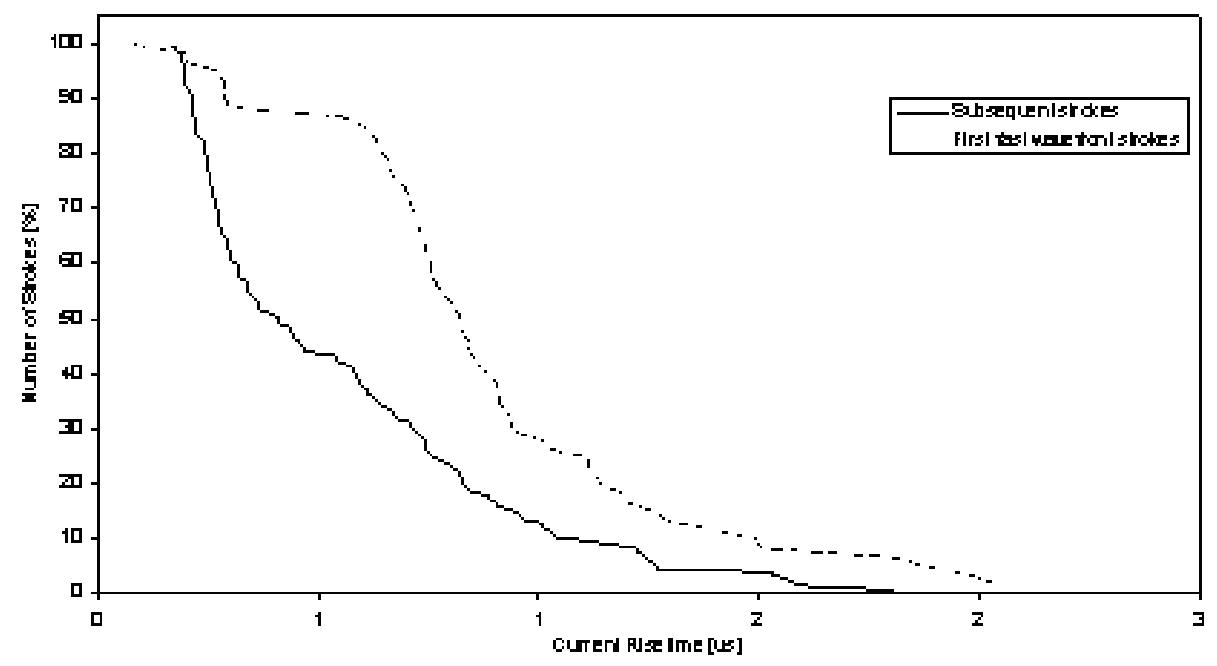

Figure 4.24 Cumulative statistics of return-stroke current risetime for fast wavefront current impulse 


\section{CHAPTER 5}

\section{Conclusions}

The analysis of $\mathrm{CN}$ Tower lightning return-stroke current impulses, based on the current data collected during a five-year period (1992 -1996), have led to the following conclusions and recommendations.

During the reporting period, the $\mathrm{CN}$ Tower current measurement system recorded 82 flashes containing 269 return-stroke current impulses. The overwhelming majority of these flashes were found to be negative (79 flashes out of a total of 82). Only two of the recorded flashes were single return-stroke positive flashes. During the 5-year reporting period, one flash was bipolar. It contains two negative strokes and one positive stroke. Current impulses with current peaks lower than $2 \mathrm{kA}$ were suspected to be M-components superimposed on either initial continuous currents or continuing currents and thus were not taken in account.

CN Tower negative lightning flashes, which represented $96 \%$ of all recorded flashes, were found to belong to two substantially distinguished categories. The first flash category only contained return strokes with fast-rising current wavefronts and represented the majority of negative flashes (61 out of 79). On the other hand, flashes in the second flash category (18 out of 79) always contained one distinguished first stroke each, which either represented first strokes in multiple-stroke flashes or the only stroke in single-stroke flashes. These first strokes were found to always have substantially slow-rising current wavefronts when compared with other negative return strokes, suggesting that they may belong to downward-initiated lightning.

Comprehensive cumulative statistics of the current derivative and the current wavefronts parameters (current derivative risetime, maximum current derivative, current risetime and current 
peak) were derived for the 269 recorded current return-stroke impulses. The statistics indicated that slow negative strokes (18 out of 269) are characterized with higher current peaks and substantially longer risetime in comparison with those of ordinary negative current fast-rising strokes (248 out of 269). The statistics also showed two positive strokes in single-stroke flashes, which were distinguished with much larger risetimes when compared with risetimes of all other strokes. The current wavefront parameters of the positive stroke in the only recorded 3-stroke bipolar flash were not very distinguished from ordinary strokes, however more data is required to substantiate this observation.

Based on the difficulty encountered since 1991 in characterizing CN Tower lightning current components, it is extremely important to have another lightning current measurement system, in addition to the presently installed current derivative measurement system. The new system must record the current directly, which means that the recording digitizers will be triggered by the current peak rather than the current maximum steepness. In this case, it would be possible to record all current components, including those that have very low derivatives, like initial continuous currents, continuing currents and M-components. Also, such a system will easily record positive flashes that have rarely been measured by the present $\mathrm{CN}$ Tower lightning current derivative measurement system. 


\section{References}

[1] M.A. Uman, The lightning Discharge, Dover publications Inc., New York, 2001.

[2] V.A. Rakov, M.A. Uman, Lightning: Physics and Effects, Cambridge University Press, 2003.

[3] A.M. Hussein, W. Janischewskyj, M. Milewski, V. Shostak, W. Chisholm,

J.S. Chang, "Current waveform parameters of CN Tower lightning return-strokes", Journal of Electrostatics, Volume 60, pp. 149-162, March 2004.

[4] I.M. Imyanitov, B.F. Evteev Electricity in Clouds, Gidrometeoizdat, Leningrad, 1971.

[5] K. Berger, "Kugelblitz und Blitzforschung“, Naturwissenschaften 60: 485-492, November 1973.

[6] A.M. Hussein, M. Milewski and Janischewskyj, Characterization of CN Tower Lightning Flash Components, Ground'2010\&4 ${ }^{\text {th }}$ Lightning Physics and effects, November 2010.

[7] D.J. Malan and H. Collens, Progressive lightning III - the fine structure of return lightning strokes. Proc. Roy. Soc. A191, pp.175-203, May 1937.

[8] R.J. Fisher, G.H. Schnetzer, R. Thottappillil, V.A. Rakov, M.A. Uman, and J. D. Goldberg, "Parameters of triggered lightning flashes in Florida and Alabama", J. Geophys. Res. 98: 22, pp 887-902, March 1993.

[9] E.R. Williams, "Problems in lightning physics- the role of polarity asymmetry", Plasma Science and Technology, Vol 15, pp 91 -108 April 2006.

[10] K. Berger, E. Garbagnati, "Lightning current parameters, Results obtained in Switzerland and in Italy|". In Proc. URSI Conf. Florence, Italy 13 pp, May 1974. 
[11] K. Berger, E. Vogelsanger, New results of lightning observations. In Planetary Electrodynamics, eds. S.C. Coroniti and J. Hughes, New York: Gordon and Breach, pp. 489-510, 1969.

[12] K. Berger, The Earth Flash, In Lightning, Vol. 1. Physics of Lightning, ed. R.H. Golde, Academic Press, pp. 119-190, New York, 1977.

[13] A. Eybert-Berard, L. Barret and J.P. Berlendis, "Campagne d'experimantions foudre RTLP 87”, NASA Kennedy Space Center, Floride, USA (in French), Grenoble, France, 1988.

[14] M.I. Fernandez, "Responses of an unenergized test power distribution system to direct and nearby lightning strikes”, M.S. Thesis, University of Florida, 1997.

[15] E.M. Bazelyan, B.N. Gorin, V. I. Levitov, Physical and Engineering Foundation of Lightning Protection, Leningrad, 1978.

[16] A. Lafkovici, A.M. Hussein, W. Janischewskyj, K. Cummins, "Performance analysis of the North American Lightning detection network using CN Tower lightning data", paper presented at $19^{\text {th }}$ International Lightning Detection Conference, Vaisal, Tucson, Ariz

[17] K.B. McEachron, "Lightning to Empire State Building", Journal of The Franklin Institute, pp 149-216, March 1939

[18] B. N. Gorin, "Lightning strikes to the Ostankino tower", Elektricestvo No 8, pp. 19-23, August 1977.

[19] B. N. Gorin, A.V. Shkilev, Measurements of lightning currents at the Ostankino tower. Elektricestvo No 8, pp 64-65, August 1984. 
[20] D. Wang, V.A. Rakov, M.A. Uman, M.I. Fernandez. K.J. Rambo, G.H. Schnetzer, R.J. Fisher, Characterization of initial stage of negative rocket-triggered lightning., J.Geophys Res. 104: pp.4213-22, 1999.

[21] C.F. Wagner, Electrical Transmission and Distribution Reference Book, $4^{\text {th }}$ Ed. Westinghouse Electric Corp.

[22] E.S. Young, J.M. Clayton, A.R. Hileman, "Shielding of Transmission Lines , IEEE Trans. on PAS, vol. 82, pp. 132-154, October 1963.

[23] G.W. Brown, E.R. Whitehead, "Field and Analytical Studies of Transmission Lines Shielding - Part II”, IEEE Volume PAS-88 No 5, May 1969.

[24] J.G. Anderson, Chapter 12 of Transmission Line Reference Book 345kV and Above, Electric Power Research Institute, 1987.

[25] A.M. Mousa, K.D. Srivastava, "Revised Electrogeometric Model for Termination of Lightning Strokes on Ground Objects”, Oklahoma City, pp.342-352, April 1988.

[26] 1243-1997 IEEE guide for improving the lightning performance of transmission lines.

[27] IEEE 998-1996 (R2002) ANSI Direct lightning stroke shielding of substations.

[28] CIGRE Brochure 63 -- Guide to procedures for estimating the lightning performance of transmission lines, 1991.

[29] H.W. Dommel, EMTP Theory Book, Report Prepared for Boneville Power Administaration, Portland, Oregon, 1986.

[30] F. Heidler, J.M. Cvetic, B.V. Stanic, "Calculation of lightning current parameters", IEEE Trans. Pow. Del. 14 (2), pp. 399-404, April 1999. 
[31] H. Kr. Høidalen ATP Draw (GUI for Alternative Transients Program) Manual, 1999.

[32] T. Horvath, Computation of Lightning Protection, Research Studies Press, 1991.

[33] K. Elrodesly, A.M. Hussein, "Modelling The Lightning Return-Stroke Current Using Heidler Function", International conference on Lightning Protection, Cagliary, Italy, September 2010 .

[34] IEC 62305 - part1: Protection against lightning, 2010.

[35] C.A. Nucci, G. Diendorfer, M.A. Uman, F. Rachidi, M. Ianoz. and Mazzeti C., Lightning return-stroke current models with specified channel base current a review and comparison, Journ. of Geophysical Research 95, pp. 20 395-408, Nov. 1990.

[36] V.A Rakov., M.A Uman,: Review of evaluation of lightning return-stroke models including some aspects of their application, IEEE Trans. on Electromagnetic Compatibility, vol. 40, no. 4, pp. 403-426, Nov. 1998.

[37] M. Ishii, T. Kawamura, T. Kouno, E. Ohsaki, K. Shiokawa, K. Murotani, T. Higuchi, "Multistory transmission tower model for lightning surge analysis", IEEE, Volume 6, pp. 13271335, July 1991.

[38] L.V., Bewley Travelling Waves on Transmission Systems, $2^{\text {nd }}$ ed., New York Wiley, 1951.

[39] M. Heimbach, Analyse der transienten Verhaltens ausgedehnter Erdungsanlagen, Doctor Thesis, University of Aachen, 1996.

[40] T. Ito. T. Ueda, H. Watanabe, T. Funabashi and A. Ametani, "Lightning flashover on 77-kV systems: Observed voltage bias effects and analysis", IEEE Trans. on Power Delivery, April 2003. 
[41] A. Ametani Y.Kasai, J.Sawada, A.Mochizuki, T. Yamada, "Frequency-dependent impedance of vertical conductors and a multi-conductor tower model", IEE Proc.-Gener. Transm. Distrib., vol. 141, no. 4, pp. 339-345, July $1994 .$. 